\title{
The Saccharomyces cerevisiae HtrA orthologue, Ynm3, is a chaperone-protease that aids survival under heat stress
}

\author{
PhD Thesis
}

\author{
in partial fulfilment of the requirements \\ for the degree "Doctor of Philosophy" \\ in the Molecular Biology Program \\ at the Georg August University Göttingen, \\ Faculty of Biology
}

submitted by

Nirmala Padmanabhan

born in

Trivandrum, India 
I hereby declare that the $\mathrm{PhD}$ thesis entitled "The Saccharomyces cerevisiae HtrA orthologue, Ynm3, is a chaperone-protease that aids survival under heat stress" has been written independently and with no other sources and aids than quoted.

Nirmala Padmanabhan 
To my grandfather, Late Mr. P. Rama Iyer 


\section{Acknowledgements}

This work was performed in the Department of Molecular Microbiology and Genetics, Institute of Microbiology and Genetics, Georg August University, Goettingen.

I am grateful to my mentor and supervisor Prof. Gerhard H. Braus for giving me the opportunity to pursue my $\mathrm{PhD}$ work in his laboratory and for his constant encouragement and support.

I am thankful to Dr. Lars Fichtner for his involvement in my work and for his friendly support throughout my $\mathrm{PhD}$.

My doctoral committee members, Prof. Christiane Gatz and Prof. Jörg B. Schulz have given me their time and support, for which I am thankful. Prof. Schulz was involved in my work from the very beginning and has invited me to regularly present my work in his departmental seminars.

I am beholden to the following people for their help and collaborations, without which this work would not be in its present form.

Ms. Maria Meyer for the vast amount of technical assistance and for organizing the activities of Lab 107, which made working easier. Dr. Achim Dickmanns for his interest in my work, which resulted in a fruitful collaboration. Ms. Annette Berndt for performing the protein purifications. Dr. Susanne Behrens-Kneip for teaching me how to perform the chaperone activity assay. Dr. Özgur Bayram for his willingness to help with difficult molecular biology techniques. Dr. Oliver Valerius for performing mass spectrometry during my search for protein interaction partners of Ynm3. Dr. Micheal Hoppert for performing electron microscopy during the initial phase of this work. Ms. Heidi Northemann and Ms. Nicole Scheiter for helping me with official tasks and ordering of chemicals. I thank all the lab rotation students who have worked with me and all the other members of the department who have helped me during the course of my work.

For an enjoyable working atmosphere, I wish to thank both past and present members of lab 107, Dr. Lars Fichtner, Ms. Maria Meyer, Ms. Seema Singh, Dr. Susanna Braus-Stromeyer, Mr. Tran Van Tuan, Mr. Christian Timpner, Ms. Peggy Findeisen, Mr. Christoph Braun, Mr. Marc Dumkow, Ms. Melanie Nolte and Ms. Katrin Hartwich.

I am thankful to Dr. Steffen Burkhardt, the co-ordinator of the International Molecular Biology Program for making life easier in Göttingen.

I would like to thank my husband Dr. Tabrez J. Siddiqui for his immense patience, love, encouragement and for being my pillar of support.

My deep fondness and gratitude for my mother Ms. Parvathy Padmanabhan and my father Mr. R. Padmanabhan for all that they have given me and my sister Ms. Sumathy Mohan for her love and support.

I remember with deep respect all my grandparents, all of whom are no more. I dedicate this work to my late grandfather, Mr. P. Rama Iyer who dreamed to see me fly in colours.

Lastly, I wish to thank all my relatives and friends for their faith in what I do. 


\section{Table of contents}

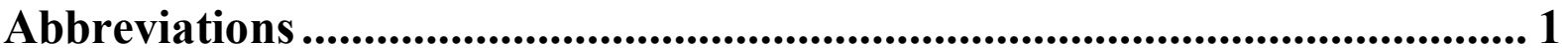

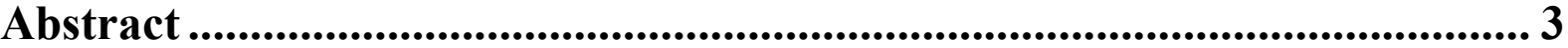

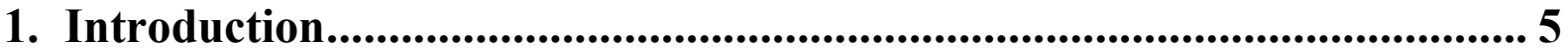

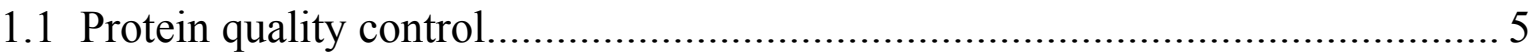

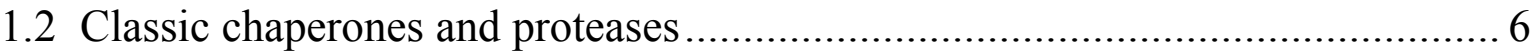

1.2.1 Molecular chaperones ………………………...........................................

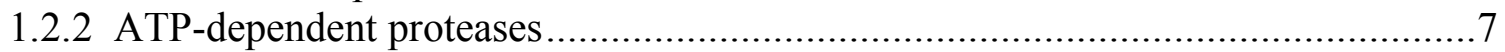

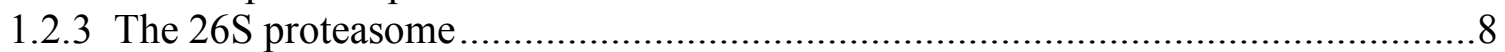

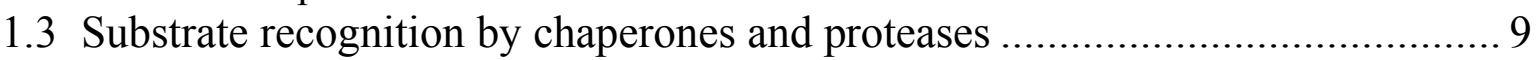

1.4 Role of chaperones in protein degradation ................................................... 11

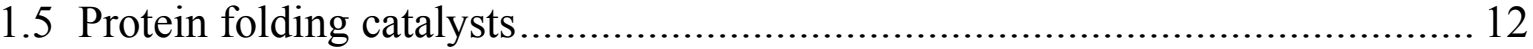

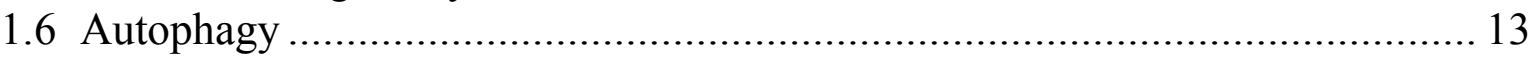

1.7 Quality control of secretory proteins ………………..................................... 14

1.8 Failure of protein quality control: implications for the development of

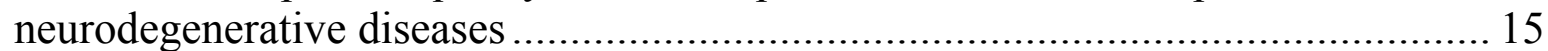

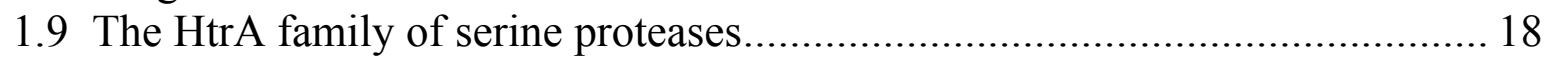

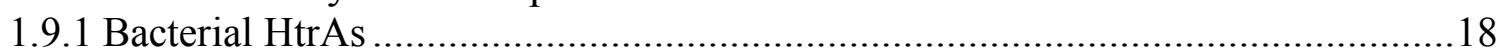

1.9.2 Mammalian HtrA2/Omi .............................................................................

1.9.3 The Saccharomyces cerevisiae HtrA orthologue Ynm3 .....................................21

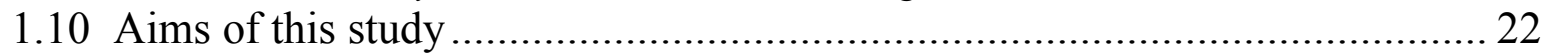

2. Materials and Methods ......................................................................... 24

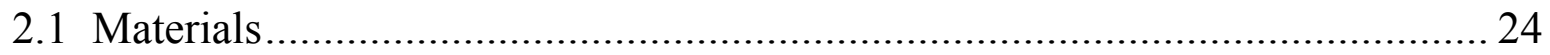

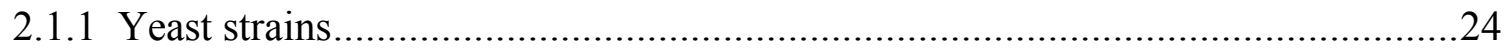

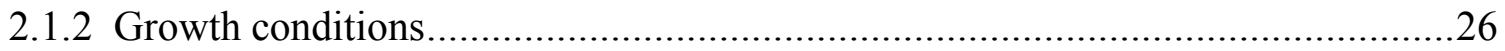

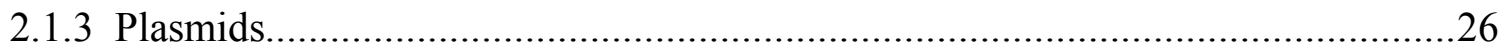

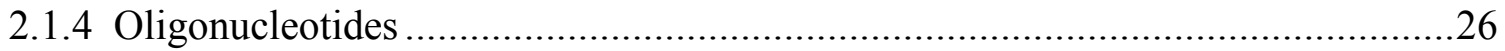

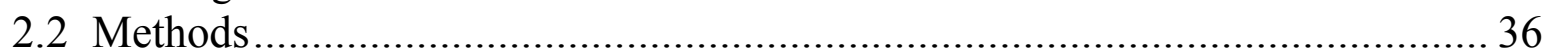

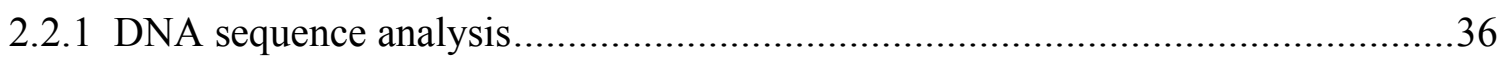

2.2.2 Polymerase Chain Reaction.........................................................................36

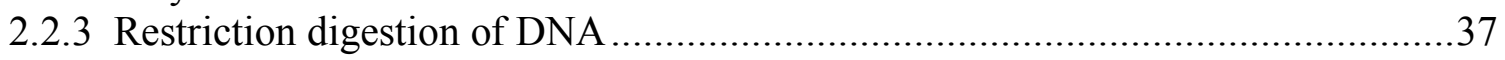

2.2.4 Preparation of DNA for ligation ......................................................................

2.2.5 Preparation of chemically competent $E$.coli cells...................................................37

2.2.6 Transformation of chemically competent E.coli cells............................................38

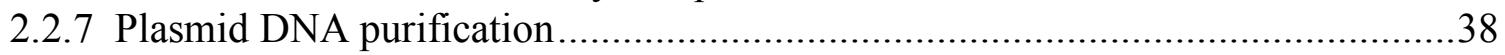

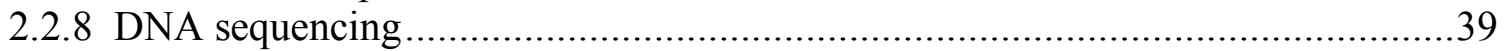

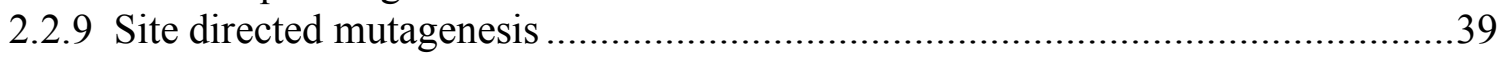

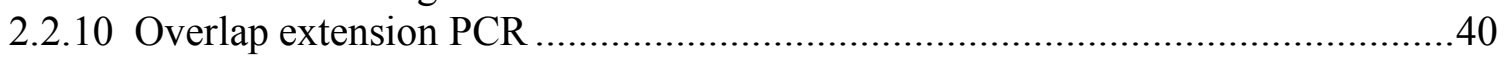

2.2.11 Amplification of DNA libraries following electroporation..................................40

2.2.12 Transformation of yeast cells....................................................................

2.2.12.1 Preparation of competent yeast cells .......................................................... 41

2.2.12.2 Transformation of competent yeast cells......................................................4

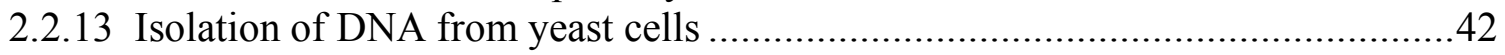

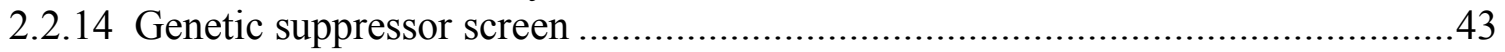

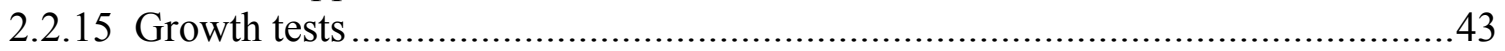

2.2.16 Survival after heat shock treatment...............................................................4

2.2.17 Preparation of yeast cell crude extracts for Western blotting................................4

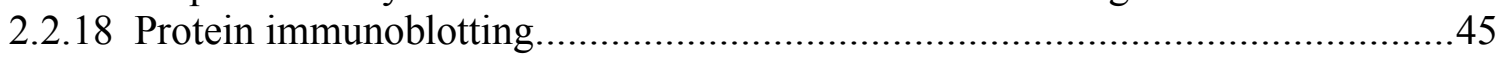




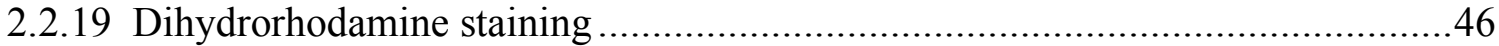

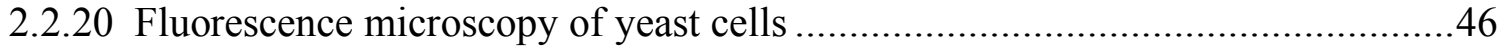

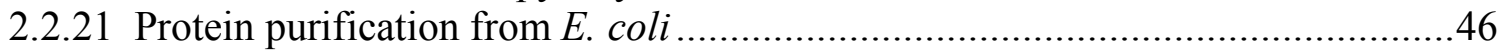

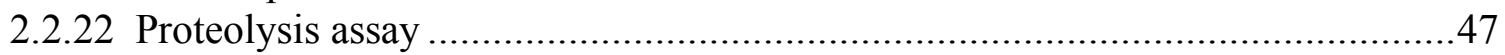

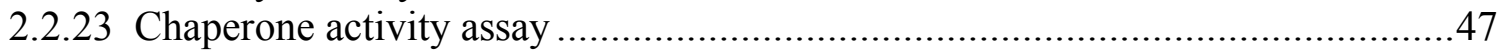

2.2.23.1 Preparation of substrate (citrate synthase) ...............................................4

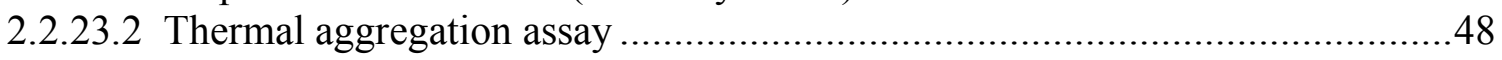

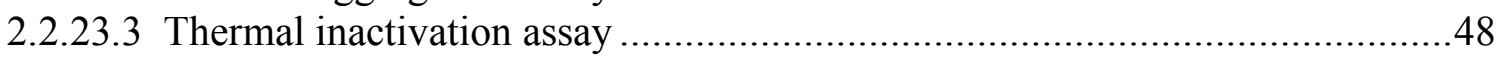

3. Results............................................................................................ 50

3.1 The Saccharomyces cerevisiae strain YB322 requires Ynm3 for survival under

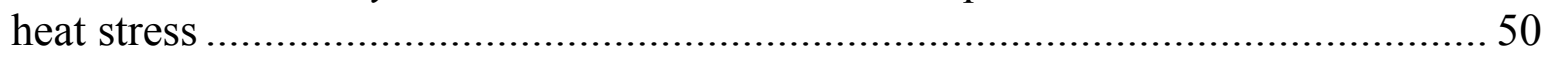

3.2 The serine protease activity of Ynm3 conferred by Ser236 mediates its

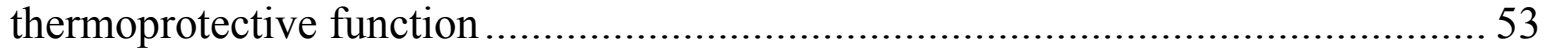

3.3 Multi copy expression of Ynm3 is deleterious....................................... 55

3.4 An in vitro autocatalysis assay further corroborated the finding that Ser236 as

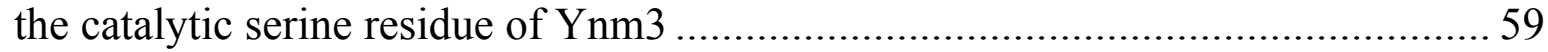

3.5 Deletion of either of its PDZ domains destabilizes Ynm3 .......................... 61

3.6 The first $100 \mathrm{~N}$-terminal amino acid stretch of Ynm3 contains its nuclear

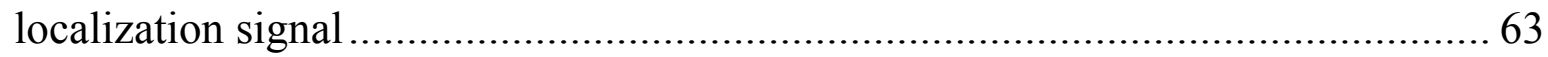

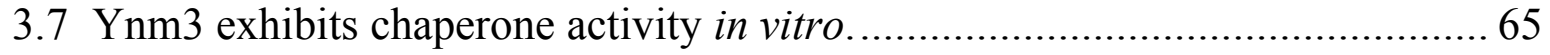

3.8 Lack of Ynm3 may lead to compromised mitochondrial function in older yeast

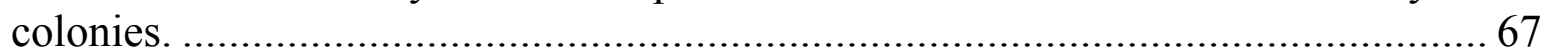

3.9 A genetic screen identified FPR3 as a suppressor of the heat sensitivity of

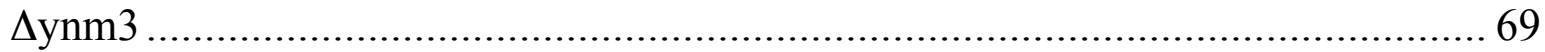

3.10 Fpr3 exhibits strong in vitro chaperone activity.................................... 72

4. Discussion ................................................................................. 74

4.1 The serine protease activity of Ynm3 mediates cell survival under heat stress. 76

4.2 Overexpression of Ynm3 is deleterious to yeast ................................. 78

4.3 The PDZ domains of Ynm3 are critical for its stability .............................. 79

4.4 Ynm3 is a dual chaperone-protease like its bacterial HtrA/DegP counterpart. 80

4.5 Ynm3 may be involved in mitochondrial homeostasis during ageing ............. 84

4.6 A genetic screen identified the yeast nucleolar PPIase Fpr3 as a partial

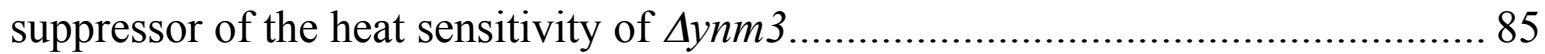

4.7 Fpr3 exhibits strong general chaperone activity .................................. 86

5. Summary and Conclusions ..................................................................... 89

6. References................................................................................ 91

Publication...................................................................................................... 105

Curriculum vitae.......................................................................................... 106 


\section{List of Figures}

Figure 1: The protein "triage" model for quality control.

Figure 2: Phylogram showing selected HtrA members.

Figure 3: Deletion of $Y N M 3$ in the YB322 yeast strain results in reduced growth 51 under sub-lethal heat stress.

Figure 4: The BY4741 yeast strain is significantly more resistant to heat stress 52 than the YB322 yeast strain.

Figure 5: The serine protease activity of Ynm3, mediated by the catalytic serine 54 residue at position 236 is required to execute its thermoprotective function.

Figure 6: Overexpression of Ynm3 is deleterious.

Figure 7: Overexpression of Ynm3 leads to growth impairment due to 58 cytotoxicity and not apoptosis.

Figure 8: Ynm3 undergoes slow autocatalysis in vitro due to its serine protease 60 activity.

Figure 9: The lack of either of its two PDZ domains destabilizes Ynm3.

Figure 10: The nuclear localization signal in Ynm3 lies in its first $100 \mathrm{~N}$-terminal 64 amino acid residues.

Figure 11: Ynm3 exhibits chaperone activity in vitro.

Figure 12: Lack of Ynm3 leads to reduced oxidative growth in older yeast cells. 
Figure 13: FPR3 is a partial knockout suppressor of $\triangle y n m 3$.

Figure 14: In the presence of Ynm3, Fpr3's thermoprotective function is dispensable.

Figure 15: Fpr3 exhibits chaperone activity, in vitro.

Figure 16: Model for Ynm3's role as a dual chaperone-protease.

Figure 17: Fpr3 partly compensates for the lack of Ynm3 under heat stress. 


\section{List of Tables}

Table 1: List of yeast strains used in this study

Table 2: Plasmids constructed in this study

Table 3: Plasmids from other sources used in this study

Table 4: List of oligonucleotides 


\section{Abbreviations}

$\mathrm{AAA}+$

AD

ATP

BFP

CEN

CHIP

CS

DHR

EDTA

ER

ERAD

FKBPs

GFP

HtrA

Hsps

IAPs

LB

mnd2

Nma111

NLS

OMPs

PAN

PBS

PCR
ATPases associated with various cellular activities

Alzeimer's disease

Adenosine triphosphate

Blue flourescent protein

Centromeric or centromere containing

C-terminus of Hsc70-interacting protein

Citrate synthase

Dihydrorhodamine 123

Ethylene diamine tetra acetic acid

Endoplasmic reticulum

Endoplasmic reticulum associated degradation

FK506 binding proteins

Green fluorescent protein

High temperature requirement $\mathrm{A}$

Heat shock proteins

Inhibitor of apoptosis proteins

Luria Bertani

Motor neuron degeneration 2

Nuclear mediator of Apoptosis $(111 \mathrm{kDa})$

Nuclear Localization Sequence

Outer membrane proteins

Proteasome activating nucleotidase

Phosphate buffered saline

Polymerase chain reaction 
PD

PDI

PDZ

PPIase

ROS

SC

SDS-PAGE

TAP

TBS

TBST

TE

UPR

YPD
Parkinson's disease

Protein disulphide isomerase

protein-protein interaction domain; stands for PSD-95, Drosophila Disc large protein, zona occludans protein 1

Peptidyl prolyl cis-trans isomerase

Reactive oxygen species

Synthetic complete

Sodium Dodecyl Sulphate Polyacrylamide Gel Electrophoresis

Tandem affinity purification

Tris buffered saline

TBS with $0.1 \%$ Tween

Tris EDTA

Unfolded protein response

Yeast peptone-yeast extract-dextrose medium 


\section{Abstract}

Ynm3 is the only budding yeast protein possessing a combination of a serine protease and PDZ domains, a defining feature of the widely conserved HtrA (high temperature requirement A) protein family. The bacterial HtrA/DegP is involved in protective stress response to aid survival at higher temperatures by cleaving irreversibly unfolded proteins in the periplasm. At ambient growth temperatures, it acts as a chaperone and aids maturation of outer membrane proteins that have escaped folding mediated by the primary periplasmic chaperone SurA. Studies involving overexpression of mammalian mitochondrial $\mathrm{HtrA} / \mathrm{Omi}$ in cell culture propose a proapoptotic role for the protein. Mice lacking HtrA2/Omi or its protease activity, however, show no evidence of reduced rate of cell death. Instead, these mice suffer loss of a population of neurons in the striatum leading to a Parkinsonian phenotype. Two mutations in the gene encoding human HtrA2/Omi, leading to partial loss of protease activity have been identified as susceptibility factors for the development of Parkinson's disease. There is mounting evidence that the mammalian $\mathrm{HtrA} 2 / \mathrm{Omi}$, a resident of the mitochondrial intermembrane space could have a protective role. The hypothesis that HtrA2/Omi might act as a chaperone-protease like its bacterial counterparts is indeed very attractive considering that mitochondria are evolutionary derivatives of ancestral $\alpha$-proteobacteria. It is noteworthy that no such definitive function has been ascribed to any eukaryotic member. This work deals with unravelling the cellular role of Ynm3, the HtrA orthologue of the simple eukaryotic model, the unicellular Saccharomyces cerevisiae with respect to unfolding stresses.

The major finding of this work is that Ynm3, like the E. coli $\mathrm{HtrA} / \mathrm{DegP}$, is a dual chaperone-protease. The proteolytic activity conferred by the serine residue at position 236 of Ynm3 is crucial for executing its protective role upon heat stress. Ynm3 also exhibits strong ATP-independent general chaperone activity in vitro, a novel finding for a eukaryotic HtrA member. I propose that the chaperone activity of Ynm3 may be important to improve the 
efficiency of proteolysis of aberrant proteins by preventing the formation of non-productive toxic aggregates and presenting them in a soluble state to its protease domain. Like in the case of the classic proteolytic complexes of bacteria and mitochondria, Ynm3's associated chaperone activity may be indispensable for sequestering proteins that need to be cleaved, in their unfolded states, in order to accommodate them in its proteolytic chamber which may be too narrow to allow the entry of misfolded or folded conformers.

Suppression studies performed in this study led to the identification of Fpr3, a nucleolar peptidyl prolyl cis-trans isomerase (PPIase), as a partial knockout suppressor of the heat sensitivity of $\Delta y n m 3$. Further analysis demonstrated that Fpr3 acts as a strong chaperone, in vitro. A similar scenario exists in the bacterial periplasm where the bacterial HtrA/DegP partly compensates the folding activity of the major periplasmic chaperone SurA, which is also a PPIase. The observed interaction with the PPIase, Fpr3 further supports the role of the eukaryotic HtrA member Ynm3 in protein quality control analogous to the bacterial HtrA/DegP.

Ynm3 is primarily nuclear but a subpopulation is associated with mitochondria. This study provides initial evidence that $\mathrm{Ynm} 3$ is presumably involved in mitochondrial homeostasis during aging. Since the budding yeast has been effectively used to derive molecular mechanisms underlying apoptosis, unfolding stresses and human neurodegenerative disorders, this work could have significant bearing on the understanding of the role of $\mathrm{HtrA} 2 / \mathrm{Omi}$, the mammalian mitochondrial HtrA counterpart implicated in Parkinson's disease, especially with respect to protein quality control. 


\section{Introduction}

Polypeptides may have the potential to fold by themselves to their native conformation, the information for which is encoded in their amino acid sequences. But the intracellular milieu, owing to molecular crowding and a high risk of aggregation, is barely conducive for such spontaneous folding to occur. Many newly synthesized polypeptides are unable to achieve the appropriate amino acid contacts and find their native conformations until chain termination is achieved. Therefore, right from the time they emerge from the ribosome, polypeptides run a high risk of aggregation. Molecular chaperones prevent such an event by carefully assisting the folding of polypeptides to their native structures. By binding exposed hydrophobic patches, chaperones prevent the aggregation of newly synthesized proteins and assist in folding to their native conformations (Hartl \& Hayer-Hartl, 2002). In a properly folded conformer, the hydrophobic residues of the protein are buried in the centre whereas the hydrophilic amino acids are exposed to the surface maintaining the protein in a soluble state.

\subsection{Protein quality control}

Successful initial folding of proteins does not guarantee their long-term stability. Proteins are constantly threatened by environmental insults like heat or chemical stresses that can lead to loss of their native conformation. Cells cope with such undesirable conditions by upregulating the synthesis of protein quality control factors: chaperones and proteases and also components of the ubiquitin-proteasome pathway in the case of eukaryotes (Imai et al., 2003; Morimoto, 1998). Damaged proteins and those proteins that have not achieved their native conformations due to mutations, inaccuracy in the transcription-translational machinery or post translational modifications or incorrect localization are subject to rescue by chaperones or degradation by quality control proteases. Failure of these quality control mechanisms often leads to aggregation due to unspecific interactions between exposed 
hydrophobic patches of denatured proteins. Oligomers leading to aggregate formation are often toxic. Aggregation can lead to sequestration of important cellular proteins or protein complexes disrupting normal cellular function (Gidalevitz et al., 2006). Moreover, proteins within aggregates are generally refractory to proteolytic attack impeding the recycling of amino acids, which could otherwise be used for de novo protein synthesis

Chaperones act by binding to sticky hydrophobic patches on proteins, maintaining them in a soluble state and giving them another chance to refold to their native state. When chaperone-mediated rescue fails, quality control proteases recognize and bind irreversibly unfolded proteins facilitating their degradation. A balance among these mechanisms determines the efficiency of protein quality control (Wickner et al., 1999). Thus chaperones and proteases function hand-in-hand in relieving the cell from the load of unfolded or misfolded proteins (Hinault \& Goloubinoff, 2006). Lack of these quality control factors or mutations in the genes encoding these factors often lead to accumulation of intracellular protein aggregates and cell cycle arrest, especially after heat stress.

\subsection{Classic chaperones and proteases}

There is significant convergence in the quality control mechanisms operating in prokaryotes and eukaryotes. The chaperone and protease machineries operating in prokaryotes and mitochondria are strikingly similar. This is not surprising since mitochondria are evolutionary derivatives of ancestral $\alpha$-proteobacteria. In addition to the ATP-dependent proteolytic complexes in their cytoplasmic organelles, eukaryotes contain a huge megacomplex called the proteasome for degradation of proteins in the nucleus and cytoplasm. Related AAA+ proteins and 20S proteasomes are also found in the archea. 


\subsubsection{Molecular chaperones}

Molecular chaperones are composed of several classes of proteins performing diverse functions ranging from assistance in protein folding and translocation across organellar membranes, prevention of aggregation, refolding of un/misfolded proteins and dissagregation of proteins (De Los Rios et al., 2006; Hinault et al., 2006). Most of them are induced by stress and hence called heat shock proteins (hsps). They have been classified depending on their apparent molecular weight on gels. The classic chaperones operating in E. coli are DnaK/Hsp70 and its cochaperones, DnaJ and GrpE (Deuerling et al., 1999; Saibil, 2008; Teter et al., 1999) and GroEL/Hsp60 and its cochaperone GroES (Bochkareva \& Girshovich, 1992; Chapman et al., 2006; Horwich et al., 2006; Horwich et al., 2007). These are ATPdependent chaperones, which function not only in de novo protein folding but also during cellular stresses by preventing aggregation and aiding the refolding of denatured proteins (Ben-Zvi et al., 2004). Hsp60 related heat shock inducible proteins are also present in Archea (Kapatai et al., 2006). Homologues of Hsp70 are present in both the cytosol and mitochondria of eukaryotes. Chaperones belonging to the Clp family in E. coli act either independently or in conjunction with a protease component. Hsp104 is a Clp family homologue in the eukaryotic cytosol and mtHsp78 is the Clp homologue present in mitochondria. Some of these chaperones, eg, yeast Hsp104 and bacterial ClpB, not only prevent aggregation of proteins but also aid in dissagregation (Bochkareva \& Girshovich, 1992; Glover \& Lindquist, 1998; Goloubinoff et al., 1999; Leidhold \& Voos, 2007; Motohashi et al., 1999; Sanchez \& Lindquist, 1990).

\subsubsection{ATP-dependent proteases}

There are three major families of ATP dependent multisubunit proteolytic complexes in the cytosol of E. coli and in organelles like mitochondria and chloroplasts of eukaryotes. These belong to the Clp family, the membrane anchored FtSH/AAA protease family and the 
Lon protease family (Reviewed in Mogk et al., 2008; Snider et al., 2008). The Lon (La) protease is a $600 \mathrm{kDa}$ ATPase complex that rapidly degrades abnormal proteins in E. coli (Chung, 1993; Goldberg, 1992; Maurizi, 1992). The mitochondrial Lon homologue is a matrix protein and is necessary for viability because it prevents accumulation of aberrant proteins within the organelle (Langer et al., 2001; Suzuki et al., 1997). Members of the Clp family, in E. coli are ClpAP (Kessel et al., 1995; Wickner et al., 1994) and ClpXP (Wawrzynow et al., 1995) in addition to ClpB. As mentioned before, the chaperone Hsp104 is the Clp homologue in the eukaryotic cytosol (Chernoff et al., 1995; Parsell et al., 1994) and mtHsp78 is the mitochondrial Clp homologue (Moczko et al., 1995). Members of the FtsH/AAA family are membrane anchored but contain cytoplasmic domains with ATPase sites and $\mathrm{Zn}^{2+}$ metalloprotease active sites (Tomoyasu et al., 1993). Mutations in the genes encoding the yeast mitochondrial FtsH family Yta10/Yta12 protease complex block degradation of abnormal proteins and mitochondrial membrane protein assembly (Pajic et al., 1994; Tauer et al., 1994). All these proteolytic complexes are composed of ATPases and proteolytic subcomplexes. ATP hydrolysis is necessary for unfolding of substrates and for their delivery into the proteolytic chambers where they are processively degraded to small peptides (Reviewed in Baker \& Sauer, 2006; Mogk et al., 2008). These proteases also fall into the category of heat shock proteins (hsps) as they are induced along with molecular chaperones under stress. Archea encode proteins similar to FtsH ATPase and the Lon protease. ClpP proteases are not present in the archea excepting $M$. thermoautotrophicum, which appears to encode a Clp-like ATPase (Maupin-Furlow et al., 2000).

\subsubsection{The 26S proteasome}

Eukaryotic cells have a single large multisubunit ATP-dependent proteolytic complex, the $26 \mathrm{~S}$ proteasome, in their nucleus and cytoplasm unlike in prokaryotes and mitochondria where several specialized ATP-hydrolyzing proteases are in operation. The proteasome 
contains sites that cleave after hydrophobic, acidic and basic residues enabling degradation of various types of substrates fed into it by multiple ubiquitin ligases with distinct specificities (Goldberg, 2003; Voges et al., 1999). The proteasome has a domain organization similar to the bacterial ClpAP but contain additional regulatory components. The $26 \mathrm{~S}$ proteasome is composed of a core of $20 \mathrm{~S}$ particles which contains the proteolytic sites and one or two $19 \mathrm{~S}$ regulatory particles responsible for substrate recognition and delivery into the core particle (Goldberg, 2003; Voges et al., 1999). The architecture of both the bacterial ATP dependent proteases and the proteasome allows the degradation of unfolded proteins in a central channel secluded from the cellular environment. In all these energy dependent proteolytic machineries, ATP hydrolysis is necessary to unfold the substrate and channel it into the proteolytic sub-compartment whose dimensions do not allow the entry of native proteins. This is mediated by the ATPase component of bacterial or organellar proteases, for example, the ClpA or ClpX component of ClpAP and ClpXP respectively mediate unfolding of substrates (Hoskins et al., 2000; Kim et al., 2000). In the base of the 19S regulatory subunit of the 26S proteosome, a ring of 6 ATPases are present that unfold ubiquitinated substrates, facilitate gate opening and translocate them into the proteolytic compartment in the $20 \mathrm{~S}$ particle (Benaroudj et al., 2003; Smith et al., 2006). Archea also have a proteasome in addition to other AAA + family related proteases. Protein degradation by the proteasome activating nucleotidase (PAN) regulatory complex of archea and its $20 \mathrm{~S}$ proteasome also involve substrate recognition, ATP-dependent unfolding, translocation and opening of the gated channel in the proteasome (Smith et al., 2006; Zwickl et al., 1999).

\subsection{Substrate recognition by chaperones and proteases}

Similar fundamentals direct substrate recognition, binding and unfolding by chaperones and the ATPase components of energy dependent proteases. These quality control proteins have evolved to recognize surface exposed hydrophobic residues on proteins that enable them 
to distinguish between native and non-native forms. Classic chaperones, namely the DnaK/Hsp70 system and the GroEL/Hsp60 system repeatedly bind hydrophobic patches on unfolded proteins and release partially folded or native conformers in an ATP dependent manner (Bukau et al., 2006; Sigler et al., 1998). Similarly, the ATPase components of proteases must recognise abnormal proteins from the cellular protein pool. The ATPase components of heterooligomeric proteases like ClpAP (Hoskins et al., 2000) or ClpXP (Schirmer et al., 1996; Wawrzynow et al., 1995) and the ATPase domains of homooligomeric proteases like the FtsH/AAA (Tomoyasu et al., 1993) or Lon protease also possess ATPdependent chaperone activities capable of remodeling or reactivating unfolded or misfolded proteins (Gottesman et al., 1997a; Mogk et al., 2008; Snider et al., 2008).

An attractive 'triage' model has been proposed explaining how classic chaperones or the regulatory ATPase components of energy dependent proteases partition substrates for either refolding or degradation by the protease components (Gottesman et al., 1997b) (Figure 1). The meaning of "triage" in the medical dictionary is "sorting of patients and allocation of treatment depending on the degree of their wounds". According to the model, if attempts at folding newly synthesized proteins or refolding damaged proteins by chaperones fail, the irreversibly unfolded or misfolded proteins are committed for degradation by the recruitment of proteases or the ubiquitination machinery, which would ultimately eliminate them. Thus chaperones or chaperone components of proteases first give aberrant proteins a chance to refold by repeated ATP dependent binding and release (Inobe \& Matouschek, 2008). Once refolded, native conformers are released owing to their low affinity for chaperones. Damaged proteins that are difficult to refold may remain associated with a chaperone for a longer duration, which might stimulate their degradation by a physically associated protease subunit. Thus the kinetics of interaction of a protein with chaperones or chaperone components of proteases determines its fate (Murata et al., 2001; Sherman \& Goldberg, 2001; Wickner et al., 1999). 


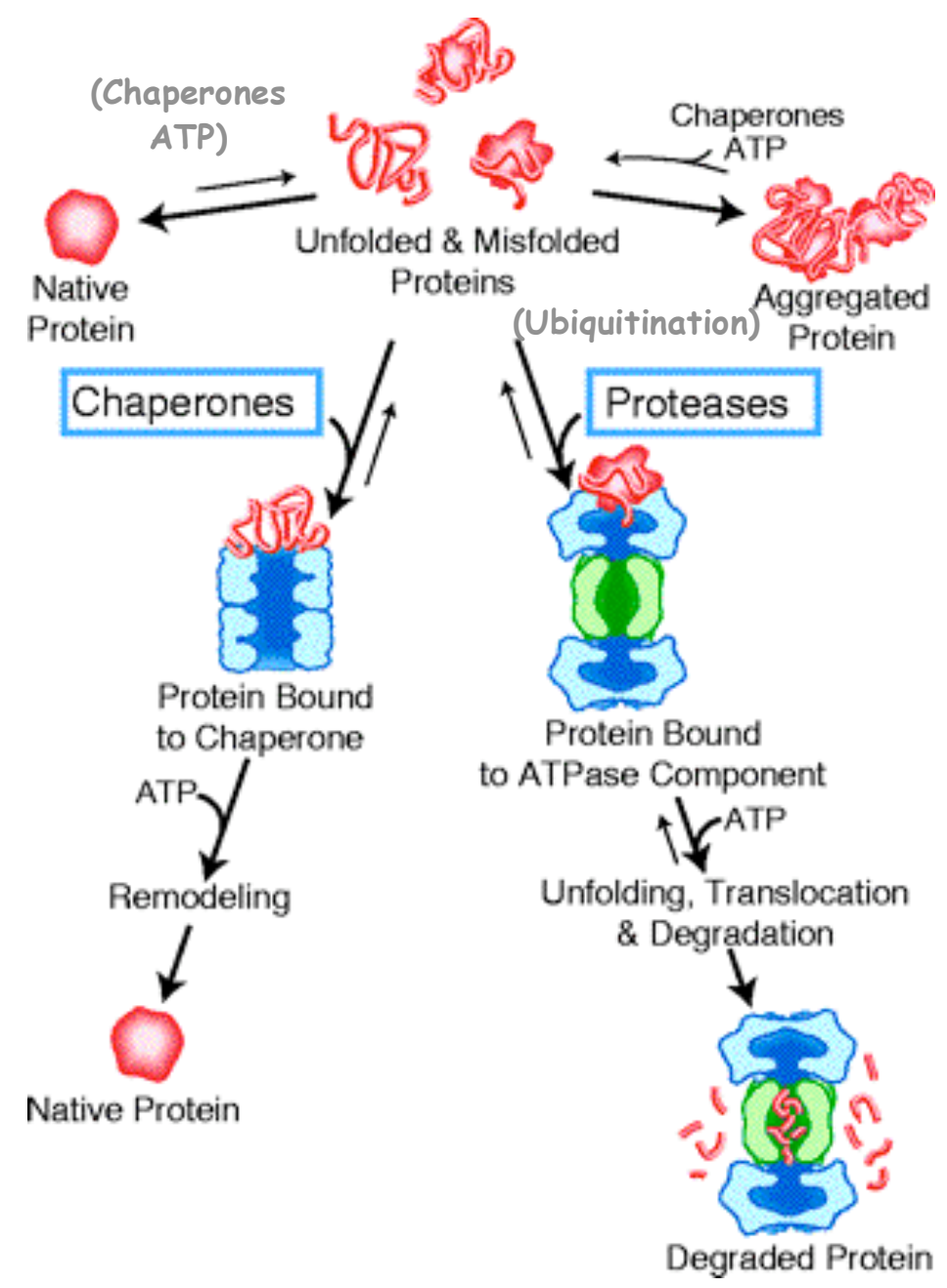

Figure 1: The protein "triage" model for quality control. Chaperones or the ATPase components of proteases bind to exposed hydrophobic patches on denatured proteins. Repeated cycles of ATP dependent binding and release allow unfolding intermediates to fold into their native conformations. If not, they remain in the pool of non-native proteins and may rebind another chaperone or a protease. Protease binding followed by ATP-dependent unfolding and subsequent degradation eliminates the protein. In eukaryotes, ubiquitination marks substrates for recognition by the proteasome. If nonnative proteins escape quality control mediated by chaperones or proteases, they eventually aggregate. Proteins in aggregates are refractory towards proteolysis. Some chaperones aid in proteolysis by simply preventing aggregation. Some of them are also able to dissolve aggregates (Adapted from Wickner et al., 1999).

\subsection{Role of chaperones in protein degradation}

In many cases, molecular chaperones are also necessary for elimination of damaged proteins by proteases. In $E$. coli, the rapid degradation of certain abnormal proteins requires the presence of $\mathrm{Hsp} 70(\mathrm{DnaK}) / \mathrm{Hsp} 40(\mathrm{DnaJ})$ and degradation of others requires the Hsp60(GroEL)/Hsp10(GroES) chaperone systems (Huang et al., 2001; Kandror et al., 1994). The yeast mitochondrial Hsp70 and Mdj1(DnaJ) are required for degradation of certain 
abnormal proteins by the Lon protease homologue, Pim1 which would otherwise form large aggregates (Leidhold \& Voos, 2007; Wagner et al., 1994). There are several different ways in which molecular chaperones can facilitate degradation of proteins. In some cases, molecular chaperones simply avert the massive aggregation of proteins thus increasing their chance of being degraded. In other cases, chaperone activities of regulatory subunits that are physically associated with proteases help in modulating the structure of the substrate, maintaining it in an unfolded form thus enabling its entry through the narrow channel leading to the proteolytic chamber, which cannot accommodate folded conformers (Bukau et al., 2006). The hexameric ring of AAA + ATPases at the base of the $19 \mathrm{~S}$ regulatory lid of the proteasome binds and unfolds proteins and translocates them into the $20 \mathrm{~S}$ protease chamber (Lee et al., 2001). Similarly, homomeric rings of the bacterial ClpA or ClpX unfold and translocate substrates into the associated $\mathrm{ClpP}$ protease which cannot function alone as a protease without the regulatory ATPase components (Hoskins et al., 2000; Kim et al., 2000; Leidhold \& Voos, 2007; Thompson \& Maurizi, 1994). These regulatory ATPase components may also provide substrate specificity to the protease (Thompson \& Maurizi, 1994; Wawrzynow et al., 1995).

Chaperone involvement in the promotion of ubiquitination of substrates for proteasome degradation has been documented. In yeast, the DnaJ homologue, Ydj1 facilitates ubiquitination whereas another DnaJ homologue, Sis promotes degradation of ubiquitinated proteins by the proteasome (Lee, D.H., M.Y. Sherman, and A.L. Goldberg. 1995. Cold Spring Harbor Symp. Quant. Biol. VX:111a.). Hsp70 and Hsp90 chaperones have been implicated in promoting substrate recognition by the E3 ligase, CHIP (Murata et al., 2001).

\subsection{Protein folding catalysts}

In addition to ATP-dependent chaperones mentioned in the earlier sections, another set of enzymes, the peptidyl prolyl cis-trans isomerases (PPIases) and protein disulphide isomerases (PDI) accelerate the proper folding of proteins to their native conformations. 
These catalysts perform steps that involve covalent changes in the folding process. PDIs present in the periplasm of bacteria and the endoplasmic reticulum of eukaryotes help proteins attain correct disulphide linkages between cysteine residues that are required to attain the final folded state (Wilkinson \& Gilbert, 2004). PPIases catalyse the rate-limiting cis-trans isomerization in a peptidyl-prolyl bond (Lu et al., 2007). One example of a PPIase is the prokaryotic trigger factor, which acts in a redundant manner with Hsp70/DnaK in binding and aiding the folding of newly synthesized polypeptides (Deuerling et al., 1999; Teter et al., 1999). This is especially important in the case of larger polypeptides and secretory proteins in which folding is delayed or when assembly into larger complexes is required (Wickner et al., 1999). PPIases fall into three categories: the cyclophilins, FK506 binding proteins (FKBPs) and parvullins. Role of the PPIase activity ranges from assisting in global protein folding, like the trigger factor to acting as a molecular switch in signal transduction pathways. Some of the PPIases like the budding yeast Cpr6, Cpr7 and the bacterial periplasmic SurA have general chaperone activity in addition to the PPIase activity (Behrens et al., 2001; Buchner et al., 1998; Mayr et al., 2000).

\subsection{Autophagy}

In addition to the quality control mechanisms described so far, another pathway exists in eukaryotes for the clearance of macromolecular aggregates or damaged intracellular organelles. This involves the recognition and engulfment of targets into membrane bound cytoplasmic structures called autophagosomes, which eventually fuse with lysosomes, or vacuoles that are enriched in digestive enzymes that cleave the substrates and generate building blocks for de novo synthesis. It is a tightly regulated process important for cellular homeostasis, growth and development. More than about 20 Atg proteins mediate this process. It is now increasingly becoming evident that autophagy is the major pathway for elimination 
of ubiquitin tagged protein aggregates, especially in neurodegenerative diseases (Komatsu et al., 2007).

\subsection{Quality control of secretory proteins}

Proteins targeted to the outer membrane or periplasm of bacteria have an N-terminal cleavable signal sequence that directs them to the secretory pathway for translocation through the inner membrane via the Sec machinery (Dalbey \& Chen, 2004). The periplasm of Gramnegative bacteria such as $E$. coli is in direct communication with the environment by the constant exchange of small molecules through the pores in the outer membrane. Therefore this compartment is easily affected by environmental fluctuations in temperature or $\mathrm{pH}$ that lead to protein unfolding and aggregation. Quality control factors are therefore copiously represented in the bacterial periplasm. The major difference between the periplasmic chaperones and the classic cytoplasmic chaperones described in the previous sections is that they must act in an ATP independent manner unlike the latter due to the absence of ATP in the periplasm. This makes them mechanistically distinct from the classic chaperones described so far.

Several chaperones like Skp, DegP and SurA which have general chaperone activity and folding catalysts like PPIases and PDIs have been identified in the periplasm (Duguay \& Silhavy, 2004). The chaperones responsible for the folding of soluble periplasmic proteins are not well understood unlike those that aid folding of envelope proteins, which have to first traverse the periplasmic space before reaching their final destination. The integral $\beta$-barrel proteins are a major class of outer membrane proteins (OMPs) in Gram-negative bacteria such as $E$. coli. These proteins first pass through the periplasm to reach their assembly site on the outer membrane. Under normal growth conditions SurA functions as the major periplasmic chaperone responsible for the maturation of OMPs. The function of the chaperones DegP and Skp, under normal conditions is to handle only those proteins that have escaped SurA 
mediated folding (Sklar et al., 2007). DegP is a member of the widely conserved HtrA family of proteins. It is a unique ATP-independent chaperone-protease, which undergoes a temperature dependent switch from a chaperone to a protease (Spiess et al., 1999). The function of DegP and Skp becomes prominent under stressful conditions when the load of misfolded proteins in the periplasm increases or in the absence of SurA (Sklar et al., 2007).

In eukaryotes, the endoplasmic reticulum (ER) is responsible for the structural maturation of secretory proteins. The ER is enriched in general chaperones Hsp70 and Hsp90 and foldases, PDIs and PPIases that aid in the rapid folding of secretory proteins. The ER also has its own surveillance mechanisms. The lectins, calnexin and calreticulin recognize specific Nlinked oligosaccharides on misfolded proteins. The ER employs two distinct quality control mechanisms- the unfolded protein response (UPR) and ER- associated degradation (ERAD) during stress (Ellgaard \& Helenius, 2003). The UPR leads to an increase in the transcription of ER chaperones, which then aid in relieving the unfolding stress. Terminally unfolded proteins are transported back into the cytosol by the ERAD pathway for degradation by the 26S proteasome (Bukau et al., 2006).

\subsection{Failure of protein quality control: implications for the development of neurodegenerative diseases}

When the cell's quality control system fails to tackle the buildup of aberrant proteins due to prolonged stress or pathogen attack, the default pathway of aggregation is followed which may be a dead end for proteins. This can lead to growth arrest manifested in unicellular organisms due to loss of a specific function or due to the general accumulation of aggregates. In higher animals, the failure of protein quality control can have dire consequences manifested as progressive neurodegenerative diseases because neurons are most affected since they are post-mitotic cells, which have lost the ability to dilute the concentration of aberrant 
proteins via multiplication (Winklhofer et al., 2008). Accumulation of unfolded proteins could also trigger an apoptotic pathway in higher animals.

The cells capacity to handle aberrant proteins also diminishes with age. Various observations indicate that aged organisms or senescent cultures are not able to efficiently induce Hsps (Heydari et al., 1994; Rattan \& Derventzi, 1991). Aged cells may also have a reduced degradative capacity (Ciechanover, 2006; Shang et al., 1997). This could explain the late onset of neurodegenerative diseases like Parkinson's (PD) or Alzheimer's (AD) where failure of protein quality control resulting in the formation of oligomers or amyloid inclusions of the associated proteins, $\alpha$-synuclein in $\mathrm{PD}$ or $\mathrm{A} \beta$ and tau in $\mathrm{AD}$, are the key pathogenic features. Proteins such as tau and $\alpha$-synuclein are natively unfolded. Under stressful conditions or due to certain toxic gain-of-function mutations, they tend to form misfolded structures rich in $\beta$-sheets. These misfolded proteins escape the quality control system either because they have surface structures that are not recognized by chaperones or proteases or because the speed at which aggregates form due to initial seeding events overwhelms the capacity of the cell's quality control system to eliminate them. Aggregates have exposed hydrophobic surfaces that can interact with other misfolded proteins and membranes. The toxic oligomers can cause membrane damage and result in ion leakage (Lashuel et al., 2002). Another example of an amyloid disease is Huntington's caused by the expansion of polyglutamine tracts beyond a repeat number of 40 . In all these diseases, soluble early intermediates and not the insoluble aggregates have been identified as the toxic species. However, the aggregates may act as reservoirs for release of soluble oligomers. Aggregates contain ubiquitinated proteins implying that the misfolded species have been recognized by the ubiquitin conjugating system (Bence et al., 2001; Bennett et al., 2005). But these inclusions result in inhibition of the proteasome probably due to "choking" of the proteasome chamber (Venkatraman et al., 2004). Evidence is now accumulating that ubiquitin 
conjugation of aggregates may target them for elimination by the autophagic pathway (Iwata et al., 2005; Ravikumar et al., 2004).

Failure of mitochondrial quality control is also a major reason for the development of neurodegenerative diseases such as PD. Mitochondria are susceptible to various extra- and intracellular stresses and form a major interface in determining life or death as they play a central role in many apoptotic pathways. Deficiency of mitochondrial Complex I (Sherer et al., 2003), located in the inner mitochondrial membrane that catalyzes the transfer of electrons from $\mathrm{NADH}$ to coenzyme $\mathrm{Q}$, and oxidative stress can trigger Lewy body formation (Ischiropoulos \& Beckman, 2003). Dysfunction of mitochondrial energy metabolism can lead to elevation in the production of reactive oxygen species (ROS), decreased ATP production and impaired calcium buffering. All these factors can either lead to necrotic or apoptotic cell death. Elevated ROS levels lead to membrane lipid peroxidation and proteolytic stress and can in turn lead to mutations in mtDNA. Again neurons in the brain are most affected because of their high oxygen consumption rate and the presence of high content of peroxidizable lipids. Mutations in several genes that affect mitochondrial homeostasis, namely those encoding Parkin, PINK1, DJ1 and HtrA2/Omi have been associated with PD. Parkin encodes an E3 ubiquitin ligase. Deletion of exon 3 of Parkin in mice results in reduced expression of several proteins involved in mitochondrial function and oxidative stress. Parkin may also be involved in the elimination of oxidatively damaged proteins. Mutations in DJ1 are extremely rare. It has been proposed to act as a redox sensor or an antioxidant protein. It has been detected in the mitochondria in addition to its cytoplasmic localization (Abou-Sleiman et al., 2006).

There is increasing interest in the function of HtrA2/Omi, a close homologue of the bacterial periplasmic HtrA/DegP (introduced in section 1.7), which is a well-characterized chaperone-protease. HtrA2/Omi is a resident of the mitochondrial inter-membrane space, analogous to the localization of bacterial HtrA/DegP in the periplasmic space. Considering 
that mitochondria are evolutionary derivatives of ancestral $\alpha$-proteobacteria, it seems possible that HtrA2/Omi could also function as a quality control factor in the mitochondrial intermembrane space.

\subsection{The HtrA family of serine proteases}

The HtrA (high temperature requirement) family constitutes of proteins that have a characteristic combination of a protease domain with at least one PDZ domain (Pallen \& Wren, 1997). HtrA proteins are widely conserved, present in most prokaryotic and eukaryotic species. Several prokaryotic HtrAs have been attributed in stress tolerance and pathogenicity (Ponting, 1997). The genome of the worm Caenorhabditis elegans lacks any HtrA homologue in contrast to Drosophila melanogaster (Challa et al., 2007). Vertebrates possess three secretory paralogs in addition to mitochondrial HtrA2/Omi (see phylogram in Figure 2). Some archea also appear to encode a HtrA-like protein (http://supfam.mrc-lmb.cam.ac.uk/).

\subsubsection{Bacterial HtrAs}

The E. coli HtrA/DegP was initially identified by two phenotypes of htrA null mutants and named accordingly. Null mutants were unable to grow at elevated temperatures (Lipinska et al., 1989) or failed to digest misfolded proteins in the periplasm (DegP) (Strauch et al., 1989). The genome of $E$. coli encodes three paralogues of HtrA: HtrA/DegP, DegQ and DegS. HtrA/DegP is an ATP-independent dual chaperone-protease. As discussed earlier (section 1.7), it is unique in that it acts as a chaperone at ambient temperatures but undergoes a temperature dependent switch to a protease at elevated temperatures cleaving irreversibly unfolded substrates in the periplasm. HtrA/DegP is therefore indispensable for survival under heat stress (Spiess et al., 1999). HtrA/DegP forms a self-compartmentalized structure similar to other energy dependent proteases. Because the periplasmic space lacks ATP, DegP does not rely on energy dependent unfoldases and rather cleaves heat-denatured proteins (Kim et al., 1999). In contrast, the archeal HtrA owing to the lack of signal sequences may form a 
self-compartmentalized structure in the cytosol depending on association with AAA+ type proteins for hydrolysis of proteins (Maupin-Furlow et al., 2000).

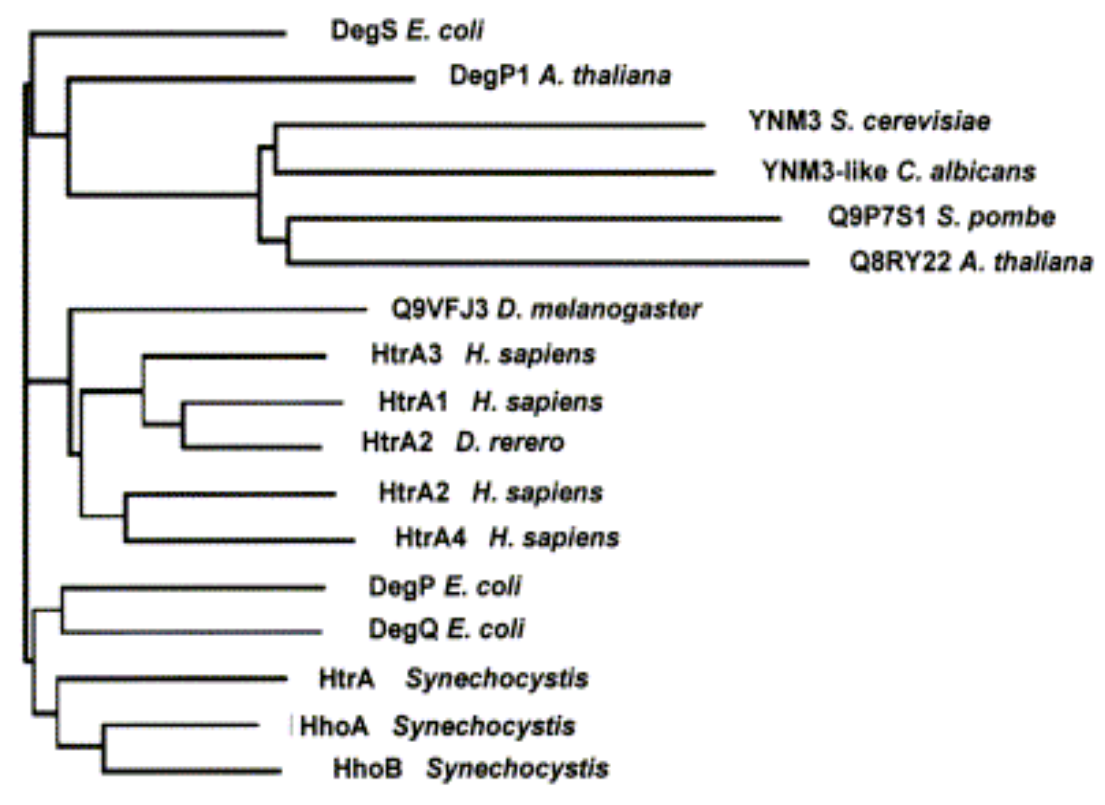

Figure 2: Phylogram showing selected HtrA members. The HtrA family members are widely conserved among both prokaryotes and eukaryotes. E.coli has three paralogues namely, HtrA/DegP, DegQ and DegS, humans have four: HtrA1-4 and the budding yeast Saccharomyces cerevisieae has one orthologue called Ynm3. The phylogram was produced by Clustal W (Adapted from Clausen et al., 2002).

The bacterial DegS is a stress sensor. When misfolded outer membrane proteins bind to its C-terminal PDZ domain, it cleaves its only substrate, the anti- $\sigma$ factor RseA that releases the alternative sigma factor $\sigma^{\mathrm{E}}$, which then induces the expression of several stress responsive proteins in the periplasm including DegP (Walsh et al., 2003). The function of DegQ is less understood. It is believed to have roles redundant with DegP and DegS. Overexpression of DegQ can substitute for the lack of DegP in E. coli (Waller \& Sauer, 1996).

\subsubsection{Mammalian HtrA2/Omi}

The mammalian HtrA member, HtrA2/Omi, resides in the mitochondrial intermembrane space which corresponds to the periplasmic localization of HtrA/DegP in bacteria (Verhagen et al., 2002). Cell culture studies suggest a proapoptotic role for this protein. A mature form of $\mathrm{Htr}$ 2/Omi is generated in the mitochondrial intermembrane space revealing an amino 
terminal motif similar to the Drosophila death promoting proteins Reaper, Grim and Hid. During apoptosis, mature HtrA2/Omi is released into the cytosol where it binds inhibitor of apoptosis proteins (IAPs) via its N-terminal IAP binding domain (Hegde et al., 2002; Suzuki et al., 2001; Verhagen et al., 2002). IAPs are proteins that inhibit caspases. Binding of HtrA2/Omi to IAPs presumably triggers its serine protease activity leading to their cleavage thereby promoting apoptosis (Hegde et al., 2002; Martins et al., 2002; Verhagen et al., 2000). This view of the function of HtrA2/Omi, which arose from cell culture studies, has been contradicted by the phenotype displayed by mice lacking HtrA2/Omi or its protease activity. The mnd2 (motor neuron degeneration 2) mutant mice, in which the corresponding gene encodes an intact IAP binding domain but carries a protease inactivating point mutation (S276C), suffer neurodegeneration leading to juvenile death (Jones et al., 2003). Interestingly, the HtrA2 knockout mice also show a similar phenotype (Martins et al., 2004). Both these mice exhibit characteristic Parkinsonian symptoms like tremor, decreased mobility and lack of coordination. Cells from these mice are more susceptible to apoptotic stimuli. A certain percentage of cells from the HtrA2/Omi knockout mice exhibit abnormal mitochondrial morphology combined with a decreased mitochondrial density (Martins et al., 2004). This suggests a more protective than a proapoptotic role for mammalian HtrA2/Omi under physiological conditions, which is more reminiscent of its bacterial homologues.

Mutations in the gene encoding HtrA2/Omi have been identified in patients suffering from PD (Strauss et al., 2005). This gene has been allocated to the locus PARK13. A study showed that PINK1 dependent phophorylation of HtrA2/Omi at a residue adjacent to one of these mutations might modulate its proteolytic activity (Plun-Favreau et al., 2007). Indeed, lower HtrA2/Omi phosphorylation was detected in PD patients having mutations in PINK1 (Plun-Favreau et al., 2007). Thus, mutations in the gene encoding either PINK1 or HtrA2/Omi that affect this phosphorylation event could abolish HtrA2/Omi induction. This could possibly lead to mitochondrial stress and neurodegeneration (Vande Walle et al., 2008). 
Recent studies report that HtrA2/Omi is activated following cytosolic proteasome inhibition and may act as a second checkpoint to counter the accumulation of its substrates in the mitochondria (Radke et al., 2008).

\subsubsection{The Saccharomyces cerevisiae HtrA orthologue Ynm3}

The eukaryotic model organism, Saccharomyces cerevisiae encodes an HtrA-like protein called Ynm3 or Nma111. It has an HtrA-like serine protease domain followed by two PDZ domains (Apweiler et al., 2000), one present immediately proximal to the protease domain and the other at the C-terminal end of the protein. The role of this HtrA-like protein in yeast is still obscure, because seemingly contradictory functions have been ascribed to it in earlier reports. It was originally proposed to be a pro-apoptotic serine protease and hence called Nma111, which stands for nuclear mediator of apoptosis $111 \mathrm{kDa}$ protein. It was reported that the absence of the corresponding gene NMA111 rendered yeast resistant to apoptosis induced by $\mathrm{H}_{2} \mathrm{O}_{2}$. Its overexpression was shown to induce apoptosis (Fahrenkrog et al., 2004). Moreover Bir1, a protein homologous to inhibitor of apoptosis proteins (IAPs) was identified as a substrate of Nma111, in vitro. It was shown that overexpression of Nma111 counters the anti-apoptotic effect which results from the overexpression of Bir1 (Walter et al., 2006). The same protein, termed Ynm3 was described as a modulator of fatty acid metabolism. Furthermore, deletion of the YNM3 locus in the yeast strain YB322 was shown to result in the inability to use non-fermentable carbon sources pointing to a possible mitochondrial role for Ynm3 (Tong et al., 2006). 


\subsection{Aims of this study}

Failure of mitochondrial quality control has been found to be one of the primary reasons for the development of neurodegenerative diseases. Among the various genes implicated in PD is the mitochondrial HtrA2/Omi whose bacterial counterparts are well-studied quality control factors. The bacterial HtrA/DegP aids cell survival under heat stress by irreversibly cleaving misfolded proteins in the periplasm and acts as a chaperone at ambient growth temperatures (Spiess et al., 1999). The function of the mammalian HtrA2/Omi is controversial. The proposed pro-apoptotic function in vitro (Verhagen et al., 2002) has been contradicted by studies on mice lacking HtrA2/Omi (Martins et al., 2004) or its serine protease activity (Jones et al., 2003), which exhibit neurodegeneration due to progressive mitochondrial impairment leading to a Parkinsonian phenotype. Recent reports indicate that Htra2/Omi may be important for protein quality control in the mitochondria following cytosolic proteasome inhibition (Plun-Favreau et al., 2007; Radke et al., 2008). The prospect that the mammalian HtrA2/Omi might act as a quality control chaperone-protease like the bacterial HtrA/DegP is immensely attractive though as yet untested. It is noteworthy that such a role is not explicit for any eukaryotic HtrA member.

The budding yeast, Saccharomyces cerevisiae is a useful model to study various aspects of neurodegenerative diseases like protein aggregation, protein misfolding, oxidative stress and apoptosis. Features of diseases like Parkinson's and Huntington's have been successfully modeled in the budding yeast. The basic cellular machinery for neuronal function is conserved in yeast making it an attractive unicellular, genetically and biochemically tractable model organism to study pathways underlying neurodegeneration.

In this study, I address the question whether a eukaryotic homologue of the HtrA family, the budding yeast Ynm3, has retained the characteristic chaperone-protease function of its prokaryotic counterparts. This possibility is dealt with by both genetic as well as biochemical methods. The role of Ynm3's serine protease activity as well as its chaperone 
activity is assessed. From the results, the mutual importance of both chaperone and protease activities in maintaining quality control are analyzed.

Both structural and functional studies have revealed that the PDZ domains of the bacterial and mammalian homologues have substrate binding as well as regulatory functions (Clausen et al., 2002; Krojer et al., 2002; Li et al., 2002). To understand the importance of the duplicated PDZ domains of Ynm3, genetic experiments are carried out with variants lacking either of them, which could provide important hints that would become the basis for future structural studies.

Attempts are made to find in vivo substrates as well as physical and genetic interactors of Ynm3. Any potential partner of $\mathrm{Ynm} 3$ is assayed in genetic as well as a biochemical experiments. I also assess whether the interaction of Ynm3 with a potential interactor is evolutionarily conserved. Finally, on the basis of my findings, a cogent working hypothesis for the function of Ynm3 and its potential interactor(s) is presented. 


\section{Materials and Methods}

\subsection{Materials}

\subsubsection{Yeast strains}

All yeast strains used in this study are listed in Table 1. All yeast strains are congenic to the wild type YB322 strain (Johnson et al., 1994) unless otherwise stated. The yeast strain RH3340 was obtained by replacing the YNM3 genomic locus with a module conferring Kanamycin resistance. The YNM3 coding sequence was deleted by homologous recombination using the kanamycin resistance cassette, amplified by PCR, containing sequences homologous to the 5' upstream and 3' downstream regions of the gene. Chromosomal DNA was isolated from the yeast colonies that grew on YPD $+200 \mu \mathrm{g} / \mathrm{ml}$ Geneticin G418 sulphate (Gibco, UK). Successful disruption of YNM3 by the cassette was confirmed by PCR using two sets of primers: one set homologous to a sequence in the 5' upstream region of YNM3 and the 5' end of the drug resistance cassette and the other set homologous to a sequence in the 3' downstream region of YNM3 and the 3' end of the drug resistance cassette.

The yeast strain RH3343 was obtained by PCR based tagging of the YNM3 genomic locus at its 5' region with the natNT2-GAL1-yeGFP module which was PCR amplified from the plasmid, pymN25 as described (Janke et al., 2004). The module was amplified using a pair of primers annealing to 45 - 55 bases upstream of the ATG (including ATG start codon) of $Y N M 3$, followed by 5' -CGTACGCTGCAGGTCGAC-3' and the reverse complement of 45 - 55 bases downstream of the ATG (start-codon) of YNM3 (excluding ATG), followed by 5'CATCGATGAATTCTCTGTCG-3' (Table 4). The resulting PCR product was transformed into the wild type YB322 strain. Genomic DNA was isolated from colonies that grew on YPD+100 $\mu \mathrm{g} / \mathrm{ml}$ Nourseothricin (ClonNAT, Werner BioAgents, Jena-Cospeda, Germany). 
Verification by PCR was done using a pair of primers annealing to a upstream region of YNM3 and the 5' end of the module as before since all these drug resistance cassettes have exactly the same promoter and terminator sequences.

The yeast strains RH3344 and RH3345 were obtained by replacing the genomic FPR3 locus in the wild type YB322 or in RH3340 respectively with the nourseothricin-resistance cassette amplified from the plasmid pFA6a-natNT2 (Janke et al., 2004) using primers containing sequences homologous to the upstream and downstream region of FPR3 (Table 4). The strains transformed with the PCR product containing the disruption cassette were plated on $\mathrm{YPD}+100 \mu \mathrm{g} / \mathrm{ml}$ Nourseothricin. Genomic DNA was isolated from colonies that grew on YPD $+100 \mu \mathrm{g} / \mathrm{ml}$ Nourseothricin. Verification by PCR was done using a pair of primers annealing to an upstream region of $Y N M 3$ and the 5' end of the cassette (Table 4). YCA1 was also disrupted in the strain YB322 in a similar manner (For primers see Table 4). The deletion strains of the BY4741 background were obtained from EUROSCARF (http://web.unifrankfurt.de/fb15/mikro/euroscarf/col_index.html).

\section{Table 1. List of yeast strains used in this study}

\begin{tabular}{|l|l|l|}
\hline Yeast Strain & Genotype & Source \\
\hline RH3339 & $\begin{array}{l}\text { YB322 wild type, } \\
\text { Mat a,ura3, his3, ade2,lys2,leu2, trp1 }\end{array}$ & (Johnson et al., 1994) \\
\hline RH3340 & $\begin{array}{l}\text { YB322, } \\
\text { Mat a,ura3, his3, ade2,lys2,leu2,trp1, } \\
\text { ynm34: }: \text { kanMX4 }\end{array}$ & This study \\
\hline RH3342 & $\begin{array}{l}\text { YB322, } \\
\text { Mat a,ura3,his3,ade2,lys2,leu2,trp1, } \\
\text { yca1 }:: \text { natNT2 }\end{array}$ & This study \\
\hline RH3343 & $\begin{array}{l}\text { YB322, } \\
\text { Mat a,ura3,his3,ade2,lys2,leu2,trp1, } \\
\text { natNT2-GAL1 }\end{array}$ & \\
\hline
\end{tabular}




\begin{tabular}{|l|l|l|}
\hline RH3344 & $\begin{array}{l}\text { YB322, } \\
\text { Mat a,ura3, his3, ade2,lys2,leu2,trp1, } \\
f p r 3 \Delta:: \text { natNT2 }\end{array}$ & This study \\
\hline RH3345 & $\begin{array}{l}\text { YB322, } \\
\text { Mat a,ura3, his3, ade2,lys2,leu2,trp1, } \\
\text { ynm34::kanMX4; fpr34: }: \text { nat NT2 }\end{array}$ & This study \\
\hline BY4741 & BY4741, his3-1,leu2,met15, ura3 & EUROSCARF \\
\hline Y02953 & $\begin{array}{l}\text { BY4741, his3-1,leu2,met15, ura3, } \\
\text { ynm34:: kanMX4 }\end{array}$ & EUROSCARF \\
\hline YNL123W-GFP & $\begin{array}{l}\text { BY4741, his3-1,leu2,met15, } \\
\text { ura3,YNM3-GFP }\end{array}$ & $\begin{array}{l}\text { INVITROGEN } \\
\text { (Huh } \text { et al., 2003) }\end{array}$ \\
\hline
\end{tabular}

\subsubsection{Growth conditions}

The yeast strains were grown in standard yeast extract-peptone-dextrose (YPD: 1\% yeast extract, $2 \%$ peptone, $2 \%$ dextrose) or yeast extract-peptone-galactose (YPGal: $1 \%$ yeast extract, $2 \%$ peptone, $2 \%$ Galactose) supplemented with adenine or in synthetic complete (SC) media (YNB: $1.5 \mathrm{~g} / 1$ yeast nitrogen base lacking amino acids, $5 \mathrm{~g} / 1$ ammonium sulfate, 2\% glucose or galactose and supplemented with amino acids).

\subsubsection{Plasmids}

All plasmids used in this study and a concise description about their construction are listed in Table 2. The plasmids obtained from other sources are listed in Table 3.

\subsubsection{Oligonucleotides}

The oligonucleotides used in this study are listed in Table 4. 
Table 2: Plasmids constructed in this study

\begin{tabular}{|c|c|c|c|}
\hline Plasmid & Insert(s) & $\begin{array}{l}\text { Background } \\
\text { Vector }\end{array}$ & Preparation of insert \\
\hline pME3325 & $Y N M 3$ & pRS416MET25 & $\begin{array}{l}\text { BamH1/Xho1 restricted PCR product } \\
\text { obtained using NP20/NP21 primers from } \\
\text { YB322 genomic DNA. }\end{array}$ \\
\hline pME3336 & $Y N M 3$ & pRS426GAL1 & $\begin{array}{l}\text { BamH1/Xho1 restricted PCR product } \\
\text { obtained using NP20/NP21 primers from } \\
\text { YB322 genomic DNA. }\end{array}$ \\
\hline pME3459 & $G F P$ & pRS416MET25 & Sma1/Cla1 restricted $G F P$ from pME2564 \\
\hline pME3449 & $Y N M 3 G F P$ & pRS416MET25 & $\begin{array}{l}\text { pME3459 containing Spe1/Sma1 restricted } \\
\text { YNM3 PCR product amplified using } \\
\text { NP26/NP25 primers from YB322 genomic } \\
\text { DNA. }\end{array}$ \\
\hline pME3360 & $\begin{array}{l}\text { YNM3 (1- } \\
\text { 1946bp) }\end{array}$ & pUC19 & $\begin{array}{l}Y N M 3 \text { (1-1946) insert cloned into } \\
\text { BamH1/Hind111 site of pUC19 }\end{array}$ \\
\hline pME3361 & $\begin{array}{l}Y N M 3 S 235 A(1- \\
1946 \mathrm{bp})\end{array}$ & pUC19 & $\begin{array}{l}\text { Obtained by site directed mutagenesis in } \\
\text { pME3360 to exchange codons for Ser } 235 \\
\text { to Ala. }\end{array}$ \\
\hline pME3362 & $\begin{array}{l}Y N M 3 S 236 A(1- \\
1946 \mathrm{bp})\end{array}$ & pUC19 & $\begin{array}{l}\text { Obtained by site directed mutagenesis in } \\
\text { pME } 3360 \text { to exchange codons for Ser } 236 \\
\text { to Ala. }\end{array}$ \\
\hline pME3326 & $Y N M 3 S 235 A$ & pRS416MET25 & $\begin{array}{l}\text { Replacement of YNM3 sequences (1- } \\
\text { 1946bp) of pME3325 with YNM3S235A(1- } \\
\text { 1946bp) obtained by BamH1/Hind111 }\end{array}$ \\
\hline
\end{tabular}




\begin{tabular}{|c|c|c|c|}
\hline & & & restriction digestion of pME3361. \\
\hline pME3327 & YNM3S236A & pRS416MET25 & $\begin{array}{l}\text { Replacement of } Y N M 3 \text { sequences (1- } \\
\text { 1946bp) of pME3325 with YNM3S236A(1- } \\
\text { 1946bp) obtained by BamH1/Hind111 } \\
\text { restriction digestion of pME3362. }\end{array}$ \\
\hline pME3451 & $\begin{array}{l}\text { YNM3S235A- } \\
\text { GFP }\end{array}$ & pRS416MET25 & $\begin{array}{l}\text { pME3459 containing Spe1/Sma1 restricted } \\
\text { YNM3S235A PCR product amplified from } \\
\text { pME3326 as template using NP26/NP25 } \\
\text { primers. }\end{array}$ \\
\hline pME3453 & $\begin{array}{l}Y N M 3 S 236 A- \\
\text { GFP }\end{array}$ & pRS416MET25 & $\begin{array}{l}\text { pME3459 containing Spe1/Sma1 restricted } \\
\text { YNM3S236A PCR product amplified from } \\
\text { pME3327 as template using NP26/NP25 } \\
\text { primers. }\end{array}$ \\
\hline pME3450 & $Y N M 3 G F P$ & pRS426MET25 & $\begin{array}{l}\text { pME2564 containing containing } \\
\text { Spe1/Sma1 restricted YNM3 PCR product } \\
\text { amplified using NP26/NP25 primers. }\end{array}$ \\
\hline pME3452 & $\begin{array}{l}\text { YNM3S235A- } \\
\text { GFP }\end{array}$ & pRS426MET25 & $\begin{array}{l}\text { pME2564 containing Spe1/Sma1 restricted } \\
\text { YNM3S235A PCR product amplified from } \\
\text { pME3326 as template using NP26/NP25 } \\
\text { primers. }\end{array}$ \\
\hline pME3454 & $\begin{array}{l}Y N M 3 S 236 A- \\
G F P\end{array}$ & pRS426MET25 & $\begin{array}{l}\text { pME2564 containing Spe1/Sma1 restricted } \\
\text { YNM3S236A PCR product amplified from } \\
\text { pME3327 as template using NP26/NP25 } \\
\text { primers. }\end{array}$ \\
\hline pME3328 & $Y N M 3 \triangle P D Z 1$ & pRS416MET25 & BamH1/Xho1 restricted $Y N M 3 \triangle P D Z 1$ PCR \\
\hline
\end{tabular}




\begin{tabular}{|c|c|c|c|}
\hline & & & $\begin{array}{l}\text { product obtained by overlap PCR as } \\
\text { described. }\end{array}$ \\
\hline pME3329 & YNM3APDZ2 & pRS416MET25 & $\begin{array}{l}\text { BamH1/Xho1 restricted YNM3 } \triangle P D Z 2 \text { PCR } \\
\text { product obtained by overlap PCR as } \\
\text { described. }\end{array}$ \\
\hline pME3455 & $\begin{array}{l}\text { YNM3APDZ1- } \\
\text { GFP }\end{array}$ & pRS416MET25 & $\begin{array}{l}\text { pME3459 containing Spe1/Sma1 restricted } \\
Y N M 3 \triangle P D Z 1 \text { PCR product amplified from } \\
\text { pME3328 as template using NP26/NP25 } \\
\text { primers. }\end{array}$ \\
\hline pME3457 & 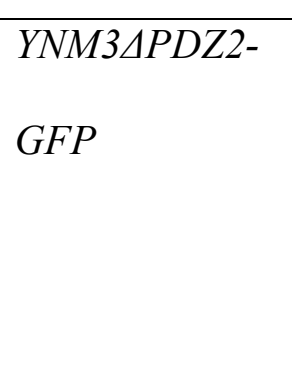 & pRS416MET25 & $\begin{array}{l}\text { pME3459 containing Spe1/Sma1 restricted } \\
Y N M 3 \triangle P D Z 2 \text { PCR product amplified from } \\
\text { pME3329 as template using NP26/NP25 } \\
\text { primers. }\end{array}$ \\
\hline pME3481 & $\begin{array}{l}Y N M 3 S 236 C- \\
G F P\end{array}$ & pRS426MET25 & $\begin{array}{l}\text { pME2564 containing Spe1/Sma1 restricted } \\
\text { YNM3S236C PCR product amplified using } \\
\text { NP26/NP25 primers. }\end{array}$ \\
\hline pME3364 & $\begin{array}{l}\text { YNM3 } 1 N 100 a a- \\
\text { GFP }\end{array}$ & pRS426MET25 & $\begin{array}{l}\text { pME2564 containing Spe1/Sma1 restricted } \\
\text { YNM3 NN100aa } \text { PCR product amplified } \\
\text { from pME3325 as template using } \\
\text { NP25/NP64 primers. }\end{array}$ \\
\hline pME3566 & $\begin{array}{l}\text { YNM3 NN100aa- } \\
\text { GFP }\end{array}$ & pRS416MET25 & $\begin{array}{l}\text { pME3459 containing Spe1/Sma1 restricted } \\
\text { YNM3 } 4 \text { N100aa } \text { PCR product amplified } \\
\text { from pME3325 as template using } \\
\text { NP25/NP64 primers. }\end{array}$ \\
\hline pME3341 & $Y N M 3$ & pGDBU-C1 & BamH1/Xho1 restricted $Y N M 3$ inserted \\
\hline
\end{tabular}




\begin{tabular}{|c|c|c|c|}
\hline & & & into BamH1/Sal1 site of pGBDU-C1 \\
\hline pME3342 & YNM3S236C & pGDBU-C1 & $\begin{array}{l}\text { BamH1/Xho1 restricted YNM3S236C } \\
\text { inserted into BamH1/Sal1 site of pGBDU- } \\
\text { C1 }\end{array}$ \\
\hline pME3567 & YNM3(1-100bp) & pRS426MET25 & $\begin{array}{l}\text { pME2564 containing Spe1/Sma1 restricted } \\
Y N M 3(1-100 \mathrm{bp}) \text { PCR amplified from } \\
\text { pME3325 as template using NP26/NP63 } \\
\text { primers. }\end{array}$ \\
\hline pME3345 & htrA/degP & pRS426GAL1 & $\begin{array}{l}\text { BamH1/Hind111 cut } h t r A / \operatorname{deg} P \text { obtained } \\
\text { from pJS13. }\end{array}$ \\
\hline pME3348 & HTRA2/OMI & pRS426GAL1 & $\begin{array}{l}\text { Xba1/Sal1 restricted HTRA2/OMI } \\
\text { amplified from cDNA using NP11/NP30 } \\
\text { primers. }\end{array}$ \\
\hline pME3363 & FPR3 & pRS416MET25 & $\begin{array}{l}\text { BamH1/Xho1 restricted FPR3 PCR } \\
\text { amplified from the candidate plasmid } \\
\text { (pRS202 library) as template using } \\
\text { NP92/91 primers. }\end{array}$ \\
\hline pME3568 & RPL6A & pRS416MET25 & $\begin{array}{l}\text { BamH1/Xho1 restricted RPL6A PCR } \\
\text { product amplified from the candidate } \\
\text { plasmid (pRS202 library) as template using } \\
\text { NP93/94 primers. }\end{array}$ \\
\hline pME3460 & YNM3 & pGEX-6P1 & BamH1/Xho1 restricted $Y N M 3$ insert \\
\hline pME3461 & YNM3S236C & pGEX-6P1 & BamH1/Xho1 restricted $Y N M 3 S 236 C$ insert \\
\hline pME3462 & $Y N M 3 S 236 A$ & pGEX-6P1 & BamH1/Xho1 restricted $Y N M 3 S 236 A$ insert \\
\hline pME3463 & FPR3 & pGEX-6P1 & BamH1/Xho1 restricted FPR3 insert \\
\hline
\end{tabular}


Table 3: Plasmids from other sources used in this study

\begin{tabular}{|c|c|c|}
\hline Plasmid & Description & Source \\
\hline pRS416 & URA3, CEN, $A m p^{R}$ (bla), ori & (Sikorski \& Hieter, 1989) \\
\hline pRS426 & URA3, $2 \mu, A m p^{R}$ (bla), ori & (Sikorski \& Hieter, 1989) \\
\hline pFA6a-natNT2 & Contains nourseothricin resistance cassette. & (Janke et al., 2004) \\
\hline pYM-N25 & $\begin{array}{l}\text { Contains GAL1-yeGFP-natNT2 promoter } \\
\text { module. }\end{array}$ & (Janke et al., 2004) \\
\hline pRS416MET25 & $\begin{array}{l}\text { pRS416 containing } M E T 25 \text { promoter and } C Y C 1 \\
\text { terminator. }\end{array}$ & (Mumberg et al., 1994) \\
\hline pRS426MET25 & $\begin{array}{l}\text { pRS426 containing } M E T 25 \text { promoter and } C Y C 1 \\
\text { terminator. }\end{array}$ & (Mumberg et al., 1994) \\
\hline $\mathrm{pRS} 426 G A L 1$ & $\begin{array}{l}\text { pRS } 426 \text { containing } G A L 1 \text { promoter and } C Y C 1 \\
\text { terminator. }\end{array}$ & (Mumberg et al., 1994) \\
\hline pME2564 & $\begin{array}{l}\text { pRS426MET25 containing GFP encoding } \\
\text { sequence in its Sma1/Cla1 site. }\end{array}$ & (Bomeke et al., 2006) \\
\hline pME3365 & $\begin{array}{l}\text { (pJS13) pT7-5 derivatives; Amp resistance; } \\
\text { htrA/degP insert cloned into BamH1/Hind111 } \\
\text { sites. }\end{array}$ & $\begin{array}{l}\text { Kindly provided by } \\
\text { Dr. Joana Skorko-Glonek, } \\
\text { University of Gdansk, } \\
\text { Poland. }\end{array}$ \\
\hline pME3366 & Plasmid encoding mitochondria targetted BFP & $\begin{array}{l}\text { Kindly provided by } \\
\text { Dr. Stefan Jakobs, MPI } \\
\text { (Biophysical Chemistry), } \\
\text { Göttingen }\end{array}$ \\
\hline
\end{tabular}




\section{Table 4: List of oligonucleotides}

\begin{tabular}{|c|c|c|}
\hline Oligo & Sequence (5'-3') & Use \\
\hline $\begin{array}{l}\text { NP01 } \\
27 \mathrm{mer}\end{array}$ & GCTGAGTCGACCTCCAACACTGTTCCA & $\begin{array}{l}\text { Check disruption of YNM3 } \\
\text { locus with } \mathrm{Kan}^{R} \text { cassette in the } \\
5 \text { ' region. }\end{array}$ \\
\hline $\begin{array}{l}\text { NP08 } \\
18 \mathrm{mer}\end{array}$ & GCGACAGTCACATCATGC & same as above \\
\hline $\begin{array}{l}\text { NP02 } \\
28 \mathrm{mer}\end{array}$ & GTTCACCTAGGGAAGCTCAACGGCTTTC & $\begin{array}{l}\text { Check disruption of YNM3 } \\
\text { locus with } \mathrm{Kan}^{R} \text { cassette in the } \\
\text { 3' region. }\end{array}$ \\
\hline $\begin{array}{l}\text { NP09 } \\
17 \text { mer }\end{array}$ & CCTCGACATCATCTGCC & same as above \\
\hline $\begin{array}{l}\text { NP14 } \\
\text { 30mer }\end{array}$ & $\begin{array}{l}\text { GCTAAGTCGACGACCCAAAGTCAACCG } \\
\text { CCA }\end{array}$ & $\begin{array}{l}\text { Amplification of } K^{R} n^{R} \\
\text { disrupted YNM3 locus from the } \\
\text { genomic DNA of BY4741 } \\
\text { Aynm3. }\end{array}$ \\
\hline $\begin{array}{l}\text { NP15 } \\
31 \text { mer }\end{array}$ & $\begin{array}{l}\text { GTTCAGGATCCCGCACCGTTAACCCCAA } \\
\text { ATC }\end{array}$ & same as above \\
\hline $\begin{array}{l}\text { NP16 } \\
69 \mathrm{mer}\end{array}$ & $\begin{array}{l}\text { ACTCTGAATACACACGTAGAGTACAGT } \\
\text { AAAGGTTTTTTAGATCTACTAATGCGTA } \\
\text { CGCTGCAGGTCGAC }\end{array}$ & $\begin{array}{l}\text { Amplification of the natNT2- } \\
G A L 1_{U A S} E G F P \text { module. }\end{array}$ \\
\hline $\begin{array}{l}\text { NP17 } \\
69 \text { mer }\end{array}$ & $\begin{array}{l}\text { CGGAAATTTTAGAATGGTCTCTTTTCTTT } \\
\text { ATATTGCTCAACGATATGGTCATCGATG } \\
\text { AATTCTCTGTCG }\end{array}$ & same as above \\
\hline $\begin{array}{l}\text { NP22 } \\
21 \mathrm{mer}\end{array}$ & GATTAAGTTGGGTAACGCCAG & $\begin{array}{l}\text { Sequencing primer for } \mathrm{pRS} 202 \\
\text { library }\end{array}$ \\
\hline
\end{tabular}




\begin{tabular}{|c|c|c|}
\hline $\begin{array}{l}\text { NP23 } \\
21 \mathrm{mer}\end{array}$ & GTGTGGAATTGTGAGCGGATA & same as above \\
\hline $\begin{array}{l}\text { NP39 } \\
71 \mathrm{mer}\end{array}$ & $\begin{array}{l}\text { TCGAAGTTTATCTAAACTACCACCAAAG } \\
\text { AAGACCGACTAGATTTACAATCATGCGT } \\
\text { ACGCTGCAGGTCGAC }\end{array}$ & $\begin{array}{l}\text { Amplification of NatR cassette } \\
\text { for disruption of the } Y C A 1 \\
\text { locus. }\end{array}$ \\
\hline $\begin{array}{l}\text { NP40 } \\
73 \text { mer }\end{array}$ & $\begin{array}{l}\text { ACATACTACACCAGTCTGAATACATCTA } \\
\text { CCAACGTACACATTCATATATTTCTAAT } \\
\text { CGATGAATTCGAGCTCG }\end{array}$ & same as above \\
\hline $\begin{array}{l}\text { NP107 } \\
71 \mathrm{mer}\end{array}$ & $\begin{array}{l}\text { TTGTGTGAAAGTTCATACATAATTGAAA } \\
\text { GCAAGCATCCAACCAGCCCAATATGCG } \\
\text { TACGCTGCAGGTCGAC }\end{array}$ & $\begin{array}{l}\text { Amplification of NatR cassette } \\
\text { for disruption of the FPR3 } \\
\text { locus. }\end{array}$ \\
\hline $\begin{array}{l}\text { NP108 } \\
76 \text { mer }\end{array}$ & $\begin{array}{l}\text { ATATTATGTAAAAAGAATAATATATATA } \\
\text { AACATCTATCCGTACGAGCGCGTGTACT } \\
\text { AATCGATGAATTCGAGCTCG }\end{array}$ & same as above \\
\hline $\begin{array}{l}\text { NP109 } \\
26 m e r\end{array}$ & CAATGCTCCAAACATTCTACTATCAC & $\begin{array}{l}\text { Check disruption of } F P R 3 \\
\text { locus with } N a t^{R} \text { cassette in the } \\
5 \text { ' region along with NP08. }\end{array}$ \\
\hline $\begin{array}{l}\text { NP20 } \\
39 \text { mer }\end{array}$ & $\begin{array}{l}\text { TTATATGGATCCATGACCATATCGTTGA } \\
\text { GCAATATAAAG }\end{array}$ & $\begin{array}{l}\text { Forward primer used to PCR } \\
\text { amplify YNM3 or its mutants } \\
\text { for cloning. Contains BamH1 } \\
\text { site. }\end{array}$ \\
\hline $\begin{array}{l}\text { NP21 } \\
37 \text { mer }\end{array}$ & $\begin{array}{l}\text { ATTATTCTCGAGCTATTTTTCACTTTGGC } \\
\text { TGTTGCCG }\end{array}$ & $\begin{array}{l}\text { Reverse primer used to PCR } \\
\text { amplify YNM3 or its mutants } \\
\text { for cloning. Contains Xho1 } \\
\text { site. }\end{array}$ \\
\hline $\begin{array}{l}\text { NP102 } \\
36 \text { mer }\end{array}$ & GCATCTGCTTCTGGCGGTGCAAGTGGTT & Primer for SDM $(Y N M 3 S 235 A)$ \\
\hline
\end{tabular}




\begin{tabular}{|c|c|c|}
\hline & CTCCAGTC & \\
\hline $\begin{array}{l}\text { NP103 } \\
\text { 36mer }\end{array}$ & $\begin{array}{l}\text { GACTGGAGAACCACTTGCACCGCCAGA } \\
\text { AGCAGATGC }\end{array}$ & same as above \\
\hline $\begin{array}{l}\text { NP104 } \\
36 \text { mer }\end{array}$ & $\begin{array}{l}\text { GCATCTGCTTCTGGCGGTTCAGCTGGTT } \\
\text { CTCCAGTC }\end{array}$ & Primer for SDM $(Y N M 3 S 236 A)$ \\
\hline $\begin{array}{l}\text { NP105 } \\
\text { 36mer }\end{array}$ & $\begin{array}{l}\text { GACTGGAGAACCAGCTGAACCGCCAGA } \\
\text { AGCAGATGC }\end{array}$ & same as above \\
\hline $\begin{array}{l}\text { NP61 } \\
\text { 36mer }\end{array}$ & $\begin{array}{l}\text { GCATCTGCTTCTGGCGGTTCATGTGGTT } \\
\text { CTCCAGTC }\end{array}$ & $\begin{array}{l}\text { Primer for SDM } \\
(Y N M 3 S 236 C)\end{array}$ \\
\hline $\begin{array}{l}\text { NP62 } \\
36 \mathrm{mer}\end{array}$ & $\begin{array}{l}\text { GACTGGAGAACCACATGAACCGCCAGA } \\
\text { AGCAGATGC }\end{array}$ & same as above \\
\hline $\begin{array}{l}\text { NP26 } \\
38 \text { mer }\end{array}$ & $\begin{array}{l}\text { AGCTTACTAGTATGACCATATCGTTGAG } \\
\text { CAATATAAAG }\end{array}$ & $\begin{array}{l}\text { Forward primer used to PCR } \\
\text { amplify } Y N M 3 \text { or its mutants } \\
\text { for cloning. Contains Spe1 site. }\end{array}$ \\
\hline $\begin{array}{l}\text { NP25 } \\
33 \text { mer }\end{array}$ & $\begin{array}{l}\text { AGCACCCGGGTTTTTCACTTTGGCTGTT } \\
\text { GCCGG }\end{array}$ & $\begin{array}{l}\text { Reverse primer used to PCR } \\
\text { amplify } Y N M 3 \text { or its mutants } \\
\text { for cloning. Contains Sma1 } \\
\text { site. }\end{array}$ \\
\hline $\begin{array}{l}\text { NP11 } \\
\text { 25mer }\end{array}$ & GAATTCTAGACTCCACCGCGGTGGC & $\begin{array}{l}\text { Forward primer used to PCR } \\
\text { amplify cDNA encoding } \\
\text { HtrA2/Omi. Contains Xba1 } \\
\text { site. }\end{array}$ \\
\hline $\begin{array}{l}\text { NP30 } \\
\text { 23mer }\end{array}$ & GCCAGTCGACTCATTCTGTGACC & $\begin{array}{l}\text { Reverse primer used to PCR } \\
\text { amplify cDNA encoding } \\
\text { HtrA2/Omi. Contains Sal1 site. }\end{array}$ \\
\hline
\end{tabular}




\begin{tabular}{|c|c|c|}
\hline $\begin{array}{l}\text { NP33 } \\
54 \mathrm{mer}\end{array}$ & $\begin{array}{l}\text { GCAGGTGACAGTACATTCGACACCGCC } \\
\text { CCTTTGAACTTGAATCGTACCACGTGT }\end{array}$ & $\begin{array}{l}\text { Overlap PCR to delete } P D Z 1 \\
\text { in } Y N M 3 .\end{array}$ \\
\hline $\begin{array}{l}\text { NP34 } \\
\text { 22mer }\end{array}$ & AGGGGCGGTGTCGAATGTACTG & same as above \\
\hline $\begin{array}{l}\text { NP57 } \\
23 \text { mer }\end{array}$ & TTCGGGCACACCTCTAATTCTGG & $\begin{array}{l}\text { Overlap PCR to delete } P D Z 2 \\
\text { in } Y N M 3 \text {. }\end{array}$ \\
\hline $\begin{array}{l}\text { NP58 } \\
72 \mathrm{mer}\end{array}$ & $\begin{array}{l}\text { TCGGTTCAATTTCCGTTCTGCAAGCCAG } \\
\text { AATTAGAGGTGTGCCCGAAACCGACCG } \\
\text { TTTTGTAATATTTGCAG }\end{array}$ & same as above \\
\hline $\begin{array}{l}\text { NP63 } \\
34 \text { mer }\end{array}$ & $\begin{array}{l}\text { AGCACCCGGGCAAAGCAGAATCGCAAT } \\
\text { CGAATGG }\end{array}$ & $\begin{array}{l}\text { Reverse primer used to PCR } \\
\text { amplify DNA encoding first } \\
100 \text { amino acids of Ynm3 } \\
\text { along with NP26 as forward } \\
\text { primer. Contains Sma1 site. }\end{array}$ \\
\hline $\begin{array}{l}\text { NP64 } \\
37 \text { mer }\end{array}$ & $\begin{array}{l}\text { AGCTTACTAGTATGGTATCTGAAGCTAC } \\
\text { CGGATTTGT }\end{array}$ & $\begin{array}{l}\text { Forward primer used to } \\
\text { amplify } Y N M 3 \triangle N 100 \text { along } \\
\text { with NP25 as the reverse } \\
\text { primer. Contains Spe1 site. }\end{array}$ \\
\hline $\begin{array}{l}\text { NP92 } \\
36 \text { mer }\end{array}$ & $\begin{array}{l}\text { ACATGGATCCATGTCTGATTTGTTACCA } \\
\text { CTAGCTAC }\end{array}$ & $\begin{array}{l}\text { Forward primer used to PCR } \\
\text { amplify FPR3 for cloning. } \\
\text { Contains BamH1 site. }\end{array}$ \\
\hline $\begin{array}{l}\text { NP91 } \\
\text { 38mer }\end{array}$ & $\begin{array}{l}\text { ACATCTCGAGCTAGTTTTTCATAGAAAC } \\
\text { CAATTTAACG }\end{array}$ & $\begin{array}{l}\text { Reverse primer used to PCR } \\
\text { amplify FPR3 for cloning. } \\
\text { Contains Xho1 site. }\end{array}$ \\
\hline $\begin{array}{l}\text { NP93 } \\
34 \text { mer }\end{array}$ & $\begin{array}{l}\text { ACATGGATCCATGAGTGCCCAAAAAGT } \\
\text { ATGTTCC }\end{array}$ & $\begin{array}{l}\text { Forward primer used to PCR } \\
\text { amplify } R P L 6 A \text { for cloning. }\end{array}$ \\
\hline
\end{tabular}




\begin{tabular}{|l|l|l|}
\hline & & Contains BamH1 site. \\
\hline $\begin{array}{l}\text { NP94 } \\
\text { 37mer }\end{array}$ & ACATCTCGAGTTAAAATTTCAACATGTG & Reverse primer used to PCR \\
& TGGCTTGTC & amplify RPL6A for cloning. \\
& & Contains Xho1 site. \\
\hline
\end{tabular}

\subsection{Methods}

\subsubsection{DNA sequence analysis}

Vectors and other DNA sequences were analysed using the LASERGENE software package from DNASTAR. Budding yeast chromosomal DNA sequences were analysed using the tools available in the Saccharomyces genome database (SGD) (www.yeastgenome.org).

\subsubsection{Polymerase Chain Reaction}

Polymerase chain reaction (PCR) (Higuchi et al., 1988) was performed for rapid amplification of DNA for various puposes. For cloning, either KOD HiFi DNA Polymerase (Novagen, Darmstadt, Germany) or Phusion $^{R} \quad$ (New England Biolabs, Frankfurt Am Main, Germany) were used. The PCR reaction constitutions and conditions were based on manufacturers's protocols. For amplification of DNA for site-specific homologous recombination, either KOD HiFi DNA Polymerase or self-made Taq polymerase available in the laboratory was used. For analytical purposes, the self- made Taq polymerase with an initial denaturation at $95^{\circ} \mathrm{C}$ for 2 minutes followed by 30 cycles of denaturation at $95^{\circ} \mathrm{C}$ for 1 minute, annealing for 45 seconds and extension at $72^{\circ} \mathrm{C}$ for 1 minute $/ \mathrm{kb}$. This was followed by a final extension at $72^{\circ} \mathrm{C}$ for 5 minutes. PCRs were performed either in Mastercycler Gradient (EPPENDORF, Hamburg, Germany) or in the PCR cycler (Mwg-BIOTECH Primus or Primus $96^{\text {plus }}$, Ebersberg, Germany). The annealing temperatures were generally between $60-$ $65^{\circ} \mathrm{C}$ 


\subsubsection{Restriction digestion of DNA}

For cloning and for analytical confirmation of the resultant clones, DNA was digested using restriction enzymes (Fermentas, St.Leon-Rot, Germany). For analytical purposes, generally 200-500 ng of plasmid DNA was digested for 1-2 hours in a total volume of $20 \mu \mathrm{l}$. For cloning, about $500 \mathrm{ng}$ of plasmid DNA was digested for 2-3 hours in a total volume of 20 $\mu 1$.

\subsubsection{Preparation of DNA for ligation}

For cloning, the restricted vector DNA was first dephosphorylated in order to remove 5' phosphates to avoid unnecessary re-ligation. This was done by incubation at $37^{\circ} \mathrm{C}$ for 45 minutes with $1 \mu \mathrm{l}$ shrimp alkaline phosphatase (SAP) (FERMENTAS, St.Leon-Rot, Germany) which was added directly to $20 \mu 1$ of the restriction digestion reaction. The restricted and dephosphorylated vector DNA was then purified following 1\% agarose gel electrophoresis using the QIAspin Nucleotide Removal Kit (QIAgEN, Hilden, Germany) according to instructions provided in the manual. For preparation of insert, the PCR product was first purified after 1\% agarose gel electrophoresis using the QIAspin Nucleotide Removal kit followed by restriction digestion. The restricted insert DNA was once again purified using the QIAspin Nucleotide Removal Kit. For ligation, about 50 ng of restricted vector DNA was incubated with atleast 5 times the amount of restricted insert DNA along with $1 \mu$ of T4 DNA ligase (FERMENTAS, St.Leon-Rot, Germany) in 1X T4 DNA ligase buffer in a total volume of $10-20 \mu 1$.

\subsubsection{Preparation of chemically competent $E$.coli cells}

About 10 colonies of E. coli were inoculated into $250 \mathrm{ml}$ of SOB medium (2\% Tryptone, $0.5 \%$ yeast extract, $10 \mathrm{mM} \mathrm{NaCl}, 2.5 \mathrm{mM} \mathrm{KCl}, 10 \mathrm{mM} \mathrm{MgCl}_{2}, 10 \mathrm{mM} \mathrm{MgSO}_{4}$ ) in a 11 flask. The culture was incubated at $20^{\circ} \mathrm{C}$ for about 20 hours until the $\mathrm{OD}_{600}$ reached approximately 0.6. The culture was cooled on ice for 10 minutes and centrifuged at 2,500 $\mathrm{g}$ for 10 minutes at 
$4^{\circ} \mathrm{C}$. The pellet was then resuspended in $80 \mathrm{ml}$ TB $\left(10 \mathrm{mM}\right.$ PIPES, $15 \mathrm{mM} \mathrm{CaCl}_{2}, 250 \mathrm{mM}$

$\mathrm{KCl}$; the $\mathrm{pH}$ was then adjusted to 6.7 with $\mathrm{KOH}$ followed by the addition of $55 \mathrm{mM} \mathrm{MnCl}_{2}$ ).

This cell suspension was incubated on ice for 10 minutes followed by centrifugation at 2,500

$\mathrm{g}$ for 10 minutes at $4^{\circ} \mathrm{C}$. The pellet obtained was then resuspended in $20 \mathrm{ml}$ TB followed by the slow addition of DMSO with swirling to obtain a final concentration of $7 \%$. This cell suspension was further incubated for 10 minutes on ice and dispensed in $0.5 \mathrm{ml}$ aliquots which were first subjected to shock freezing in liquid $\mathrm{N}_{2}$ before storage at $-80^{\circ} \mathrm{C}$.

\subsubsection{Transformation of chemically competent $E$.coli cells}

An aliquot of competent cells was first allowed to thaw on ice. About 3-4 $\mu 1$ of the ligation reaction was added to about $200 \mu 1$ of the competent cells and incubated for 30 minutes on ice. The cells were then subjected to heat shock at $42^{\circ} \mathrm{C}$ for 45 seconds and then placed on ice for 5 minutes. $800 \mu \mathrm{l}$ of SOC medium (SOB $+20 \mathrm{mM}$ Glucose) was added to the mixture followed by recovery at $37^{\circ} \mathrm{C}$ with shaking at $180 \mathrm{rpm}$ for 1 hour. The cells were then centrifuged at 2,500 rpm for 3 minutes on a tabletop centifuge (Biofuge pico, HERAEUS, Hanau, Germany) and plated on LB agar supplemented with ampicillin to a final concentration of $100 \mu \mathrm{g} / \mathrm{ml}$.

\subsubsection{Plasmid DNA purification}

Plasmid DNA was purified using the QIAPrep Spin Miniprep Kit (QIAGEN, Hilden, Germany). A single colony of $E$. coli was inoculated into $5 \mathrm{ml} \mathrm{LB}$ medium supplemented with Ampicillin to a final concentration of $100 \mu \mathrm{g} / \mathrm{ml}$ and incubated for 16 hours at $37^{\circ} \mathrm{C}$ with shaking $(180 \mathrm{rpm})$. The cells were harvested by centrifugation at $13,000 \mathrm{rpm}$ on a tabletop centrifuge (Biofuge pico, Heraeus, Hanau, Germany). The remaining steps were exactly based on the instruction manual provided. 


\subsubsection{DNA sequencing}

Crucial cloning steps were validated by sequencing on an ABI Prism 310 capillary sequencer (PE BIOSYSTEMS). DNA sequences were verified using the 4Peaks software (www.mekentosj.com).

\subsubsection{Site directed mutagenesis}

Site directed mutagenesis was used to mutate codons encoding Ser235 or Ser236 of Ynm3 to Cysteine or Alanine. The QuikChange II Site Directed Mutagenesis Kit (STRATAgEnE, La Jolla, CA, USA) was used for this purpose. The primer design and reaction conditions were according to the instructions provided in the manual. Two primers containing the desired mutations were designed spanning the target region in opposing directions (Table 4). A region of YNM3, 1-1946 base pairs, containing the codon to be altered was cloned into a smaller PUC 19 vector so that the dsDNA template size does not exceed the limit prescribed in the manual. A series of different concentrations of the dsDNA $(5,10,20$ and $50 \mathrm{ng})$ were used in the reaction to which the various components of the kit were added as prescribed in the manual, including the primers at $125 \mathrm{ng}$ /reaction. Lastly, $1 \mu \mathrm{l}$ of PfuUltra HF DNA polymerase was added and the reaction mixture was cycled in a PCR thermal cycler (MWGBIOTECH). The annealling temperature used was $55^{\circ} \mathrm{C}$ and the number of cycles used was 16 decided based on the instructions manual. After this, the reaction was cooled below $37^{\circ} \mathrm{C}$ and $1 \mu l$ of Dpn I restriction enzyme was added to each reaction and incubated at $37^{\circ} \mathrm{C}$ for 1 hour. The Dpn I enzyme is specific to methylated and hemi-methylated DNA and therefore digests the parental DNA template but does not digest the mutant-synthesized DNA. As most E.coli strains produce methylated DNA, they are not resistant to Dpn I digestion. Undigested DNA was then used to transform the XL1-Blue supercompetant cells provided with the kit. The cells were alliquoted into Falcon 2059 polypopylene tubes prior to transformation. Transformed cells were incubated in SOC medium for 1 hour in an orbital shaker and then 
plated on LB agar containing ampicillin (final conc. of $100 \mathrm{mg} / \mathrm{ml}$ ).

Plasmids were isolated from the resulting colonies and sequenced to confirm the presence of the desired mutation. The mutated PUC19 insert was then excised and ligated with BamH1/Hind111 digested pME3325 (Table 2) in order to replace the 1-1946 base pairs of wild type $Y N M 3$ with the region containing the desired mutations.

\subsubsection{Overlap extension PCR}

An overlap extension PCR method was used to delete the region encoding either of the two PDZ domains of YNM3. For generation of YNM3 $\triangle P D Z 1$ or $Y N M 3 \triangle P D Z 2$, two individual PCRs were performed on YNM3 template to amplify only those regions 5' and 3 ' of the region encoding the PDZ domain which is to be excluded. The 5' end of one of the primers spanning a sequence immediately before or after the region encoding the PDZ domain to be deleted contains an added sequence that overlaps with a small part of the other PCR product. These overlapping fragments of YNM3 obtained by individual PCR reactions were then used as templates in a single PCR reaction in which only the 5' and 3' end-specific primers of YNM3 (Table 4) were used for amplification, thus generating a product that lacks the region encoding a PDZ domain.

\subsubsection{Amplification of DNA libraries following electroporation}

DNA libraries were transformed by high-voltage electroporation into electro-competent $E$. coli cells $\left(\right.$ ElectroMAX ${ }^{\mathrm{TM}} \mathrm{Stb} 14^{\mathrm{TM}}$, InVITROGEN, Karlsruhe, Germany). The cells were thawed on ice and mixed with $1 \mu 1$ of the library DNA and mixed gently. The mixture was transferred into a gene pulser cuvette (BIORAD, Herts, UK) already placed on ice. The cells in the cuvette were then subjected to a $1.2 \mathrm{KV}$ single pulse lasting for $5 \mathrm{~ms}$ in a Gene Pulser (BIORAD, Herts, UK). The cells were incubated for 1.5 hours in $1 \mathrm{ml} \mathrm{SOC}$ medium in a $15 \mathrm{ml}$ reaction tube at $37^{\circ} \mathrm{C}$ on a shaker $(180 \mathrm{rpm})$. The contents were inoculated into $500 \mathrm{ml}$ 
Terrific Broth (12 g Tryptone, $24 \mathrm{~g}$ Yeast Extract, $4 \mathrm{ml}$ Glycerol in a total volume of $900 \mathrm{ml}$ $\mathrm{H}_{2} \mathrm{O}$ to which $100 \mathrm{ml}$ of sterile $10 \mathrm{X}$ TB salt solution containing $2.312 \mathrm{~g} \mathrm{KH}_{2} \mathrm{PO}_{4}$ and $12.514 \mathrm{~g}$ $\mathrm{K}_{2} \mathrm{HPO}_{4}$ was added after autoclaving followed by cooling). The culture was incubated overnight at $37^{\circ} \mathrm{C}$ on a shaker. The library DNA was isolated using the QIAGEN Maxi Prep Kit according to the instructions provided in the manual.

\subsubsection{Transformation of yeast cells}

\subsubsection{Preparation of competent yeast cells}

$10 \mathrm{ml}$ of YPD was inoculated with the yeast strain to be transformed. The culture was incubated on a shaker at $30^{\circ} \mathrm{C}$ overnight. The culture was then centrifuged at minimal speed (SIGMA 4K15C) and resuspended in $10 \mathrm{ml} 100 \mathrm{mM} \mathrm{LiOAc/TE} \mathrm{(5} \mathrm{ml} \mathrm{1M} \mathrm{Tris-Cl} \mathrm{pH:} \mathrm{8.0,} 1$ $\mathrm{ml}$ 0.5 M Na.EDTA pH:8.0, $100 \mathrm{mM}$ LiOAc in a total volume of $50 \mathrm{ml} \mathrm{H}_{2} \mathrm{O}$ ). The suspension was allowed to shake slowly for 1 hour at $30^{\circ} \mathrm{C}$, then centrifuged at minimal speed and resuspended in $1 \mathrm{ml} 100 \mathrm{mM} \mathrm{LiOAc/TE}$.

\subsubsection{Transformation of competent yeast cells}

To transform linear DNA, the PCR product was precipitated using $1 / 20^{\text {th }}$ of its volume of 3 $\mathrm{M} \mathrm{NaOAc}$ and 2.5 times its volume of $100 \%$ ethanol for about 1 hour on ice. The DNA was pelleted by centrifugation at 13,000 rpm (Biofuge fresco, HERAEUS, Hanau, Germany) for 10 minutes. The pellet was dried in a vacuum dryer (Speed Vac RC3B plus, SAVANT) and dissolved in $20 \mu \mathrm{l}$ of TE buffer. About $20 \mu \mathrm{l}$ of carrier DNA (salmon sperm DNA) was added to it and mixed with $100 \mu 1$ of competent yeast cells in a microfuge tube. $0.5 \mathrm{ml}$ of $50 \%$ PEG 4000 was added and the tubes were inverted several times and incubated at $30^{\circ} \mathrm{C}$ on a shaker for 1 hour. The cells were then subjected to heat shock at $42{ }^{\circ} \mathrm{C}$ for $10-15$ minutes and centrifuged at minimal speed. The supernatant was discarded, the cells resuspended in $500 \mu 1$ YPD and incubated at $30^{\circ} \mathrm{C}$ for 2 hours on a shaker. The cells were then pelletted at minimal speed for 2-5 minutes and resuspended in $200 \mu \mathrm{l}$ of sterile $\mathrm{H}_{2} \mathrm{O}$ and spread on YPD agar 
plates containing the appropriate drug for selection and incubated at $30^{\circ} \mathrm{C}$ for 4 days. Transformation of plasmids was done in a similar manner except that there is no requirement for DNA precipitation or for the presence of carrier DNA. About $1 \mu \mathrm{g}$ of each plasmid was used for transformation and the yeast cells plated on selective SC medium lacking the amino acids to select for auxotrophic maker(s) on the plasmid(s).

\subsubsection{Isolation of DNA from yeast cells}

An overnight culture of the yeast strain in $10 \mathrm{ml}$ YPD was centrifuged and the pellet resuspended in $0.5 \mathrm{ml} \mathrm{H} \mathrm{H}_{2} \mathrm{O}$. The suspension was again centrifuged for 5 seconds in a tabletop centrifuge (Biofuge pico, Heraeus, Hanau, Germany). The supernatant was discarded and the pellet was disrupted by vortexing briefly. It was then resuspended in $200 \mu \mathrm{l}$ breaking buffer (2\% V/V TritonX 100, 1\% V/V SDS, $100 \mathrm{mM} \mathrm{NaCl,} 10 \mathrm{mM}$ Tris-Cl, pH8.0, $1 \mathrm{mM}$ EDTA, pH8.0). About $0.3 \mathrm{~g}(200 \mu \mathrm{l})$ of $0.45 \mathrm{~mm}$ glass beads were added and the suspension was vortexed at high power for 5 minutes. $200 \mu \mathrm{l}$ of TE buffer $(10 \mathrm{mM}$ Tris-Cl pH7.5/8.0, $1 \mathrm{mM}$ EDTA, pH8.0) was added and the suspension was again vortex briefly. This was centrifuged for 5 minutes at 13,000 rpm at room temperature in a tabletop centifuge (Biofuge pico, Heraeus, Hanau, Germany). The aqueous layer was transferred to a clean microfuge tube to which $1 \mathrm{ml} 100 \%$ ETOH was added and mixed gently by inversion. This was further centrifuged at high speed for 3 minutes at room temperature. The supernatent was removed and the pellet was resuspended in $100 \mu \mathrm{TE}$ after drying at room temperature. The DNA thus obtained was used for analytical purposes like PCR. If pure DNA is required, the RNA contaminants have to be removed. For this purpose, the DNA obtained after the previously described ETOH precipitation step was resuspended in $0.4 \mathrm{ml} \mathrm{TE}$ to which $30 \mu \mathrm{lof} 1 \mathrm{mg} / \mathrm{ml}$ RNase A was added, mixed and incubated for 5 minutes at $37^{\circ} \mathrm{C} .10 \mu \mathrm{l}$ of $4 \mathrm{M} \mathrm{NH}_{4} \mathrm{COOCH}_{3}$ and $1 \mathrm{ml} 100 \% \mathrm{ETOH}$ was then added to it and mixed gently by inversion. This was centrifuged at high speed for 3 minutes at room temperature. The supernatant was discarded 
and the pellet was allowed to dry at room temperature or at slow speed in a vacuum dryer (Speed Vac RC3B plus, SAVANT). The pellet was then resuspended in $100 \mu l$ of TE buffer. The amount of DNA present in the solution was determined spectrophotometrically (Ultrospec 4000, Pharmacia Biotech, Munich, Germany) at a wavelength of $260 \mathrm{~nm}$. A value of $A_{260}=10$ corresponds to $50 \mathrm{mg} / \mathrm{ml}$ of double stranded DNA.

\subsubsection{Genetic suppressor screen}

For the gain of function screen, the pRS202 genomic DNA library was used (Connelly and Hieter, unpublished, June 1990). Inserts from this library are approximately 6-8 Kbps in length. The $\Delta y n m 3$ strain was transformed with $1 \mu l$ of the library, plated on SC-Ura as the plasmids in the library have a $U R A 3$ auxotrophic selectable marker and incubated for a week at $38^{\circ} \mathrm{C}$. Twenty individual transformations were performed. Colonies that appeared large were picked and growth tests were performed (spot dilution assay) at $38^{\circ} \mathrm{C}$ to avoid any false positives. Plasmids contained in the colonies that grew better at $38^{\circ} \mathrm{C}$ were isolated and retransformed into the $\Delta y n m 3$ strain for a further verification of their ability to induce better growth at $38^{\circ} \mathrm{C}$. The inserts contained in the plasmids were sequenced using specific primers (Table 4).

\subsubsection{Growth tests}

For spot dilution assays, 10-fold dilutions of overnight cultures of each strain starting with an $\mathrm{OD}_{600}$ of 0.5 were made in sterile water. $10 \mu 1$ of each dilution were spotted on plates containing appropriate selective media (SC-Ura or SC-Met-Ura or SC-Ura+galactose) or rich medium containing either glucose or galactose and incubated at the temperatures indicated for at least 2-3 days or otherwise indicated. For assaying growth in liquid culture, overnight cultures of each strain were diluted in $100 \mathrm{ml}$ of the appropriate selective inducing medium (SC-Met-Ura) in duplicate in unbaffled flasks $(300 \mathrm{ml})$ to obtain a final $\mathrm{OD}_{600}$ between 0.1 and 0.2. The flasks were incubated at $39^{\circ} \mathrm{C}$ with shaking $(220 \mathrm{rpm})$. OD at $600 \mathrm{~nm}$ was 
measured every two hours for the next 12 hours in duplicate per flask resulting in four readings per strain. A graph was plotted using the $\mathrm{OD}_{600}$ values.

\subsubsection{Survival after heat shock treatment}

Logarithmic cultures $\left(\mathrm{OD}_{600}=0.5\right)$ of the wild type BY4741 strain and the congenic $\Delta y n m 3$ strain in liquid YPD were subjected to heat shock at $50^{\circ} \mathrm{C}$ in a prewarmed water bath for the indicated durations. Serial 10 fold dilutions of each culture were then made starting with an $\mathrm{OD}_{600}$ of 0.5 and spotted on YPD agar. The plates were incubated at $30^{\circ} \mathrm{C}$ for 1 day.

\subsubsection{Preparation of yeast cell crude extracts for Western blotting}

Yeast strains were allowed to grow in appropriate selective medium overnight. Cells were pelleted at minimal speed (SIGMA 4K15C) at room temperature and resuspended in $10 \mathrm{ml}$ of the appropriate inducing medium depending on the promoter driving the expression of the protein that is to be detected. The culture was induced for at least 2 hours and the cells were pelleted at $4{ }^{\circ} \mathrm{C}$ and stored at $-80^{\circ} \mathrm{C}$ until use. For preparation of extracts, the cell pellets were allowed to thaw on ice. The cells were washed with $1 \mathrm{ml}$ ice cold TE (10 mM Tris-Cl pH7.5/8.0, $1 \mathrm{mM}$ EDTA, pH8.0) centrifuged at 13,000 rpm using a tabletop centrifuge (Biofuge pico, Heraeus, Hanau, Germany) and resuspended in $200 \mu 1$ of R-buffer $(150 \mu 1$ $1 \mathrm{M}$ Tris $\mathrm{pH}$ 7.5, $6 \mu 10.5 \mathrm{M}$ EDTA, $150 \mu \mathrm{l}$ 1M DTT, $120 \mu \mathrm{l}$ PIM complete (Roche, Mannheim, Germany). The suspension was transferred to a $2 \mathrm{ml}$ microfuge tube filled with $250 \mu \mathrm{l}$ of $0.45 \mathrm{~mm}$ glass beads and vortexed at maximum power for 5 minutes at $4^{\circ} \mathrm{C}$ and then centrifuged at $13,000 \mathrm{rpm}$ for 10 minutes at $4{ }^{\circ} \mathrm{C}$ (Biofuge fresco, HerAEus, Hanau, Germany). The amount of protein in the supernatant was determined using the Bradford method (RotiQuant, Roth, Karlsruhe, Germany). $50 \mu 1$ of the supernatant was transferred to a $1.5 \mathrm{ml}$ microfuge tube containing $10 \mu 1$ of $6 \mathrm{x}$ SDS loading buffer and stored at $-20^{\circ} \mathrm{C}$ until use. 


\subsubsection{Protein immunoblotting}

Yeast cell extracts were prepared for Western blotting as described in section 2.2.7. Extracts containing equal amounts of protein from each strain were separated by $12 \%$ SDSPAGE prior to Western blotting. The proteins were transferred on to a nitrocellulose membrane by Western blot (wet transfer) for $1 \mathrm{hr}$ at $100 \mathrm{~V}$. The membrane was stained with Ponceau S stain $(0.2 \%$ Ponceau $\mathrm{S}$ in $3 \% \mathrm{TCA})$ to confirm the transfer of protein bands and then washed repeatedly with $1 \mathrm{X}$ TBST $(0.1 \%$ Tween 20 in TBS: $25 \mathrm{mM}$ Tris Base, $155 \mathrm{mM}$ $\mathrm{NaCl}, \mathrm{pH}$ adjusted to 7.4 with $\mathrm{HCl}$ ) until the Ponceau $\mathrm{S}$ stain disappeared completely. Blocking was done for 1 hour at room temperature with blocking buffer (5\% non-fat milk powder in $1 \mathrm{X}$ TBST). The membrane was probed with a 1:500 dilution in blocking buffer of mouse anti-GFP monoclonal antibody (CLONTECH, Heidelberg, Germany) or 1:2000 dilution of Rabbit polyclonal antiserum against $\mathrm{Cdc} 28$ either for 1.5 hours at room temperature or overnight at $4^{\circ} \mathrm{C}$. The membrane was then washed for 45 minutes with repeated changes of 1X TBST. 1:2500 dilution of peroxidase coupled rabbit anti-mouse or goat anti-rabbit IgG were used as secondary antibodies (DiAnOva, Hamburg, Germany). The membrane was again washed for 45 minutes with repeated changes of 1X TBST and developed by the Enhanced Chemiluminisence (ECL) method. The ECL solution $1(100 \mu 1$ of $2.5 \mathrm{mM}$ Luminol and $44 \mu 1$ of $40 \mu \mathrm{M}$ Paracoumaric acid in a total volume of $10 \mathrm{ml}$ of $10 \mathrm{mM}$ Tris, $\mathrm{pH} 8.5$ ) was mixed with ECL solution $2\left(6.15 \mu \mathrm{l}\right.$ of $30 \% \mathrm{H}_{2} \mathrm{O}_{2}$ in $10 \mathrm{ml}$ of $10 \mathrm{mM}$ Tris, $\left.\mathrm{pH} 8.5\right)$ just prior to use. The membrane was incubated in the reagent for 1 minute and exposed to the ECL film (Amersham Biosciences, Munich, Germany) for 1-10 minutes in the dark until the signal intensity on the film was appropriately strong for viewing. The film was developed using a film-developing machine (Protec Processor TECHNOLOGY). 


\subsubsection{Dihydrorhodamine staining}

Free intracellular radicals were determined using dihydrorhodamine123 (RocHE, Mannheim, Germany) according to the procedure described (Madeo et al., 1999). Logarithmic cultures of each strain were subjected to $1 \mathrm{mM} \mathrm{H}_{2} \mathrm{O}_{2}$ for 4 hours and stained for the presence of reactive oxygen species. Fluorescence images were taken with a ZEISS Axiovert S100 microscope supported with a HAMAMATSU OCRA-ER digital camera employing the Openlab tmV 5.0.1 software package (IMPROVISION, Coventry, UK).

\subsubsection{Fluorescence microscopy of yeast cells}

Yeast cultures were grown in appropriate selective medium containing glucose supplemented with amino acids. A drop of culture was spread on the slide and allowed to dry. 1-2 $\mu$ l of mounting medium (VECTASHIELD HARD $\mathrm{SET}^{\mathrm{TM}}$, Vector Laboratories Inc, Burlingame, CA, USA) was added and a coverslip was placed and sealed avoiding air bubbles. Cells were viewed with either the GFP filter or DAPI filter using a ZEISS Axiovert S100 microscope. Images showing colocalization of Ynm3-GFP with mito-BFP were taken using a LEICA DM 6000 widefield microscope.

\subsubsection{Protein purification from $E$. coli}

Ynm3, Ynm3S236C and Ynm3S236A were expressed from the constructs pME3460, pME3461 and pME3462 respectively and Fpr3 from pME3463 (Table 2). Recombinant proteins were expressed as GST fusions containing a PRESCISSION protease site in the RosettaII strain (Novagen, Darmstadt, Germany) of E. coli for about $12 \mathrm{~h}$ at $20^{\circ} \mathrm{C}$ after induction with $250 \mu \mathrm{l} 1 \mathrm{mM}$ IPTG in a total culture volume of $112 \mathrm{X}-\mathrm{YT}$ medium (16 $\mathrm{g}$ Tryptone, $10 \mathrm{~g}$ Yeast extract and $5 \mathrm{~g} \mathrm{NaCl}$ ) containing 2\% glucose with $100 \mu \mathrm{g} / \mathrm{ml}$ Ampicillin and $100 \mu \mathrm{g} / \mathrm{ml}$ Chloramphenicol. Cells were pelleted after centrifugation at $4000 \mathrm{~g}$ for 30 minutes at $4^{\circ} \mathrm{C}$. The cell pellets were resuspended in $30 \mathrm{mM}$ PBS, pH 7.5. Cells were disrupted by passing the suspension through a microfluidizer five times at $80 \mathrm{psi}$ and then 
centrifuged at 10,000 $\mathrm{g}$ for $15 \mathrm{~min}$. The supernatant containing the GST fusion protein was applied onto GSH-Sepharose, washed with PBS and eluted with a buffer containing $20 \mathrm{mM}$ Tris, $100 \mathrm{mM} \mathrm{NaCl}$ and $25 \mathrm{mM} \mathrm{GSH}, \mathrm{pH}$ 7.5. The fusion proteins were cleaved overnight with PreScission protease (molar ratio 1:50) (Ge Healthcare, Munich, Germany) at $4^{\circ} \mathrm{C}$. After concentration using the Vivaspin 20 (MWCO 30,000) concentrator (SARTORIUS, Goettingen, Germany), the samples were passed through either Superdex 200 26/60 (GE HealthCARe, Munich, Germany) for the Ynm3 variants or Superdex 200 16/60 (GE HeAlthCARE, Munich, Germany) for purifying Fpr3 and eluted in a buffer containing $20 \mathrm{mM}$ Tris, $100 \mathrm{mM} \mathrm{NaCl}, \mathrm{pH}$ 7.5. For the Ynm3 variants, an additional purification step using GSH-Sepharose matrix was performed.

\subsubsection{Proteolysis assay}

Reaction mixtures containing $1 \mu \mathrm{M}$ purified Ynm3, Ynm3S236C or Ynm3S236A were incubated with $1.6 \mu \mathrm{M}$ heat denatured $\beta$-casein in a total volume of $250 \mu 1$ of $50 \mathrm{mM}$ Hepes$\mathrm{KOH}, \mathrm{pH}$ 7.3. $20 \mu \mathrm{l}$ samples were withdrawn at the beginning of the reaction and after overnight incubation $(16 \mathrm{~h})$ at $37^{\circ} \mathrm{C}$ which were boiled immediately after the addition of $4 \mu \mathrm{l}$ of $6 \mathrm{X}$ loading dye. The samples were separated by $15 \%$ SDS-PAGE and the protein bands were visualized by staining with Brilliant Blue G-Colloidal Coomasie (SIGMA-ALDRICH, Steinheim, Germany) and quantified using the KoDAK 1D Image Analysis Software (EASTMAN KODAK, Rochester, NY).

\subsubsection{Chaperone activity assay}

\subsubsection{Preparation of substrate (citrate synthase)}

An ammonium sulfate suspension of citrate synthase (CS) from porcine heart mitochondria (BOEHRINGER INGELHEIM, Heidelberg, Germany) was dialyzed using Spectra/Por ${ }^{\circledR}$ dialysis membrane (MWCO 25,000) (RoTH, Karlsruhe, Germany) against TE buffer (50 mM Tris, $2 \mathrm{mM}$ EDTA, $\mathrm{pH} 8.0$ ) overnight at $4{ }^{\circ} \mathrm{C}$ and concentrated to about 17 
mg/ml using Vivaspin 20 (MWCO 30,000) concentrator (SARTORIUS, Goettingen, Germany). To remove precipitated proteins, the solution was then centrifuged at $13,000 \mathrm{rpm}$ in a microcentrifuge (Biofuge fresco, Heraeus, Hanau, Germany) for 30 minutes at $4^{\circ} \mathrm{C}$. The exact concentration of the supernatant was determined using the published extinction coefficient of 1.78 for a $1 \mathrm{mg} / \mathrm{ml}$ solution in a $1 \mathrm{~cm}$ quartz cuvette (West et al., 1990). Aliquots were prepared and stored at $-20^{\circ} \mathrm{C}$. For each set of experiment, appropriate volume of TE buffer was added to an aliquot of CS to yield a final concentration of $30 \mu \mathrm{M} \mathrm{CS}$ monomer.

\subsubsection{Thermal aggregation assay}

The assay is based on the thermal aggregation of citrate synthase (CS) (Buchner et al., 1998). A fluorescence spectrophotometer (HITACHI F-4500) equipped with a stirrable, thermostatted cell holder was used in this assay. The reaction mixture containing $0.15 \mu \mathrm{M} \mathrm{CS}$ in the presence or absence of the indicated amounts of chaperones or a negative control protein like chymotrypsinogen in a total volume of $1 \mathrm{ml}$ of $40 \mathrm{mM}$ HEPES-KOH, pH 7.5 was subjected to $43^{\circ} \mathrm{C}$ temperature with constant stirring in a $3 \mathrm{ml}$ quartz cuvvette placed in the thermostatted cell holder. Aggregation was monitored using the spectroflourometer with both excitation and emission wavelengths set to $500 \mathrm{~nm}$ at a spectral bandwidth of $2.5 \mathrm{~nm}$. Data points were recorded every $0.5 \mathrm{~s}$ for 20 minutes. As a further step to prove that the observed suppression of light scattering was not due to proteolysis of CS, $20 \mu \mathrm{l}$ samples were withdrawn at several time points during the course of the reaction and subjected to $15 \%$ SDSPAGE followed by silver staining.

\subsubsection{Thermal inactivation assay}

The assay for thermal inactivation of CS was also performed as described (Buchner et al., 1998). In brief, thermal denaturation of $\mathrm{CS}$ at $43^{\circ} \mathrm{C}$ was performed as described for the thermal aggregation assay in the presence or absence of chaperone or a negative control 
(chymotrypsinogen) in a total volume of $1 \mathrm{ml}$ of $40 \mathrm{mM}$ HEPES-KOH, pH7.5. $20 \mu \mathrm{l}$ of the reaction mixture was withdrawn at several time points and the specific activity of CS was determined using an assay based on the first step of the citric acid cycle. For each activity assay, the reaction mixture consists of $930 \mu \mathrm{l}$ of TE buffer $(50 \mathrm{mM}$ Tris, $2 \mathrm{mM}$ EDTA, pH8.0), $10 \mu \mathrm{l}$ of $10 \mathrm{mM}$ oxaloacetic acid (SIGMA-ALDRICH, Steinheim, Germany) $10 \mu 1$ of 10 mM DTNB (PIERCE, Rockford, IL, USA) in TE buffer and $30 \mu 1$ of $5 \mathrm{mM}$ acetyl-CoA (SIGMA-AlDRICH, Steinheim, Germany) in TE buffer. This reaction mixture was prepared in advance for at least 20 test assays and used within 1 hour of preparation. The reaction mixture was preincubated at $25^{\circ} \mathrm{C}$. Before the activity test, $980 \mu \mathrm{l}$ of the reaction mixture was pipetted into $1.5 \mathrm{ml}$ plastic cuvettes and the reaction was started by the addition of $20 \mu \mathrm{l}$ of $0.15 \mu \mathrm{M}$ CS monomer. The coenzyme A formed in this assay stoichiometrically reduces the Ellmann's reagent dithio-1,4-nitrobenzoic acid (DTNB) resulting in an increased absorbance at $412 \mathrm{~nm}$. The linear slope of the initial increase in absorbance recorded online spectrophotometrically (UV-1601, SHIMADZU) for 1 minute, was used to calculate specific activity. The specific activity obtained before the start of the thermal inactivation was considered as $100 \%$ specific activity. The calculated specific activities during the course of each reaction were expressed as percentage of this value. 


\section{Results}

\subsection{The Saccharomyces cerevisiae strain YB322 requires Ynm3 for survival under heat stress}

The bacterial periplasmic HtrA/DegP is required for survival of E.coli at temperatures above $40^{\circ} \mathrm{C}$ (Lipinska et al., 1990). It functions by degrading denatured cell envelope proteins when subjected to heat stress and is therefore an indispensable quality control factor in the bacterial periplasm. The budding yeast HtrA-like protein, Ynm3 is localized to the nucleus (Fahrenkrog et al., 2004). To test if Ynm3 has a similar role in cell survival at higher temperatures, the YNM3 coding sequence was deleted in the yeast strain YB322 by homologous recombination of a kanamycin (G418) resistance cassette containing sequences homologous to the 5' upstream and 3' downstream regions of the gene. The deletion was verified by PCR.

Growth of wild type YB322 yeast strain and $\Delta y n m 3$ was compared at both ambient growth temperature $\left(30^{\circ} \mathrm{C}\right)$ and at a sub-lethal higher temperature $\left(38^{\circ} \mathrm{C}\right)$ on solid medium. At $30^{\circ} \mathrm{C}$, growth of the wild type strain and $\triangle y n m 3$ was comparable, indicating that $Y N M 3$ is not an essential gene. At $38^{\circ} \mathrm{C}$, growth of $\Delta y n m 3$ was reduced compared to that of the wild type strain (Figure 3B). The DNA encoding YNM3 amplified by PCR from the genomic DNA of the wild type YB322 yeast strain was cloned into a single copy $(C E N)$ yeast vector under the control of the MET25 promoter (Figure 3A). To prove that the heat sensitivity of $\triangle y n m 3$ was indeed due to the lack of Ynm3, growth of the $\Delta y n m 3$ strain transformed with this construct was compared with that of both the wild type YB322 strain and the $4 y n m 3$ strain transformed with empty vector at both $30^{\circ} \mathrm{C}$ and $38^{\circ} \mathrm{C}$. As shown in Figure $3 \mathrm{~B}$, the growth impairment of $\triangle y n m 3$ at $38^{\circ} \mathrm{C}$ could be rescued by the construct carrying wild type $Y N M 3$. The difference in the growth pattern of wild type YB322 and $\Delta y n m 3$ in liquid culture was more pronounced at $39^{\circ} \mathrm{C}$ (Figure 3C). 
A

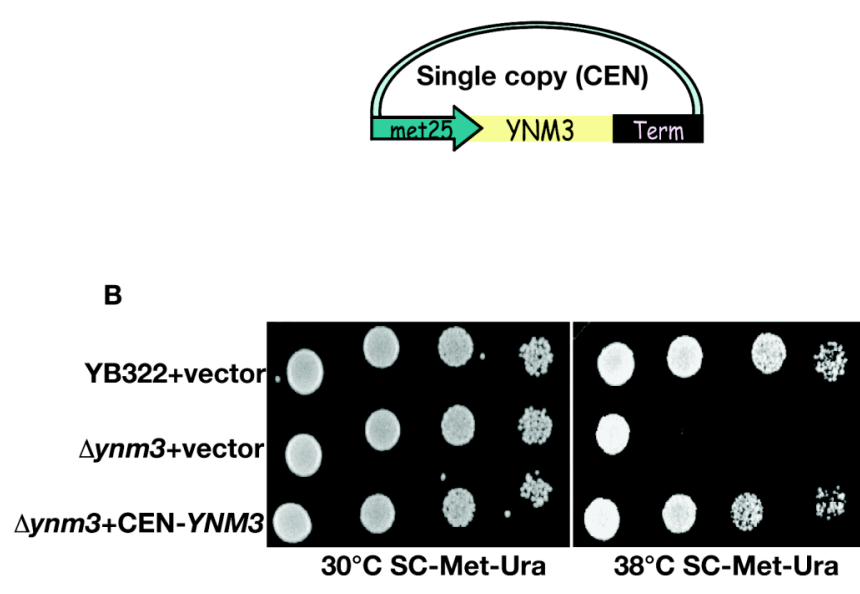

C Growth curve at $39^{\circ} \mathrm{C}$

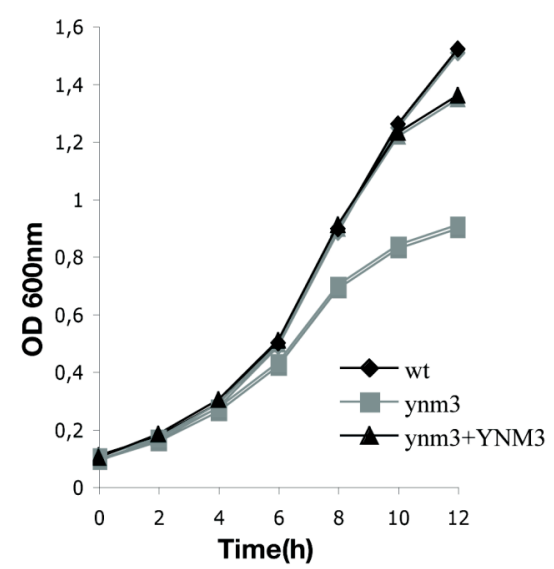

E

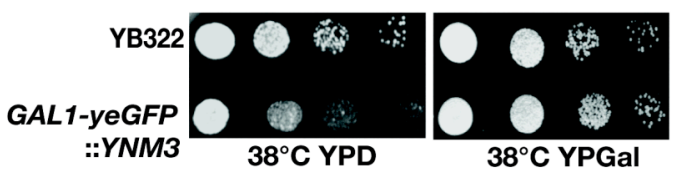

natNT2 GAL1 yeGFP YNM3

Figure 3: Deletion of $Y N M 3$ in the YB322 yeast strain results in reduced growth under sublethal heat stress. (A) The YNM3 coding sequence was cloned in a single copy vector under the control of the MET25 promoter. (B) The growth impairment of a $\triangle y n m 3$ strain at $38^{\circ} \mathrm{C}$ was rescued by the single copy plasmid carrying YNM3 under the control of the MET25 promoter. (C) Growth of the indicated strains was also assessed in liquid SC-Met-Ura medium at $39^{\circ} \mathrm{C}$. (D) The endogenous promoter of the chromosomal copy of YNM3 was replaced with a module containing a GAL1 promoter and yeGFP encoding sequence with a kanamycin resistance cassette as a selectable marker. The module was PCR amplified using primers containing sequences homologous to the regions flanking the 5' end of YNM3 as shown. The PCR product was transformed into the YB322 yeast strain for homologous recombination, which resulted in its insertion immediately upstream and inframe with the coding sequence of $Y N M 3$. (E) The resulting yeast strain $G A L 1_{U A S}-y e G F P: \because Y N M 3$, in which $Y N M 3$ is under the control of the inducible-repressible GAL1 promoter, exhibited impaired growth on YPD at $38^{\circ} \mathrm{C}$ due to complete repression of the GAL1 promoter in the presence of glucose. This growth impairment was alleviated on YPGal due to the induction of the GAL1 promoter.

The aforementioned phenotype was also confirmed by an alternate approach. The endogenous promoter of the chromosomal copy of the $Y N M 3$ gene was replaced with the GAL1 repressible-inducible promoter. This was achieved by the PCR based epitope tagging method using the cassette natNT2-GAL1 $1_{U A S^{-}} y e G F P$ (Janke et al., 2004) as depicted in Figure 3D. Growth of the resultant strain $G A L 1_{U A S^{-}} y e G F P:: Y N M 3$ was compared with that of the 
wild type on solid rich medium containing either glucose (YPD), which completely represses the GAL1 promoter or galactose (YPGal), which induces the GAL1 promoter. As expected, growth of the above strain was reduced compared with that of the wild type YB322 strain at $38^{\circ} \mathrm{C}$ on YPD. This was due to repression of the GAL1 promoter in the presence of glucose (Figure 3E). The observed growth defect was absent on YPGal as galactose present in the medium led to the induction of the GAL1 promoter and therefore expression of the yeGFPYnm3 fusion protein (Figure 3E).

A

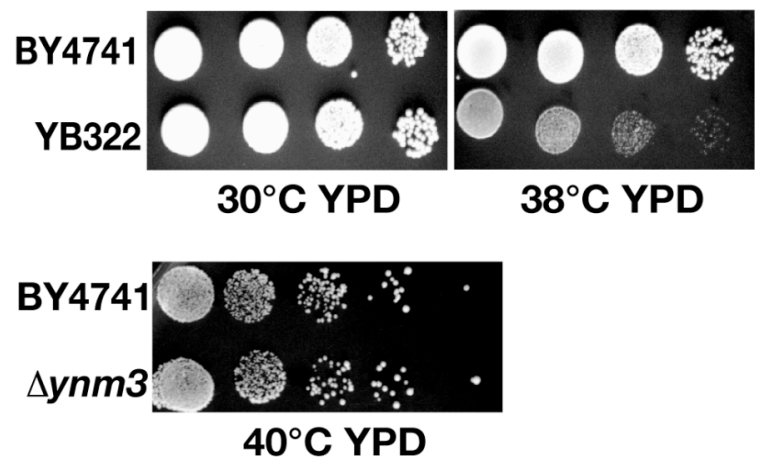

B

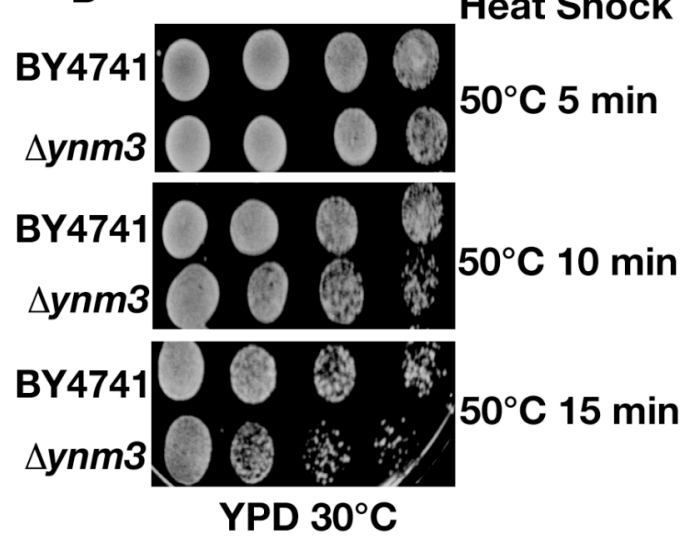

Figure 4: The BY4741 yeast strain is significantly more resistant to heat stress than the YB322 yeast strain. (A) After just a single day of incubation, the BY4741 wild type strain exhibited much better growth compared to the YB322 wild type yeast strain at $38^{\circ} \mathrm{C}$. Deletion of $Y N M 3$ in the BY4741 strain background did not result in enhanced heat sensitivity. (B) Only when subjected to prior heat shock at $50^{\circ} \mathrm{C}$ for the indicated durations, the $\Delta y n m 3$ strain in the BY4741 background exhibited poor viability at $30^{\circ} \mathrm{C}$ indicating that the penetrance of the phenotype in this strain is lower compared to that in the YB322 strain.

Although both the wild type YB322 and the wild type BY4741 yeast strains are descendents of the same ancestral strain S288C, the former is more sensitive to heat compared to the latter as observed after just 24 hours of incubation on YPD at $38^{\circ} \mathrm{C}$ (Figure $4 \mathrm{~A}$ ). Consequently, the $\Delta y n m 3$ strain in the BY4741 background (EUROSCARF) was not more sensitive to growth at higher temperatures compared to the wild type strain (Figure 4A). This indicates that the genome of the YB322 wild type strain has undergone changes during evolution after its divergence from the ancestral strain. However, the BY4741 Aynm3 strain 
displayed poor viability at $30^{\circ} \mathrm{C}$ after subjection to heat shock at $50^{\circ} \mathrm{C}$ for the indicated durations (Figure 4B). Thus the penetrance of the phenotype in the BY4741 background is much lower compared to that in the YB322 background.

\subsection{The serine protease activity of Ynm3 conferred by Ser236 mediates its thermoprotective function}

The serine protease activity of the bacterial HtrA/DegP executes its protective function in response to heat stress by degrading irreversibly unfolded proteins in the periplasm (Lipinska et al., 1990; Skorko-Glonek et al., 1995; Spiess et al., 1999). Ynm3 has an HtrA-like serine protease domain and two PDZ domains (Apweiler et al., 2000). Ynm3 is a chymotrypsin Alike serine peptidase belonging to the clan PA with a serine nucleophile and catalytic residues in the order His, Asp, Ser (http://merops.sanger.ac.uk/). To determine whether the serine protease activity of Ynm3 is crucial to execute its thermoprotective function, site directed mutagenesis was performed to mutate the codons for two putative active site serine residues, namely Ser235 and Ser236, to those encoding alanine. Earlier reports published by the same group proposed Ser235 to be the catalytic serine residue (Fahrenkrog et al., 2004; Walter et al., 2006). The adjacent serine at position 236 was however, predicted to be the catalytic serine residue by an earlier version of the MEROPs peptidase database.

Wildtype $Y N M 3$ and the mutants, $Y N M 3 S 235 A$ and $Y N M 3 S 236 A$ were cloned into a single copy $(C E N)$ vector, which enables expression of the variants as fusion proteins with a C-terminal GFP tag (Figure 5A). The GFP-tag enabled verification of the level of protein expressed by immunoblotting. The $\Delta y n m 3$ strain was transformed with these constructs for further experiments. An assay was performed to test growth of strains carrying these constructs in comparison with the wild type YB322 and $\Delta y n m 3$ encoding GFP alone. The growth assays were carried out at both $30^{\circ} \mathrm{C}$ and $38^{\circ} \mathrm{C}$ on plates containing SC-Met-Ura to 
select for the URA3 auxotrophy marker in the expression vectors and because the MET25 promoter is induced only in the absence of the amino acid methionine.

A

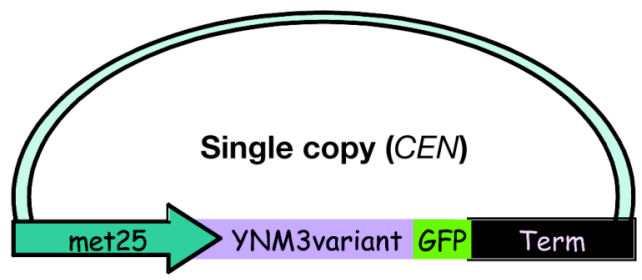

B

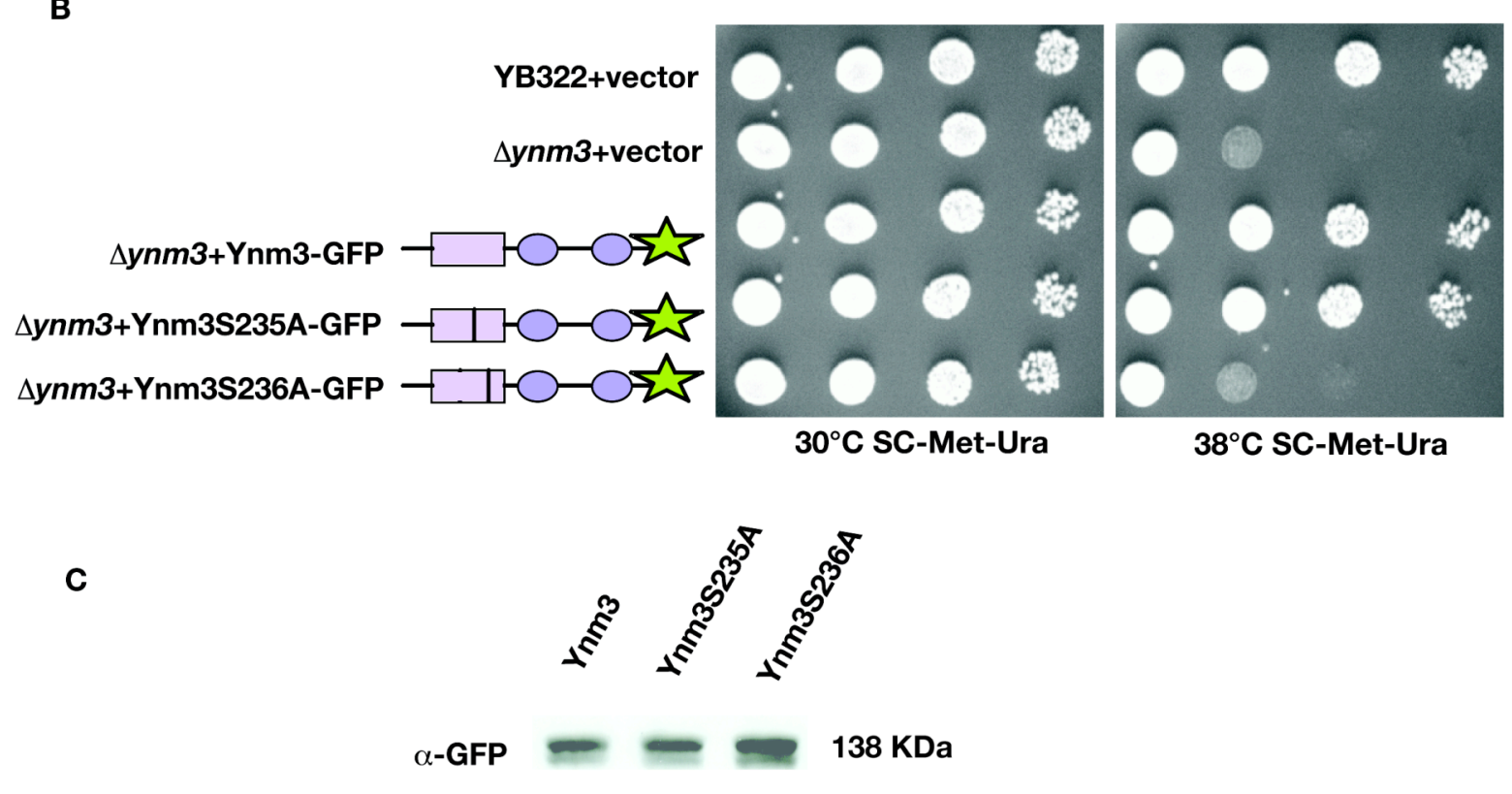

$\alpha-C d c 28$

$34 \mathrm{KDa}$

Figure 5: The serine protease activity of $\mathrm{Ynm} 3$, mediated by the catalytic serine residue at position 236 is required to execute its thermoprotective function. (A) The GFP fusion proteins in this set of experiments are encoded by a single copy $(C E N)$ vector under the control of the MET25 promoter, which is induced in the absence of the amino acid methionine. (B) The reduced growth of $\Delta y n m 3$ strain at higher temperatures was completely rescued by either Ynm3-GFP or Ynm3S235AGFP. Ynm3S236A-GFP could not confer thermoprotection. (C) All these variants were expressed to similar levels as seen in the Western blot probed with mouse monoclonal anti-GFP antibody. The blots were stripped and reprobed with rabbit antiserum raised against $\mathrm{Cdc} 28$ to ensure equal loading of protein.

The growth defect of $\Delta y n m 3$ at $38^{\circ} \mathrm{C}$ was completely rescued by the construct encoding Ynm3-GFP and Ynm3S235A-GFP (Figure 5B). However, the construct encoding Ynm3S236A-GFP could not rescue the growth defect of the $\Delta y n m 3$ strain (Figure 5B). 
Immunoblotting with the antibody targeted against GFP revealed comparable levels of expression of the variants showing that the mutations do not affect the stability of the variants. Equal loading of protein extracts was ensured by probing with the antiserum against Cdc28. As shown in Figure 5C, there were no marked differences in the amounts of the Ynm3 variants expressed by the strains used in the growth assay. Therefore, it is evident that the serine protease activity of the budding yeast Ynm3 plays an important role in executing its protective function at higher temperatures and the serine residue at position 236 is the catalytic serine.

\subsection{Multi copy expression of $\mathrm{Ynm} 3$ is deleterious}

Expression of Ynm3 from a single copy vector was beneficial, being sufficient to rescue the heat sensitivity of $\Delta y n m 3$. In order to assess the consequence of overexpression, $Y N M 3$ and the mutants $Y N M 3 S 235 A$ and $Y N M 3 S 236 A$ were cloned into muti copy $(2 \mu)$ vectors enabling overexpression of these variants as GFP fusion proteins (Figure 6A). These constructs were transformed into the $\Delta y n m 3$ strain. The growth of the resultant strains were compared with the wild type YB322 strain and the $\Delta y n m 3$ strain transformed with vector encoding GFP alone at both ambient growth temperature $30^{\circ} \mathrm{C}$ and under elevated temperature $\left(38^{\circ} \mathrm{C}\right)$ on SC-Met-Ura as described before. Whereas a single copy of Ynm3-GFP or Ynm3S235A-GFP rescued the heat sensitivity of $\Delta y n m 3$ (Figure 5B), multi copy expression of these variants resulted in growth impairment which was even more acute at $38^{\circ} \mathrm{C}$. Multi copy expression of Ynm3-GFP or Ynm3S235A-GFP could therefore not relieve the stress experienced by $\Delta y n m 3$ at elevated temperatures (Figure 6B). On the contrary, multi copy expression of Ynm3S236A-GFP did not lead to growth impairment (Figure 6B). This suggests that toxicity due to overexpression of Ynm3 was solely due to excessive serine protease activity, which was abolished simply by the modification of the active site serine. Again, all these variants were expressed equally as shown by immunoblotting using anti-GFP 
antibody. The blot was again probed with antiserum targeted against Cdc 28 to ensure equal loading of cell extracts (Figure 6C).

A
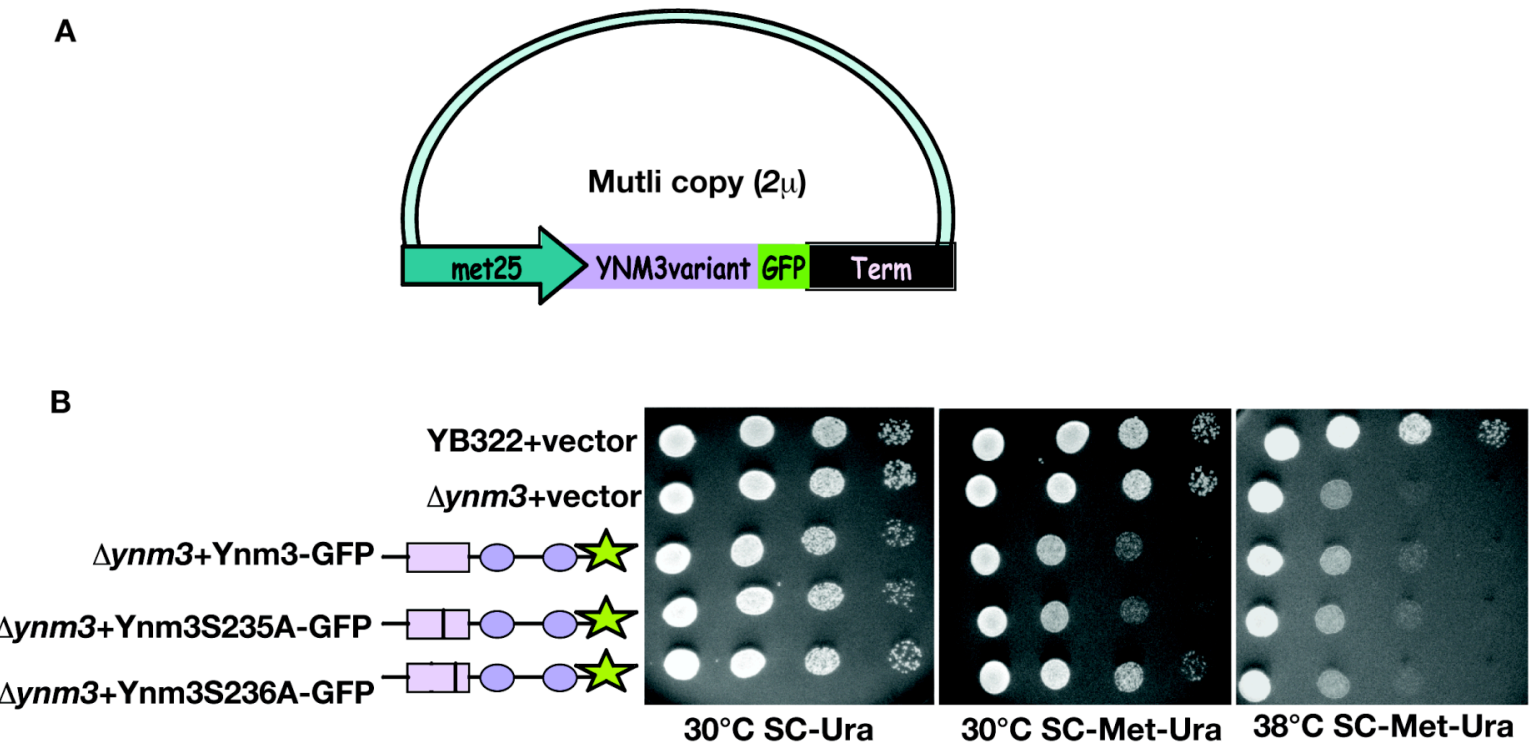

C

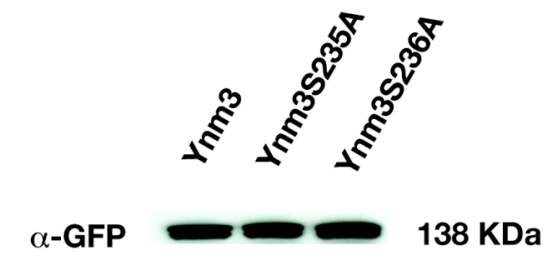

$\alpha-$ Cdc28

$34 \mathrm{KDa}$

Figure 6: Overexpression of $\mathbf{Y n m} 3$ is deleterious. (A) The GFP fusion proteins in this set of experiments are encoded by a multi copy $(2 \mu)$ vector under the control of the MET25 promoter, which is induced in the absence of the amino acid methionine. (A) Ynm3-GFP or its S235A variant, when overexpressed led to growth impairment even at $30^{\circ} \mathrm{C}$ and therefore could not confer thermoprotection at $38^{\circ} \mathrm{C}$. The overexpression of the S236A variant did not lead to growth impairment. (B) The fusion proteins were expressed at similar levels as seen in the immunoblot probed with mouse monoclonal anti-GFP antibody. The blots were stripped and reprobed with rabbit antiserum raised against Cdc28 to ensure equal loading of protein.

Cell culture experiments that involve the overexpression of $\mathrm{HtrA} 2 / \mathrm{Omi}$ in mammalian cells has led to the conclusion that it has a pro-apoptotic function (Verhagen et al., 2002). Yeast has an apoptotic pathway showing characteristic features of apoptosis such as accumulation of reactive oxygen species, membrane blebbing or nuclear fragmentation (Madeo et al., 1997; Madeo et al., 2002a). I therefore analysed whether the overexpression of Ynm3 in yeast enhanced apoptosis. For this purpose, YNM3 was cloned into a multi copy 
vector that enables expression of the protein from the stronger GAL1 promoter. This construct was transformed into the wild type YB322 yeast strain. Spot dilution assays were performed under both inducing and repressing conditions, i.e, in the presence of galactose or glucose respectively. As shown in Figure 7A, overexpression of Ynm3 from a multi copy vector under the control of the GAL1 promoter led to a drastic impairment in growth. The growth impairment was visibly strong even when Ynm3 was expressed from a multi copy vector under the control of the MET25 promoter (Figure 6B). The deletion of the gene encoding the yeast metacaspase (YCAl) has been shown to result in increased cell survival (Madeo et al., 2002b). However, the deletion of the yeast metacaspace locus YCA1 was unable to rescue the growth defect that resulted from Ynm3 overexpression (Figure 7A). This suggests that the observed growth impairment was not a result of a caspase mediated cell death pathway. To rule out the existence of any caspase independent mechanisms of apoptosis that may be operative, the YB322 strain overexpressing Ynm3 or the mammalian HtrA2/Omi were subjected to mild oxidative stress $\left(1 \mathrm{mM} \mathrm{H}_{2} \mathrm{O}_{2}\right.$ for $\left.4 \mathrm{hr}\right)$ and the presence of reactive oxygen species (ROS), the key regulators of apoptosis in yeast (Madeo et al., 1999), was assessed using the dihydrorhodamine (DHR) staining protocol. DHR stains ROS and emits a red fluorescence. Neither overexpression of Ynm3 nor the mammalian HtrA2/Omi led to an elevation in the number of cells stained for ROS compared with the control strain transformed with empty vector (Figure 7B), ruling out the mediation of caspase independent apoptosis.

Apoptosis is not known in bacteria. Therefore, one would not expect the bacterial HtrA/DegP to possess a programmed cell-death promoting activity. Yet, overexpression of the bacterial HtrA/DegP led to an even more drastic growth impairment of yeast. The overexpression of the mammalian HtrA2/Omi in yeast also led to growth impairment, albeit mild (Figure 7C). It is notable that excessive amounts of quality control factors can be toxic due to unsupervised elimination of cellular proteins (Wickner et al., 1999) which could explain why the overexpression of all these HtrA members led to toxicity in yeast. 
A

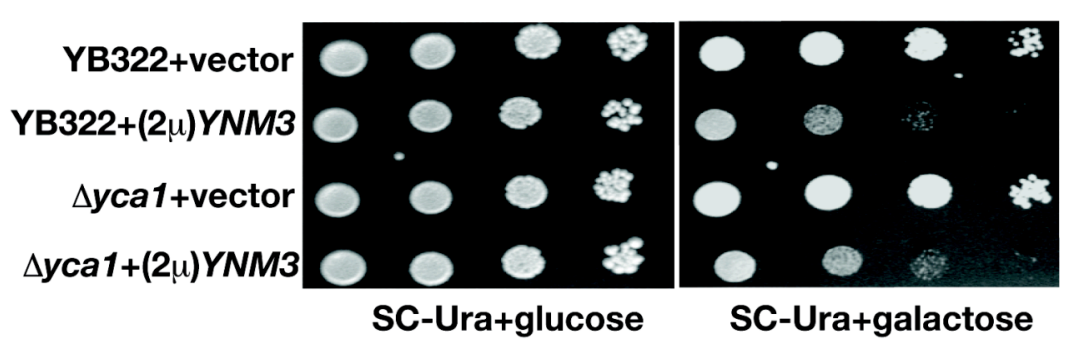

B

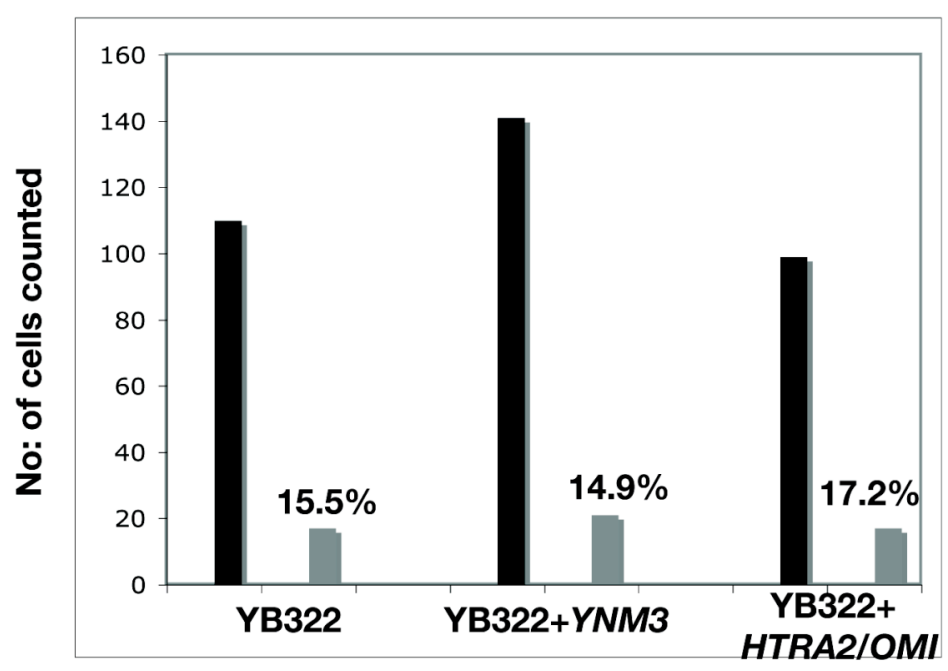

C

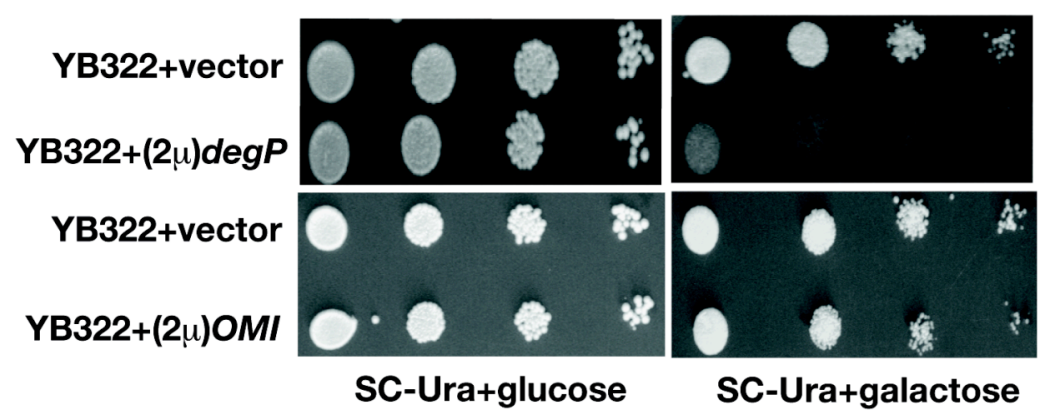

Figure 7: Overexpression of Ynm3 leads to growth impairment due to cytotoxicity and not apoptosis. (A) Overexpression of Ynm3 under the control of the GAL1 promoter from a multi copy vector led to growth impairment. This growth impairment could not be rescued by the deletion of the yeast metacaspase YCA1. (B) The wild type YB322 strains overexpressing Ynm3 or mammalian $\mathrm{HtrA} 2 / \mathrm{Omi}$ were subjected to mild oxidative stress $\left(1 \mathrm{mM} \mathrm{H}_{2} \mathrm{O}_{2}\right)$ for 4 hours and then stained to detect the presence of reactive oxygen species (ROS), the key regulators of apoptosis in yeast, using dihydrorhodamine (DHR). Cells overexpressing Ynm3 or HtrA2/Omi did not show an increase in the number of cells stained for ROS. Calculation from a single representative experimental set is shown here. (C) Overexpression of the bacterial HtrA/DegP from a multi copy vector from the GAL1 promoter also led to a drastic growth impairment of yeast. Overexpression of the mammalian HtrA homologue, HtrA2/ Omi also led to very mild growth impairment. 


\subsection{An in vitro autocatalysis assay further corroborated the finding that Ser236 is the catalytic serine residue of $\mathrm{Ynm} 3$}

Several attempts were made during the course of this work to find in vivo substrates or interaction partners of Ynm3 by both yeast two-hybrid assay using the GAL4 system and the tandem affinity purification (TAP) method (data not shown). None of these attempts proved to be fruitful probably due to transient enzyme-substrate interactions in vivo. The bacterial HtrA/DegP cleaves a heterogenous group of unfolded proteins in vitro in addition to its native substrate MalS (Clausen et al., 2002; Spiess et al., 1999). Although purified Ynm3 had no effect on a non-native substrate like $\beta$-casein, it underwent slow autocatalysis, which could be monitored by SDS-PAGE (Figure 8A). The protein bands on the Coomassie stained gel were quantified and the net intensities plotted (Figure 8B). After 16 hours of incubation at $37^{\circ} \mathrm{C}$ in the presence of denatured $\beta$-casein, the amount of native Ynm3 in the reaction mixture was reduced to less than $17 \%$ as shown by the intensity of the protein band on the Coomassie stained gel, whereas the S236A variant was significantly stable with more than $86 \%$ of the protein remaining intact after 16 hours (Figure $8 \mathrm{~B}$ ). This clearly validates the in vivo finding that the serine at position 236 confers protease activity on Ynm3 since the modification of this serine residue led to stabilization of the protein. In some viral proteases, it has been documented that exchange of active site serines to cysteines does not necessarily abolish proteolytic activity completely which remains to varying degrees in different proteases (Hahn \& Strauss, 1990; Tautz et al., 2000). In the case of Ynm3, exchanging Ser236 to alanine significantly reduced its autocatalytic activity thereby enhancing its stability but exchanging to cysteine was not as effective with only $65 \%$ of the initial amount of protein left in the reaction after 16 hours (Figure $8 \mathrm{~B}$ ). 
A
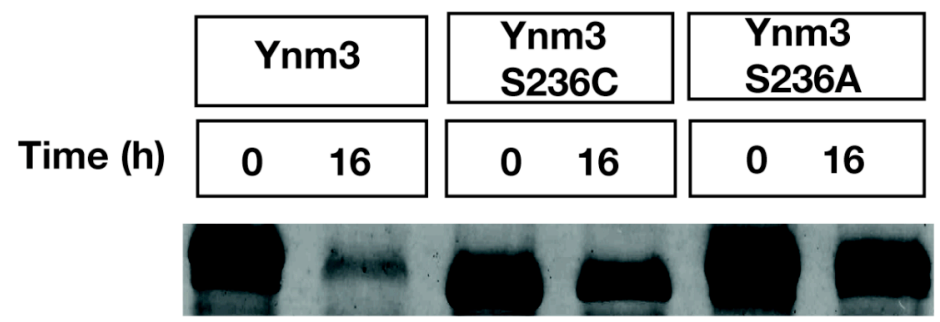

B

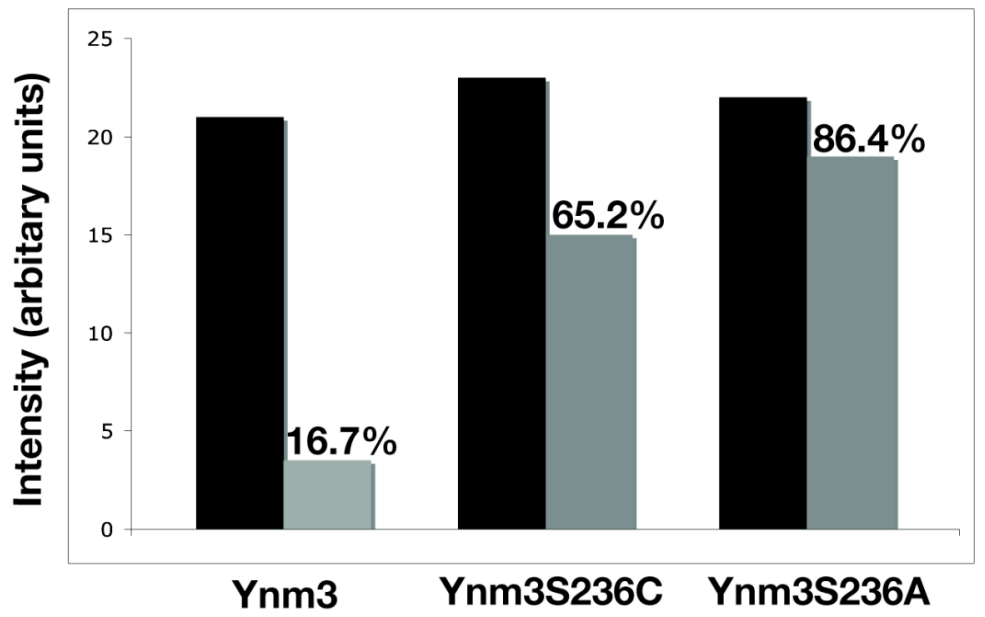

C

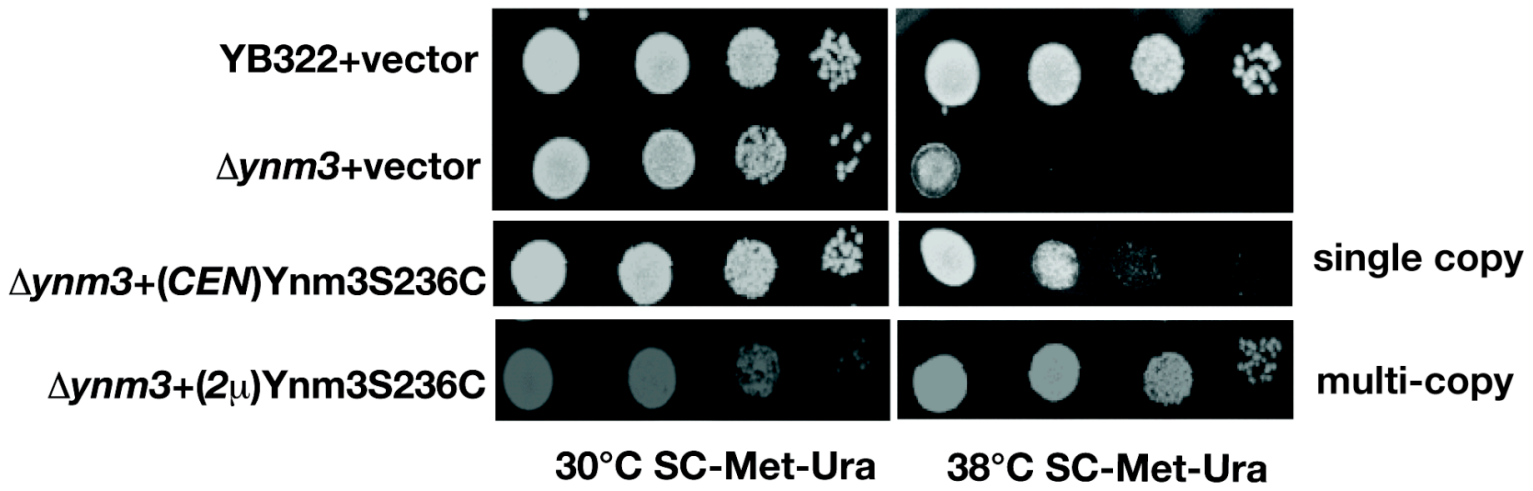

Figure 8: Ynm3 undergoes slow autocatalysis in vitro due to its serine protease activity. (A) Upon incubation of a reaction mixture containing Ynm3 in the presence of heat denatured $\beta$-casein at $37^{\circ} \mathrm{C}$, it underwent slow autocatalysis which was dramatically reduced in the S236A variant. (B) The protein bands were quantified and the net intensities plotted. The percentage intensity that remained after $16 \mathrm{~h}$ of incubation is shown. Exchange of the catalytic serine of Ynm3 to cysteine was not so effective in reducing autocatalytic activity when compared to exchange with alanine. (C) A single copy of Ynm3S236C could not rescue the heat sensitivity of $\Delta y n m 3$ completely. However, multi copy expression of Ynm3S236C could do so. This confirms the in vitro observation that exchange of Ser236 to cysteine does not completely abrogate its catalytic activity.

A single copy of Ynm3-GFP is sufficient to complement the heat sensitivity of $\Delta y n m 3$ (Figure 5B) whereas Ynm3S236A-GFP does not complement, even when present in multiple copies (Figure 6B). A single copy of Ynm3S236C-GFP also could not completely rescue the heat sensitivity of $\Delta y n m 3$ but multi copy expression of this variant provided sufficient 
proteolytic activity to rescue the heat sensitivity of $\Delta y n m 3$ (Figure $8 \mathrm{C}$ ). This again shows that the exchange of the catalytic Ser236 of Ynm3 to cysteine does not completely abrogate its proteolytic activity whereas exchange to alanine effectively abolishes its proteolytic activity.

\subsection{Deletion of either of its PDZ domains destabilizes Ynm3}

The HtrA family of proteins is characterized by the presence of a serine protease domain and at least one PDZ domain. PDZ domains are modular protein-protein interaction domains that possess unique structural features, which enable interaction with C-terminal residues of ligand proteins. The PDZ domains of the bacterial HtrAs and the mammalian HtrA2/Omi are important for regulating their protease activities and are also required for substrate binding or multimerization (Clausen et al., 2002; Krojer et al., 2002; Li et al., 2002). The budding yeast Ynm3 is unique in that its PDZ domain is duplicated. The functional significance of this duplication remains to be established.

The PDZ domain present immediately proximal to the protease domain (residues 290 to 375) was designated as PDZ1 and the other predicted PDZ domain at the C-terminal end of the protein as PDZ2 (779-868). To investigate whether the predicted PDZ domains of the budding yeast HtrA orthologue, Ynm3, have any aforementioned essential roles, either the PDZ1 or PDZ2 encoding regions were deleted using an overlap PCR method. The resultant products were cloned into single copy vectors enabling expression of these variants as Cterminal GFP fusion proteins (Figure 9A).

The $\triangle y n m 3$ strain was transformed with $C E N$ vectors encoding either Ynm3 $\mathrm{PDDZ1-GFP}$ or Ynm3 $\mathrm{PDZ} 2-\mathrm{GFP}$ fusion proteins. Growth assay of strains carrying these constructs in comparison to the wild type YB322 and $\triangle y n m 3$ encoding GFP alone were performed under inducing conditions in plates containing SC-Met-Ura at $30^{\circ} \mathrm{C}$ and $38^{\circ} \mathrm{C}$. As shown in Figure 9B, only full length Ynm3 was able to completely rescue the heat sensitivity of the $\Delta y n m 3$ strain at higher temperatures. The lack of PDZ1 or PDZ2 domains drastically reduced its 
protective function. This was because the absence of one or the other PDZ domain dramatically reduced the stability of the protein as shown in the immunoblot probed with antiGFP antibody (Figure 9C).

A

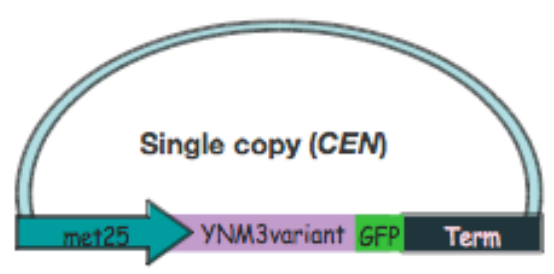

B

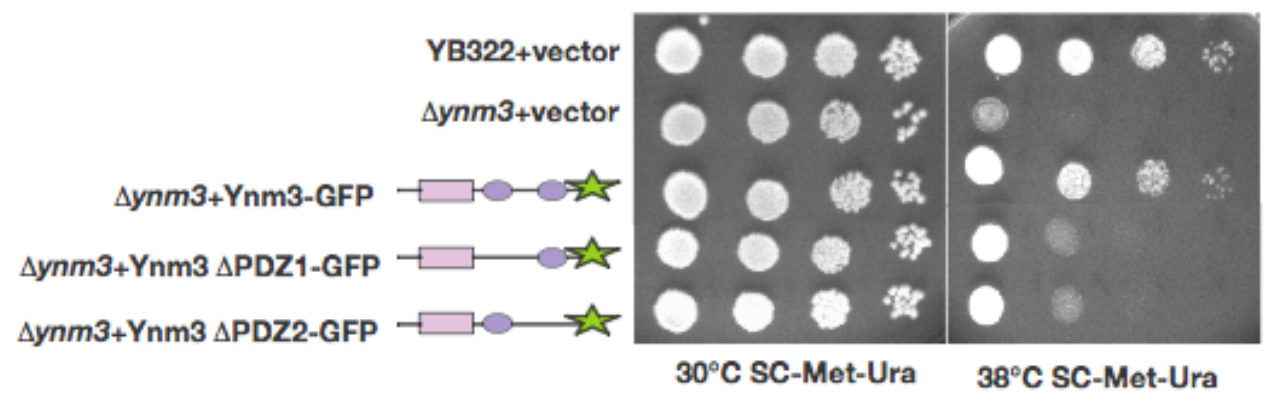

c

D
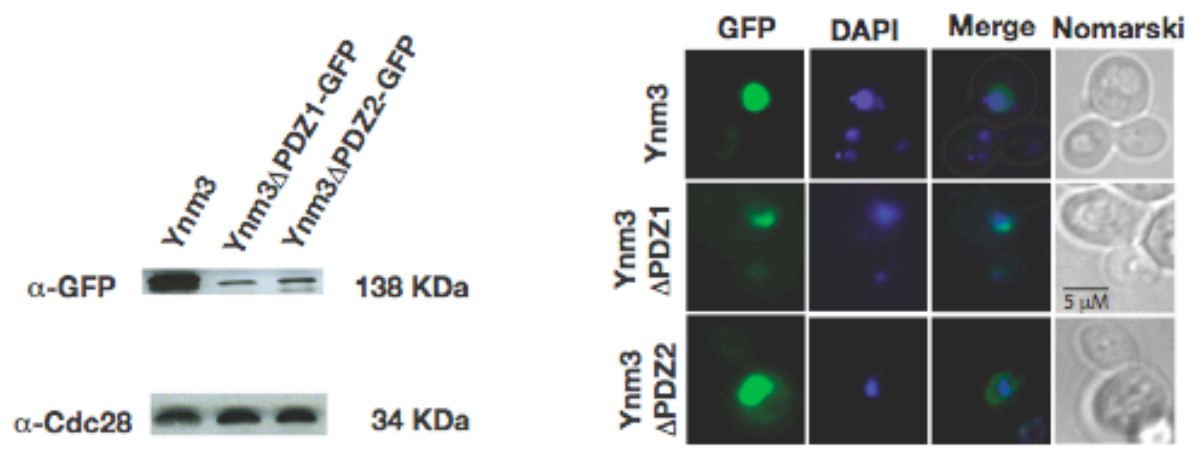

Figure 9: The lack of either of its two PDZ domains destabilizes Ynm3. (A) The GFP fusion proteins in this set of experiments are encoded by a single copy $(C E N)$ vector under the control of the MET25 promoter, which is induced in the absence of the amino acid methionine. (B) Deletion of either of the two PDZ domains of Ynm3 drastically reduced its function. (C) The lack of either PDZ domain led to drastic destabilization of $\mathrm{Ynm} 3$ as seen in the immunoblot probed with mouse monoclonal anti-GFP antibody. The blots were stripped and reprobed with rabbit antiserum raised against yeast Cdc28 to ensure equal loading of protein. (D) Lack of PDZ domains did not mislocalize the protein. Ynm3 PDZ1-GFP and Ynm3 
It was speculated in an earlier report that the second PDZ domain of Ynm3 could be important for its nuclear localization as it was observed that the variant lacking it was not present exclusively in the nucleus (Fahrenkrog et al., 2004). However, in this study, the Ynm3 variants lacking either of its PDZ domains were correctly localized to the nucleus (Figure 9D). Thus the lack of PDZ domains markedly reduced the stability of Ynm3 rendering it insufficient for conferring thermoprotection although it did not affect its nuclear localization.

\subsection{The first $100 \mathrm{~N}$-terminal amino acid stretch of Ynm3 contains its nuclear localization signal}

In order to define the nuclear localization sequence (NLS) of Ynm3, constructs were made encoding GFP fused C-terminally to 100 amino acid stretches of Ynm3 spanning its entire length. These vectors were transformed into $\Delta y n m 3$ to determine the nuclear localization of these 100 amino acid stretches of Ynm3 by fluorescence microscopy. The NLS of Ynm3 was narrowed down to its first $100 \mathrm{~N}$-terminal amino acids because the variant lacking these residues (Ynm3 $\mathrm{N} 100 \mathrm{aa}$ ) fused with GFP was localized entirely outside the nucleus (Figure 10A). The first $100 \mathrm{~N}$-terminal amino acid stretch of Ynm3 (N100aa) fused with GFP on its own was localized in the nucleus confirming that the NLS of Ynm3 lies in this region. The PDZ domains of Ynm3 are therefore not important for its nuclear localization. It was interesting to determine if $\mathrm{Ynm} 3 \Delta \mathrm{N} 100$, which lies entirely outside the nucleus could still rescue the heat sensitivity of a $\Delta y n m 3$ strain. For this purpose, both single and multi copy vectors encoding GFP tagged fusions of Ynm3 $\Delta$ N100 were transformed into the $\Delta y n m 3$ strain. Growth tests were performed as described in the previous section at both $30^{\circ} \mathrm{C}$ and $38^{\circ} \mathrm{C}$ on plates containing SC-Met-Ura. As shown in Figure $10 \mathrm{~B}, \mathrm{Ynm} 3 \Delta \mathrm{N} 100$ in either single or multiple copies could not confer thermoprotection although multi copy 
expression of Ynm $3 \Delta \mathrm{N} 100$ led to growth impairment indicating that it is a functional protease.
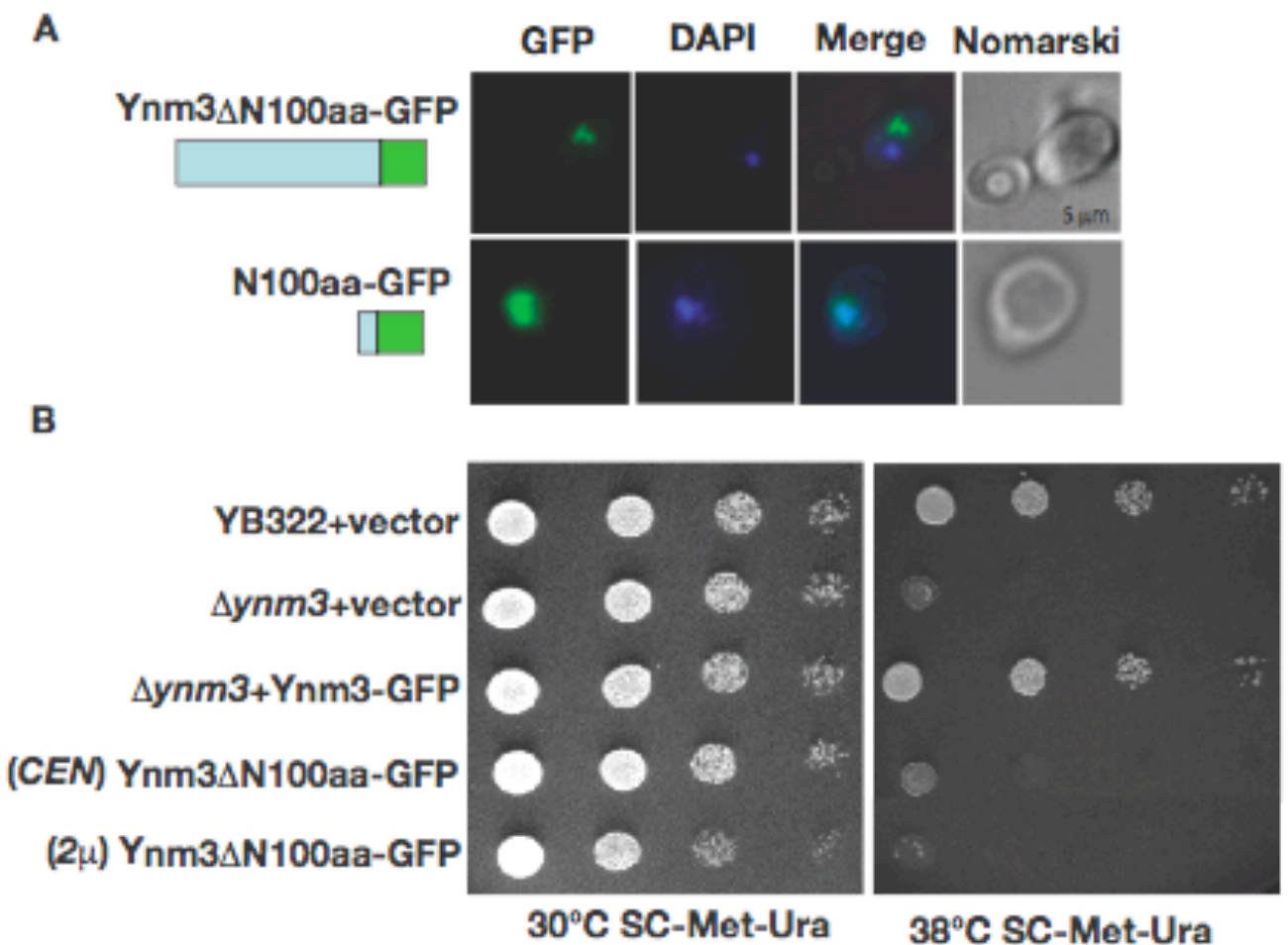

C
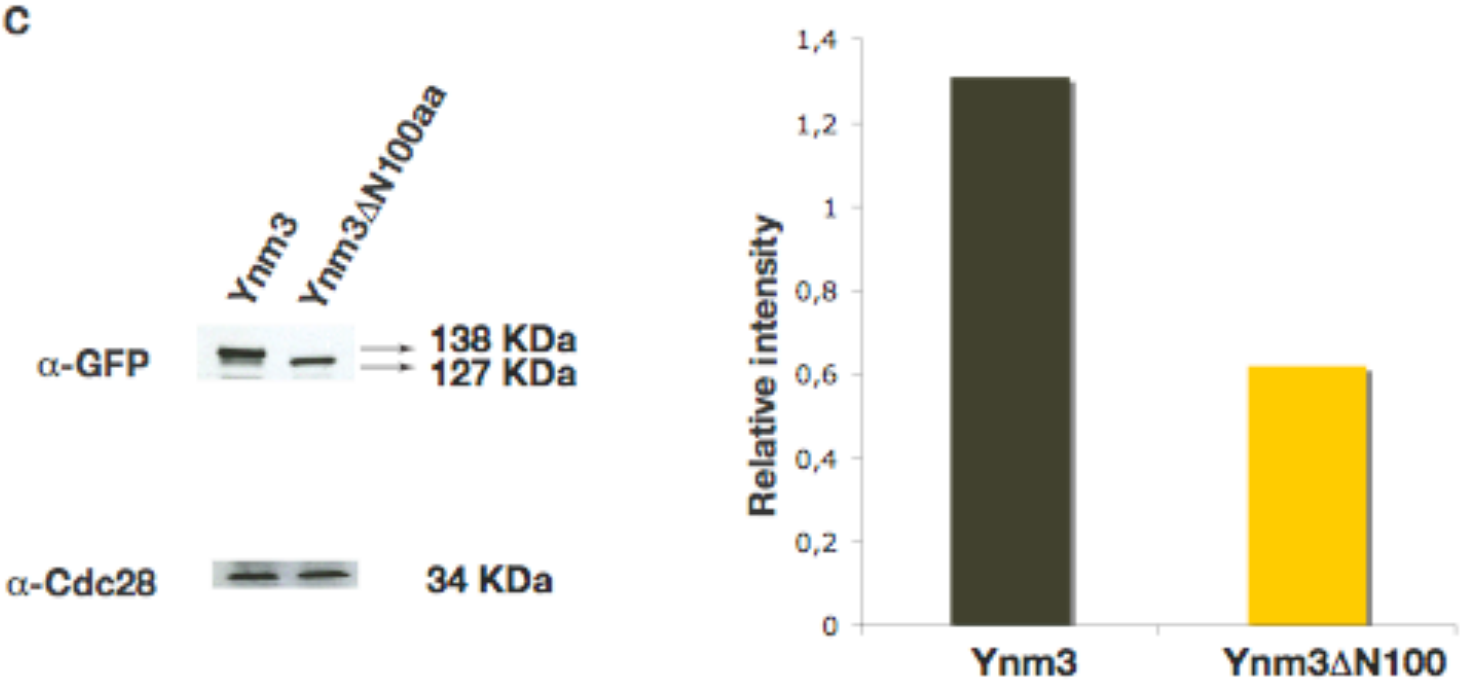

Figure 10: The nuclear localization signal in $\mathrm{Ynm} 3$ lies in its first $100 \mathrm{~N}$-terminal amino acid residues. (A) GFP tagged Ynm3 $\Delta$ N100aa lacking the first $100 \mathrm{~N}$-terminal amino acids was localized entirely outside the nucleus whereas the first 100 amino acid stretch of Ynm3 (N100aa) tagged with GFP on its own was entirely localized in the nucleus. This indicates that the nuclear localization signal of Ynm3 lies in the region containing the first $100 \mathrm{~N}$-terminal amino acids. (B) Ynm3 $\Delta$ N100 could not rescue the heat sensitivity of a $\triangle y n m 3$ strain when expressed from either a single or a multi copy vector under the control of the MET25 promoter. Multi copy expression of Ynm3 $\Delta$ N100 resulted in growth impairment indicating that it retains protease activity. (C) Ynm3 $3 \mathrm{~N} 100$ expressed from a single copy vector was only half as stable as native $\mathrm{Ynm} 3$ as indicated by the immunoblot probed with anti-GFP antibody. The blot was stripped and reprobed with anti-Cdc28 antiserum. The bands were quantified and the relative intensity plotted. 
This suggests that the nuclear localization of Ynm3 is important to confer its protective function under higher temperatures. Immunoblotting with anti-GFP antibody revealed that Ynm3 $3 \Delta 100$ expressed from a single copy vector was only half as stable as native Ynm3 (Figure 10C).

\subsection{Ynm3 exhibits chaperone activity, in vitro.}

The prokaryotic HtrA members are dual chaperone-proteases. Chaperone activity in any eukaryotic HtrA has not been recognised so far. I analyzed if the budding yeast Ynm3 exhibits chaperone activity employing a widely used assay based on the thermal aggregation of citrate synthase (CS), a non-native substrate (Buchner et al., 1998). CS when subjected to heat, denatures and forms aggregates, which renders the solution turbid because these aggregates scatter light that increases with time. The increase in the amount of light scattered with time is due to both increase in the number and also the size of aggregates formed by thermally denaturing CS (Buchner et al., 1998). As shown in Figure 11A, in the absence of chaperones, the reaction mixture containing $0.15 \mu \mathrm{M}$ CS scattered light at $500 \mathrm{~nm}$ which increased with time when subjected to a temperature of $43^{\circ} \mathrm{C}$. Presence of equimolar amounts of Ynm3 in the reaction mixture completely suppressed this light scattering whereas the negative control protein, chymotrypsinogen, did not (Figure 11A). This indicates that Ynm3 possesses ATP-independent general chaperone activity due to its ability to bind unfolding intermediates of a non-native substrate like $\mathrm{CS}$ at $43^{\circ} \mathrm{C}$ thereby preventing its aggregation without any energy requirement. Several known chaperones like GroEL, Hsp70, Hsp90 and small heat shock proteins have been shown to possess the ability to suppress the aggregation of thermally denatured CS (Buchner et al., 1998). 
A

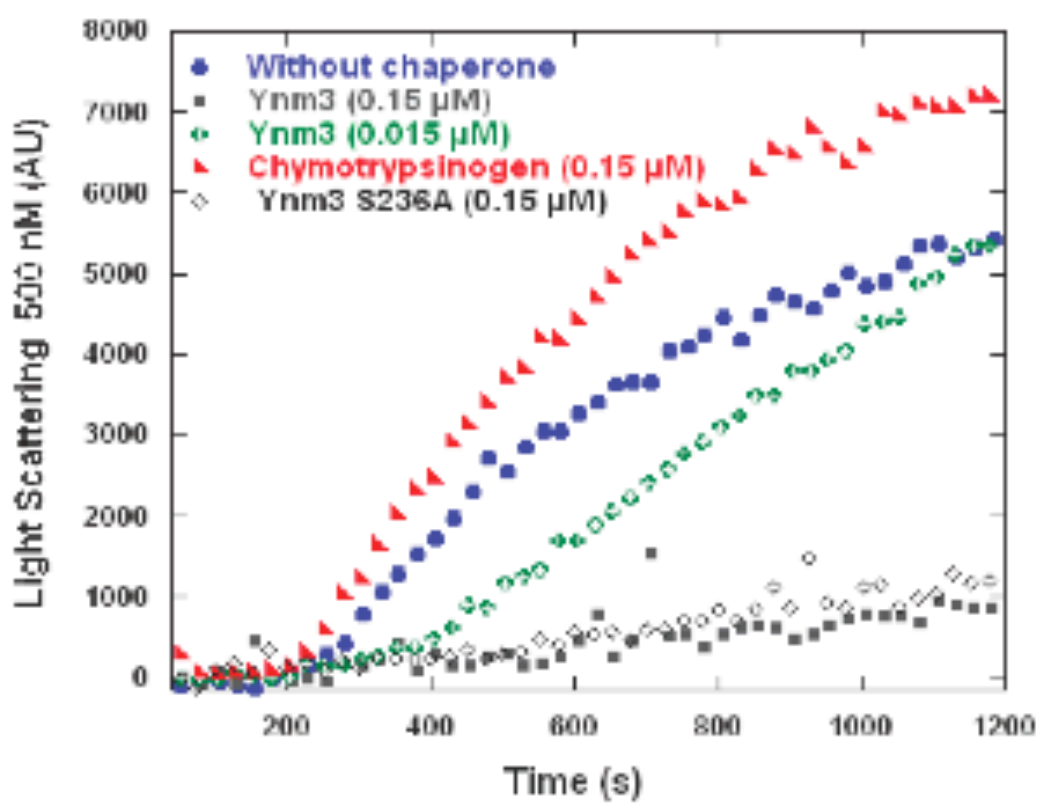

B

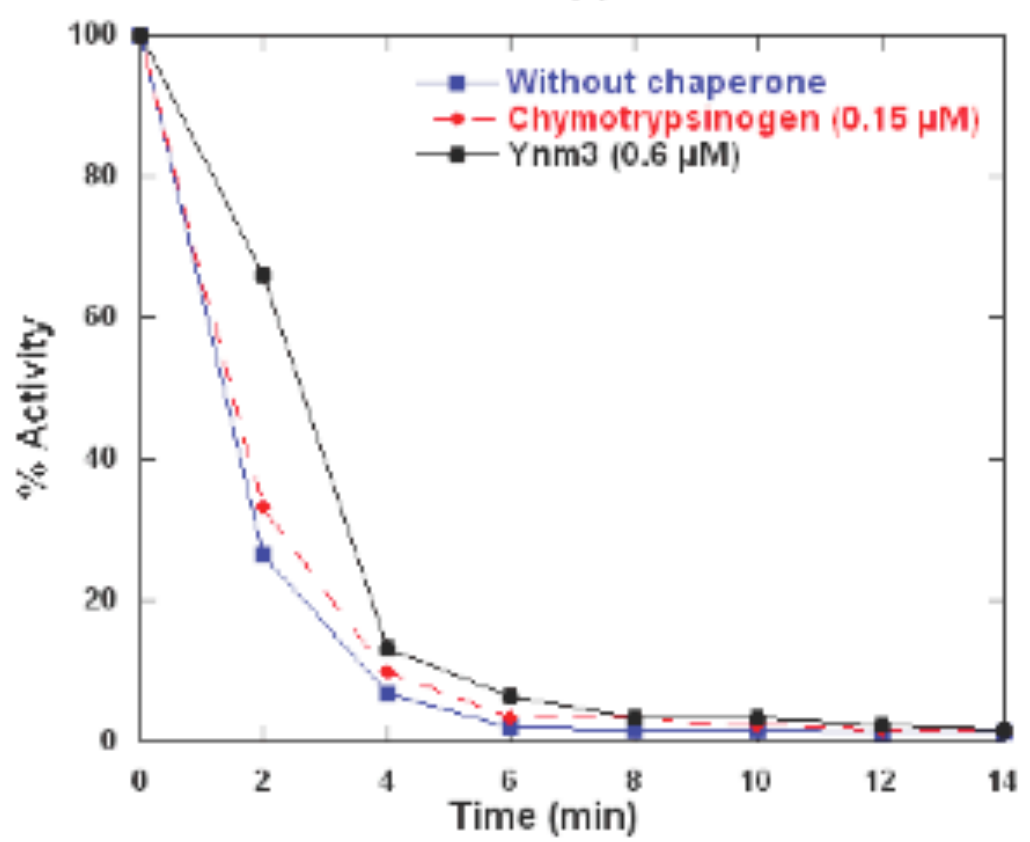

Figure 11: Ynm3 exhibits chaperone activity, in vitro. (A) In the absence of chaperones, the reaction mixture containing $0.15 \mu \mathrm{M}$ citrate synthase (CS) scattered light in an increasing manner at $43^{\circ} \mathrm{C}$ due to thermal aggregation of CS. In the presence of equimolar amounts of $\mathrm{Ynm} 3$ or Ynm3S236A, this light scattering was completely suppressed. (B) Presence of Ynm3 did not affect the thermal inactivation kinetics of CS.

The E.coli HtrA/DegP is a chaperone at lower temperatures and switches to being a protease only at higher temperatures (Spiess et al., 1999). In contrast, Ynm3 acts as a chaperone at $43^{\circ} \mathrm{C}$ in vitro, a condition similar to heat shock temperatures in vivo. But the protease dead S210A variant of bacterial HtrA/DegP retains chaperoning ability even at higher temperatures which is sufficient to rescue the heat sensitivity of a $\operatorname{deg} P$ mutant when 
overexpressed (Spiess et al., 1999). This does not seem to be the case with the budding yeast Ynm3. Although the protease dead variant Ynm3S236A exhibited chaperone activity at $43^{\circ} \mathrm{C}$ (Figure 11A), even its overexpression could not compensate for the lack of its proteolytic activity (Figure 6B), which seems to be indispensable for protection against heat stress.

Ynm3 could prevent the aggregation of CS, yet it had no significant influence on the thermal inactivation of $\mathrm{CS}$ at $43^{\circ} \mathrm{C}$ (Figure 11B) suggesting that Ynm3 tightly binds those unfolding intermediates of CS which are no more in equilibrium with their native state.

\subsection{Lack of Ynm3 may lead to compromised mitochondrial function in older yeast colonies}

There is increasing evidence that the mammalian HtrA2/Omi might play an important role in maintaining mitochondrial homeostasis. Although, Ynm3 is predominantly localized in the nucleus, its absence in the budding yeast YB322 strain was also reported to result in respiratory deficiency (Tong et al., 2006). The $\Delta y n m 3$ strains generated in this study did not show such a strong respiratory deficient phenotype although a small fraction of the $\Delta y n m 3$ transformants was respiration deficient. Nevertheless, a distinct difference between the colour of YB322 wild type and the $\Delta y n m 3$ colonies was repeatedly noticed upon prolonged incubation for about 15-20 days on synthetic complete (SC) agar containing glucose and 100 $\mathrm{mg} / \mathrm{l}$ adenine at $30^{\circ} \mathrm{C}$ (Figure 12A). Strains like $\mathrm{YB} 322$ that have an ade2 mutation accumulate an intermediate of the adenine biosynthetic pathway, which is converted into a red pigment by a series of covalent and oxidative reactions. This pigment formation pathway is defective due to the lack of OXPHOS enzymes in strains that have damaged mitochondrial DNA which therefore remain white (Shadel, 1999). The colonies of the wild type YB322 strain developed a deep red colour upon prolonged incubation whereas the $\Delta y n m 3$ colonies remained light pink (Figure 12A). The deep red colour was completely restored in the $\Delta y n m 3$ strain by introducing single copy $(C E N)$ plasmid carrying the gene encoding native Ynm3 
under the control of the MET25 promoter (Figure 12A). The pink coloration of the $\triangle y n m 3$ colonies in contrast to the deep red coloration of the wild type YB322 colonies on the same plate at ambient growth temperature $\left(30^{\circ} \mathrm{C}\right)$ is indicative of compromised oxidative growth in old $\triangle y n m 3$ colonies, which is restored upon re-introduction of a copy of YNM3. As aging is often associated with compromised protein quality control, these observations hint at the possibility that in addition to its primary function in the nucleus, Ynm3 may also become important for mitochondrial homeostasis in aging yeast cells.

The mammalian HtrA2/Omi is predominantly localized in the mitochondria. It was observed that Ynm3-GFP, encoded by its endogenous promoter, was localized mainly in the nucleus. Since the lack of Ynm3 hints at mitochondrial dysfunction, I wondered if Ynm3, like its mammalian homologue, is at least partially localized to the mitochondria. Interestingly, a subpopulation of cells from overnight cultures of the BY4741 strain background, expressing Ynm3-GFP from its endogenous promoter grown in SC medium showed a distinct dotted pattern of GFP fluorescence in the cytoplasm. This was also described in a different strain background in a previous report (Fahrenkrog et al., 2004). Considering the predominant localization of the mammalian HtrA homologue, HtrA2/Omi, in the mitochondrial intermembrane space, I suspected that this dotted GFP fluorescence pattern represented mitochondria. The BY4741 Ynm3-GFP encoding strain was transformed with a plasmid encoding mitochondria-targeted blue fluorescent protein (BFP). Fluoresence microscopy of overnight cultures of this strain revealed colocalization of Ynm3-GFP with the mitochondriatargeted BFP signal in a subset of cells (Figure 12B), thus indicating that a fraction of Ynm3 is associated with mitochondria. To address the possibility that the BFP signal could have bled through the GFP channel, snapshots of the same cells were obtained after completely bleaching the BFP signal by overexposure to UV light. The mitochondrial GFP signal in these cells, however, remained intact, making it clear that there was no bleed through of the BFP signal in the GFP channel. 
A

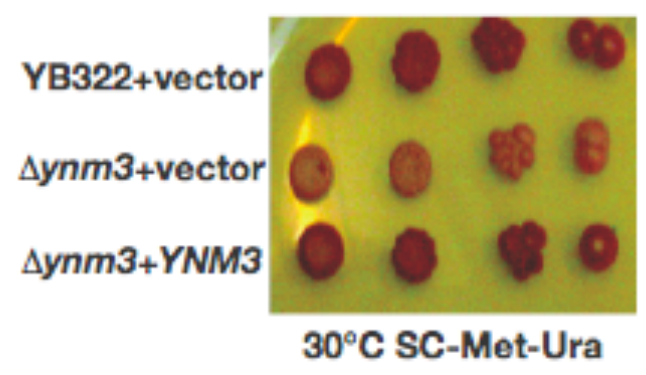

C

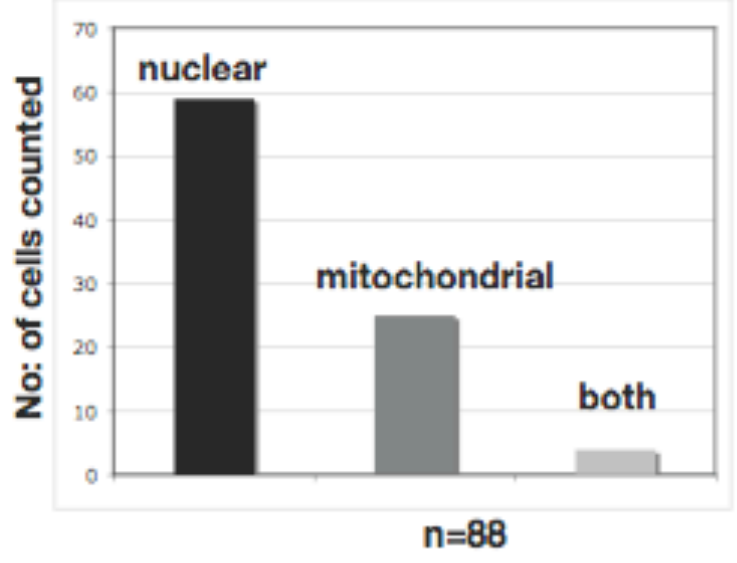

B

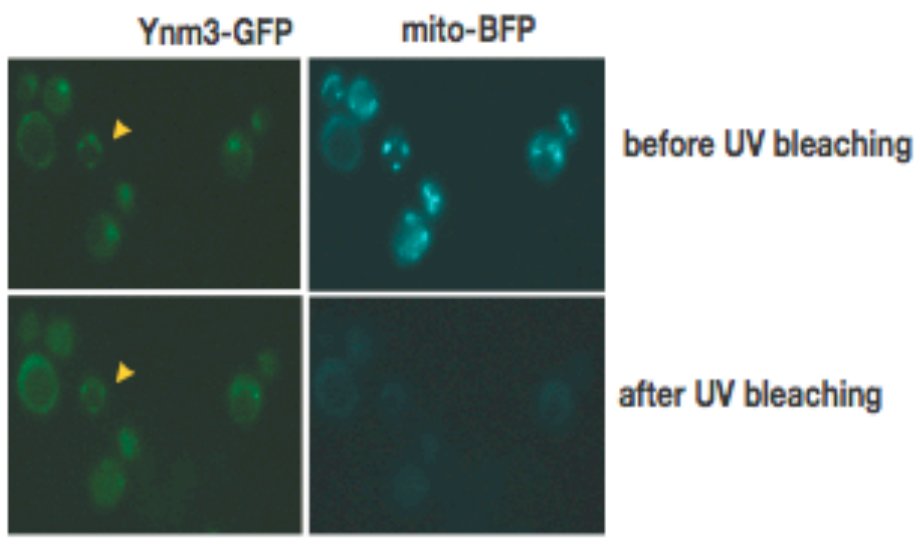

Figure 12: Lack of Ynm3 leads to reduced oxidative growth in older yeast cells. (A) Prolonged incubation of the indicated strains for about 20 days revealed a difference in the intensity of red pigment formation characteristic of ade 2 yeast strains growing oxidatively. The lighter colour attained by the $\Delta y n m 3$ strain could be restored to wild type levels (deep red) by a single copy plasmid expressing Ynm3 (B) In addition to nuclear localization, Ynm3-GFP expressed under the control of its endogenous promoter from its chromosomal locus, in the strain BY4741 was found to be colocalized with mitochondria targetted BFP in a subpopulation of cells (indicated by arrow) in overnight cultures. Images of GFP were also taken after photobleaching of the BFP signal in order to rule out any bleed through between the channels. (C) The number of cells exhibiting either nuclear or mitochondrial localization of Ynm3-GFP or both were counted from a set of eleven snapshots. About $25 \%$ of the cells counted from a total of 88 showed colocalization of Ynm3-GFP with mito-BFP.

\subsection{A genetic screen identified $F P R 3$ as a suppressor of the heat sensitivity of $\Delta y \mathrm{~nm} 3$}

A suppressor screen was performed in this study by transforming a yeast genomic DNA library (Connelly and Hieter, unpublished, June 1990) into $\Delta y n m 3$ to identify other genes that could suppress its heat sensitivity. Plasmids were isolated from those $\Delta y n m 3$ colonies that 
appeared larger at $38^{\circ} \mathrm{C}$. From the screen, only one candidate plasmid was found to contain complete coding sequences and was able to partially rescue the heat sensitivity of $\Delta y n m 3$ even upon isolation and retransformation. Upon blasting the insert sequence of the plasmid against the yeast genome database (http://seq.yeastgenome.org/cgi-bin/blast-sgd.pl), complete coding sequences of adjacent genes on chromosome XIII namely FPR3, encoding a PPIase and $R P L 6 A$, encoding a ribosomal subunit, along with their upstream and downstream sequences were identified. The two genes were individually cloned and transformed into $\Delta y n m 3$ to identify, which one of these was responsible for conferring better growth for $\Delta y n m 3$ at elevated temperatures. An additional copy of FPR3 but not RPL6A was sufficient to partly rescue the heat sensitivity of $\Delta y n m 3$ as observed in the genetic screen (Figure 13).

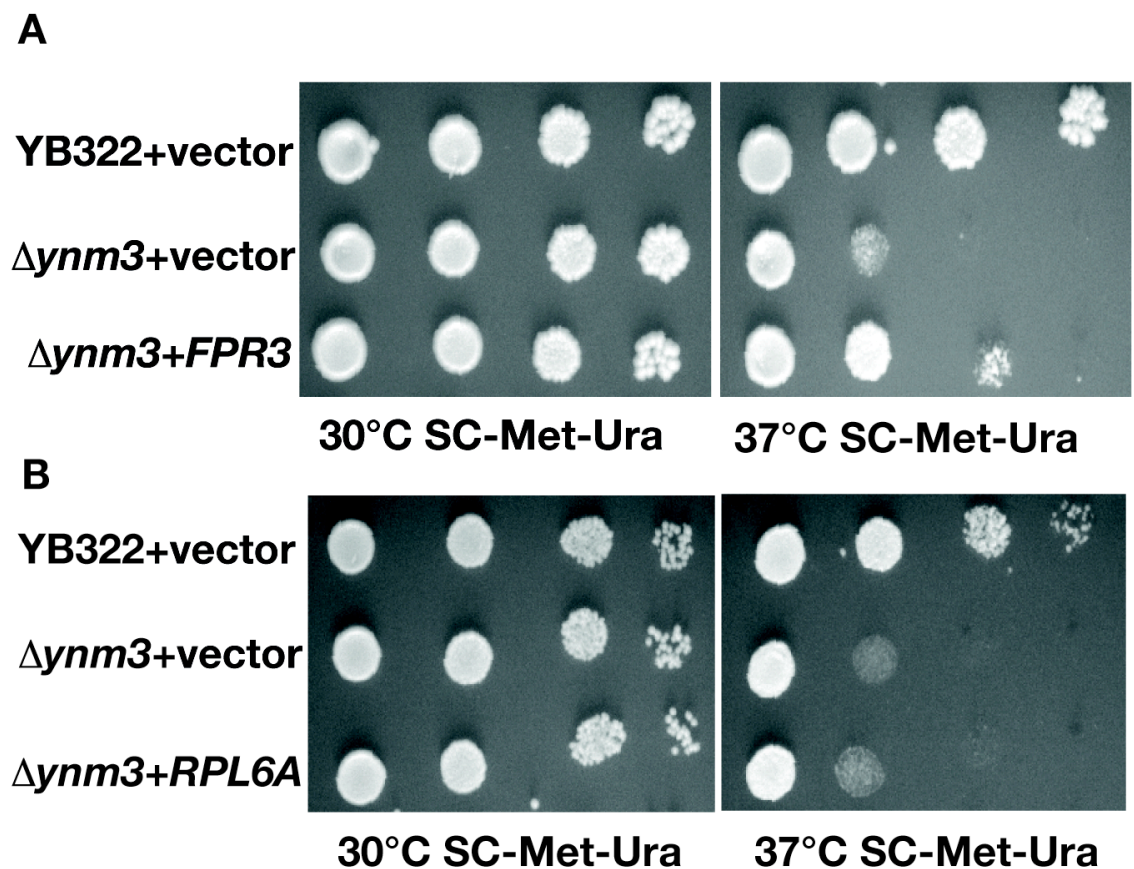

Figure 13: FPR3 is a partial knockout suppressor of $\triangle y \boldsymbol{y m} 3$. (A) A single copy plasmid carrying FPR3 under the control of the MET25 promoter partially rescued the heat sensitivity of a $\triangle y n m 3$ strain under inducing conditions whereas (B) that carrying RPL6A, whose coding sequence is present adjacent to FPR3 on the chromosome, could not.

FPR3 encodes a peptidyl-prolyl cis-trans isomerase (PPIase) localized to the nucleolus of the budding yeast (Shan et al., 1994). Surprisingly, in E. coli too, a functional relationship exists between HtrA/DegP and the periplasmic PPIase, SurA, which is mainly responsible for 
the maturation of outer membrane proteins (OMPs). HtrA/DegP is not essential for bacteria under normal conditions. Its role is only to rescue OMPs that have escaped SurA mediated folding and maturation. However it's role is amplified in the absence of SurA or under stressful conditions. HtrA/DegP along with another periplasmic chaperone Skp can substitute for the absence of SurA (Sklar et al., 2007) and therefore surA/degP double deletion is synthetic lethal (Rizzitello et al., 2001).

To test if such a genetic interaction exists between Ynm3 and the PPIase, Fpr3, I deleted FPR3 in the wild type YB322 strain and also in the $\triangle y n m 3$ strain using a cassette conferring nourseothricin (cloNAT) resistance. Genomic DNA was isolated from colonies that could grow on plates containing YPD+cloNAT. The presence of the drug resistance cassette disrupting the FPR3 locus was verified by PCR. As shown in Figure 14, the double deletion of FPR3 and YNM3 was not synthetically lethal and deletion of FPR3 alone did not lead to discernable heat sensitivity. I speculated that Fpr3 like some other PPIases of yeast like Cpr6 and Cpr7 might in addition to its PPIase activity, have chaperone activities that would gain prominence only when other quality control mechanisms fail.

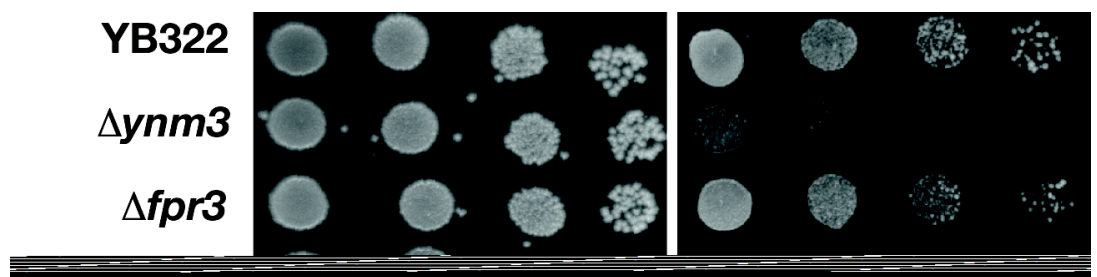

Figure 14: In the presence of Ynm3, Fpr3's thermoprotective function is dispensable. Lack of Fpr3 alone does not lead to noticeable heat sensitivity in the YB322 strain. Moreover, double deletion of YNM3 and FPR3 was not synthetically lethal. 




\section{Discussion}

A variety of intracellular and extracellular factors, can threaten the quality of proteins in the cell. Gene mutations or biosynthetic errors lead to accumulation of aberrant proteins, which are unable to attain their native conformations. External factors like high temperatures can affect the tertiary structure of proteins resulting in unfolding or misfolding which can lead to aggregate formation. To prevent such an occurring, cells have developed an elaborate machinery of quality control factors: chaperones and proteases, which ensure that proteins are maintained in their natively folded and active forms, thereby safeguarding cell viability and function. Mutations in genes encoding chaperones and proteases can lead to failure of quality control and accumulation of aberrant proteins, which is deleterious to the cell as this might interfere with efficient functioning of cellular pathways or lead to sequestration of proteins into aggregates due to the inherent stickiness of the exposed hydrophobic surfaces of misfolded proteins. Toxic gain-of-function mutations acquired by proteins as in neurodegenerative disorders such as Parkinson's disease that enable them to escape quality control can lead to massive aggregation. Efficiency of the cellular quality control system also dwindles with age. This is the reason for the late onset of most neurodegenerative disorders where failure of protein quality control may be both the cause and the consequence.

Mitochondrial dysfunction is a common feature of neurodegenerative diseases like Parkinson's disease (PD). Mutations in genes encoding proteins that directly or indirectly affect mitochondrial homeostasis have been associated with PD. One such factor is the serine protease HtrA2/Omi. Mammalian HtrA2/Omi was first identified as a homologue of the bacterial HtrA proteins that are stress responsive serine proteases in the periplasmic space required for survival at higher temperatures (Faccio et al., 2000; Gray et al., 2000). HtrA2/Omi was originally described as an apoptosis inducer in cell cuture. According to 
various reports, $\mathrm{HtrA} / \mathrm{Omi}$, a resident of the mitochondrial intermembrane space, exits the organelle and enters the cytoplasm when cells receive apoptotic stimuli. In the cytoplasm, it binds and cleaves a group of proteins called the inhibitor of apoptosis (IAP) proteins thereby relieving their inhibitory effect towards caspaces (Hegde et al., 2002; Martins et al., 2002; Suzuki et al., 2001; Verhagen et al., 2000). In the mean time, studies using mutant mice have revealed a contradictory physiological function for HtrA2/Omi. The mnd2 (motor neuron degeneration 2) mutant mice, in which the corresponding gene encodes an intact IAP binding domain but carries a protease inactivating point mutation (S276C), suffer neurodegeneration leading to juvenile death (Jones et al., 2003). Interestingly, the HtrA2 knockout mice also show a similar phenotype underscoring the physiological relevance of the serine protease activity of this protein (Jones et al., 2003; Martins et al., 2004). Cells from these mice are more prone to apoptosis rather than being resistant. A certain percentage of cells from HtrA2/Omi knockout mice exhibit abnormal mitochondrial morphology combined with a decreased mitochondrial density (Martins et al., 2004). Moreover, mutations affecting its protease activity resulting in increased sensitivity to cell death and compromised mitochondrial complex I activity have been identified as susceptibility factors in PD (Strauss et al., 2005). Since HtrA2/Omi closely resembles the bacterial HtrAs, which aid cell survival at elevated temperatures, it is indeed debatable whether a close homologue of a bacterial cell survival protein has switched functions to becoming a cell death-promoting factor in higher organisms. Recent reports have provided hints further strengthening the view that HtrA2/Omi could have a more protective role in the physiological milieu. It has been shown that HtrA2/Omi phosphorylation in a PINK1 dependent manner (another factor associated with PD), which increases its proteolytic activity is involved in mitochondrial stress response (Plun-Favreau et al., 2007). A second checkpoint function for HtrA/Omi in the mitochondria following proteasomal inhibition in the cytoplasm has also been reported (Radke et al., 2008). Considering that mitochondria are evolutionary derivatives of ancestral $\alpha$-proteobacteria, it is 
tempting to suspect that HtrA2/Omi and other eukaryotic HtrAs have conserved their original bacterial function i.e, protection against unfolding stresses. The possibility that the mammalian HtrA2/Omi might also act as a dual chaperone-protease like the bacterial HtrA/DegP is an immensely attractive hypothesis though as yet untested. So far, no such definitive function has been ascribed to a eukaryotic HtrA member. In this study, this issue was addressed for the budding yeast HtrA representative, Ynm3, a eukaryotic HtrA member whose cellular function is not yet clear since contradictory ideas regarding its function has been put forth leading to a contention similar to that of the mammalian homologue (Fahrenkrog et al., 2004; Tong et al., 2006).

\subsection{The serine protease activity of $\mathrm{Ynm} 3$ mediates cell survival under heat stress}

Mutational loss of quality control factors often lead to growth arrest especially under heat stress due to structural damage to proteins and accumulation of protein inclusions. If Ynm3 were a quality control protease like HtrA/DegP in bacteria, the lack of it would be manifested as retarded growth of yeast under stressful conditions. Here, the growth of the wild type YB322 yeast strain was compared with the $\Delta y n m 3$ strain at a higher temperature and indeed the loss of Ynm3 led to visible growth impairment, which could be rescued by just a single copy of the wild type protein. As mentioned earlier, the E. coli HtrA/DegP is a serine protease that protects the bacterial cell at elevated temperatures by eliminating unfolded proteins in the periplasm by its serine protease activity (Lipinska et al., 1990; Spiess et al., 1999). Ynm3 is a chymotrypsin A- like serine peptidase with a serine nucleophile and catalytic residues in the order His, Asp, Ser (http://merops.sanger.ac.uk/). Two adjacent serine residues were selected, namely Ser235 and S236, for exchange to alanine. Ser235 was proposed as the catalytic serine by the same group in two of their reports (Fahrenkrog et al., 2004; Walter et al., 2006). The adjacent serine at position 236 was predicted to be the catalytic serine residue by the 
2007 version of the MEROPs peptidase database. Expression of the Ynm3S235A variant could completely rescue the heat sensitivity of $\Delta y n m 3$ whereas the Ynm3S236A variant could not do so indicating the importance of the serine protease activity of Ynm3 conferred by the serine residue at position 236, in executing its protective function in response to heat stress. Therefore, it is very likely that Ynm3, like its bacterial counterpart HtrA/DegP in the periplasm, binds and proteolytically cleaves toxic aberrant proteins in the nucleus of the budding yeast. A range of specialized ATP dependent proteolytic machines mediate proteolysis in bacteria and organelles such as mitochondria of eukaryotes whereas the proteasome is the only proteolytic machinery involved in protein quality control in the nucleus and cytoplasm of eukaryotes. The existence of a second proteolytic machinery, Ynm3, mediating protein quality control in the budding yeast nucleus is therefore a novel finding.

In vitro, HtrA/DegP cleaves a heterogenous group of unfolded proteins (Clausen et al., 2002). Ynm3 had no effect on heat denatured non-native substrates like $\beta$-casein. Nevertheless it underwent slow autocatalysis in vitro. It is possible that a specific modification triggers its proteolytic activity, which is available only in the physiological milieu, or on the other hand Ynm3 may target only a specific class of proteins. Several attempts made during the course of this work to find in vivo substrates of Ynm3 using yeast two-hybrid assay and tandem affinity purification method failed probably due to transient enzyme-substrate interactions in vivo.

An interesting observation emerged from the in vitro autocatalysis assay of Ynm3. The amount of purified wild type Ynm3 in the reaction had reduced to less than 17\% after 16 hours of incubation as observed by Coomassie staining after SDS-PAGE. As expected, exchange of its catalytic serine residue to alanine dramatically reduced the autocatalytic activity of Ynm3 with more than $86 \%$ of the initial amount of protein remaining in the reaction mixture. This again validates the in vivo finding that the protease activity of $\mathrm{Ynm} 3$ is 
conferred by the serine at position 236. Although the exchange of the active site serine to cysteine also greatly reduced the autocatalytic activity of Ynm3, it was not as effective as in the case of the Ynm3S236A variant with only $65 \%$ of Ynm3S236C left in the reaction after 16 hours. This indicates that Ynm3S236C retains some residual catalytic activity. Consequently, the overexpression but not single copy expression of Ynm3S236C could provide sufficient proteolytic activity to execute its protective function upon heat stress. This was not the case with the overexpression of Ynm3S236A suggesting that it is completely protease dead. It has been documented for some viral proteases that exchange of active site serines to cysteines does not necessarily abolish proteolytic activity completely which remains to varying degrees in different proteases (Hahn \& Strauss, 1990; Tautz et al., 2000). Here, this seems to be the case with the budding yeast Ynm3 also.

\subsection{Over expression of $\mathrm{Ynm} 3$ is deleterious to yeast}

Whereas an optimal amount of Ynm3 is beneficial to yeast, especially at elevated temperatures, overexpression of Ynm3 led to growth impairment, which was enhanced under heat stress. As mentioned in the previous section, Ynm3 expressed form a single copy vector could completely rescue the heat sensitivity of a $\Delta y n m 3$ strain. In contrast, multi copy expression of Ynm3 proved to be deleterious. However, multi copy expression of Ynm3S236A did not lead to any growth impairment unlike the case with the Ynm3S235A variant. Thus abrogating the serine protease activity of Ynm3 by exchanging the serine at position 236 to alanine could abolish its overexpression induced toxicity. This is an additional confirmation that the catalytic activity of the Ynm3 protease is conferred by the serine residue present at position 236 of the polypeptide and not the one present at position 235 as proposed earlier (Fahrenkrog et al., 2004).

The cellular quality control mechanism works efficiently because it has devised a strategy to target only misfolded or unfolded proteins by recognizing exposed hydrophobic 
patches on their surface thus avoiding native proteins since they have buried hydrophobic residues. Overexpression can disturb the balance between the amount of quality control proteases and the load of unfolded proteins present in the cell. Thus at optimal levels, quality control proteases aid cells by eliminating dysfunctional proteins but forced overproduction of these otherwise beneficial proteases can create havoc in the cell as they may also target native functional proteins for degradation. This would deny the cell of essential proteins leading to disruption of the normal functioning of cellular pathways resulting in growth impairment.

It was proposed in the first report (Fahrenkrog et al., 2004) that overexpression of Ynm3 resulted in apoptosis in yeast similar to the overexpression of mammalian HtrA2/Omi in cell culture. Hence the protein was termed nuclear mediator of apoptosis, $111 \mathrm{kDa}$ protein (Nma111). As there was no indication for either caspase mediated cell death or increased ROS production that could trigger a caspase independent cell death pathway, I conclude that the observed growth impairment was solely due to the cytotoxicity mediated by Ynm3's serine protease activity when present in excess.

\subsection{The PDZ domains of Ynm3 are critical for its stability}

The HtrA family of proteins is characterized by the presence of a serine protease domain in combination with at least one PDZ domain. PDZ domains represent a common protein protein interaction motif, and their name was derived from the first three proteins in which such domains were identified, namely PSD-95, Drosophila melanogaster Disc large protein, and zonula occludens protein 1 . The PDZ domains of the HtrA family members are important for substrate binding and/or regulating the proteolytic activity of the enzyme (Krojer et al., 2002; Li et al., 2002; Wilken et al., 2004). The PDZ domains of the thermophillic bacterium Thermotoga maritima HtrA (TmHtrA), which is a DegQ homologue, is important for dimerization of individual trimers (Kim \& Kim, 2005). Interestingly, the eukaryotic budding yeast Ynm3 has two PDZ domains, one present immediately proximal to the protease domain 
and the other at the $\mathrm{C}$-terminus of the protein. The functional significance of this duplication is not known. In this study, Ynm3 lacking either of the two PDZ domains could not confer thermoprotection to the $\Delta y n m 3$ strain although these variants were localized correctly to the nucleus. Immunoblotting revealed that these variants were highly unstable in comparison to the wild type protein. The instability of these variants could be due to disruption of their native tertiary structure because of the absence of a PDZ domain. This could in turn lead to their elimination by the quality control apparatus of the cell. Most quality control proteases studied so far exists as oligomeric complexes forming a compartmentalized structure in which their catalytic chambers are hidden from the environment. As in $\operatorname{Tm} H \operatorname{tr} A$, it is plausible that Ynm3 may exist as a stable oligomeric complex via interactions mediated by the PDZ domains. The oligomerization of Ynm3 may inturn be important for its function. Structural studies are necessary to probe into the intra and intermolecular interactions within or between the monomers and to explain why the lack of PDZ domains destabilizes the protein. The lack of either PDZ domain of Ynm3 although has a great impact on its stability, it does not effect the nuclear localization of the protein contrary to what was speculated in an earlier report (Fahrenkrog et al., 2004). The s of Ynm3 rather lies in its first 100 aminoacids residues.

\subsection{Ynm3 is a dual chaperone-protease like its bacterial HtrA/DegP counterpart}

The idea that chaperone activity could be assosciated with HtrA/DegP emerged from studies in the intracellular parasite, Rickettsia where a DegP homologue lacking the catalytic triad and two others lacking one catalytic residue were discovered (Bass et al., 1996). Subsequently, the chaperone activity of $E$. coli HtrA/DegP towards its native substrate, the periplasmic MalS and a non-native substrate, citrate synthase was characterized (Spiess et al., 1999). Eukaryotic HtrA homologues have been characterized as serine proteases involved in 
cell growth and development, stress response, apoptosis and ageing. The existence of chaperone activity in a eukaryotic HtrA has not been described so far.

I addressed this possibility for Ynm3, the HtrA counterpart of the simple eukaryotic model organism, the budding yeast and could indeed demonstrate the existence of general chaperone activity reminiscent of its prokaryotic homologues. In vitro, Ynm3 in equimolar amounts was able to completely prevent the thermal aggregation of a non-native substrate like citrate synthase in an ATP independent manner. Citrate synthase (CS) is a widely used substrate for assaying chaperone activity in vitro and its folding pathway has been well characterized (Buchner et al., 1998). In contrast to bacterial DegP, which is a chaperone only at ambient growth temperatures, Ynm3 exhibited chaperone activity even at higher temperatures. Ynm3 did not influence the thermal inactivation kinetics of CS suggesting that it functions by strongly sequestering and preventing the aggregation of those unfolding intermediates, which are unable to refold to their native state. The protease dead Ynm3S236A alone could not rescue the heat sensitivity of $\Delta y n m 3$ even in excessive amounts despite being a robust chaperone in vitro unlike the situation in bacteria where DegPS210A in excessive amounts is sufficient to do so (Spiess et al., 1999). This implies that the protease activity of Ynm3 is crucial for handling irreversibly unfolded proteins, which may otherwise continue to accumulate forming toxic aggregates, a non-productive side reaction that not only renders damaged proteins refractory to proteolysis but also disrupts cellular pathways by sequestering functional proteins. Moreover, in the in vitro assay, although Ynm3 prevented the thermal aggregation of CS, it could not prevent its thermal inactivation, which suggests that Ynm3 binds only to irreversibly unfolded proteins that cannot refold to their native conformations. Consequently, in the absence of its protease activity, the chaperone activity of Ynm3 alone was unable to tackle unfolding stresses.

The ATP dependent proteolytic machines in bacteria like the ClpXP or ClpAP and that of the eukaryotic mitochondria like the Lon and Ftsh homologues have associated ATP- 
dependent chaperone activites either in the same or in physically associated subunits which aid in the unfolding of substrates facilitating their entry into the proteolytic chamber whose dimensions make it inaccessible for native or partially folded substrates to enter (Gottesman et al., 1997a). The ATPase subunits of the proteasomal lid also function in a similar manner (Benaroudj et al., 2003; Lee et al., 2001). Evolution has probably preserved the chaperone activity of $\mathrm{Ynm} 3$ for a similar purpose so that it recognizes heat-denatured proteins, preventing their aggregation and delivering them in a more soluble state to its protease domain thereby increasing the efficiency of proteolysis. The existence of a chaperone component in Ynm3 is probably meant only for effective recognition and sequestration of irreversible unfolded proteins and allowing their entry into the proteolytic center, which may not be able to accommodate folded or even partially folded conformers like in the classic proteases of bacteria and mitochondria, thereby avoiding unsupervised degradation. The protease subcomponents of the classic proteolytic complexes of bacteria and mitochondria are totally dependent on their associated chaperone components for substrate unfolding and delivery and hence cannot function all alone separated from their associated chaperone subunits. It would be interesting to find out if this is the case for Ynm3, too. This would require identification and subsequent mutation or deletion of the domain of Ynm3 that confers its chaperone activity.

The essence of this work describing Ynm3's role in protein quality control is summarized in the model (Figure 16) in which Ynm3 is a dual chaperone protease with the chaperone and protease activity residing in the same protein. Ynm3, by its chaperone activity is able to bind and sequester irreversibly unfolded proteins thereby preventing their aggregation. In addition, like the ATP dependent proteases of bacteria and the eukaryotic mitochondria, the chaperone activity of Ynm3 could help bind heat denatured irreversibly unfolded proteins to deliver them into its catalytic center in an ATP-independent manner for degradation. The only proteolytic machine in eukaryotes other than the ones present in 
cytoplasmic organelles is the $26 \mathrm{~S}$ ATP dependent proteasome. Structural studies will further our understanding of the organization of this novel ATP-independent chaperone-protease apparatus present in the nucleus of the budding yeast.

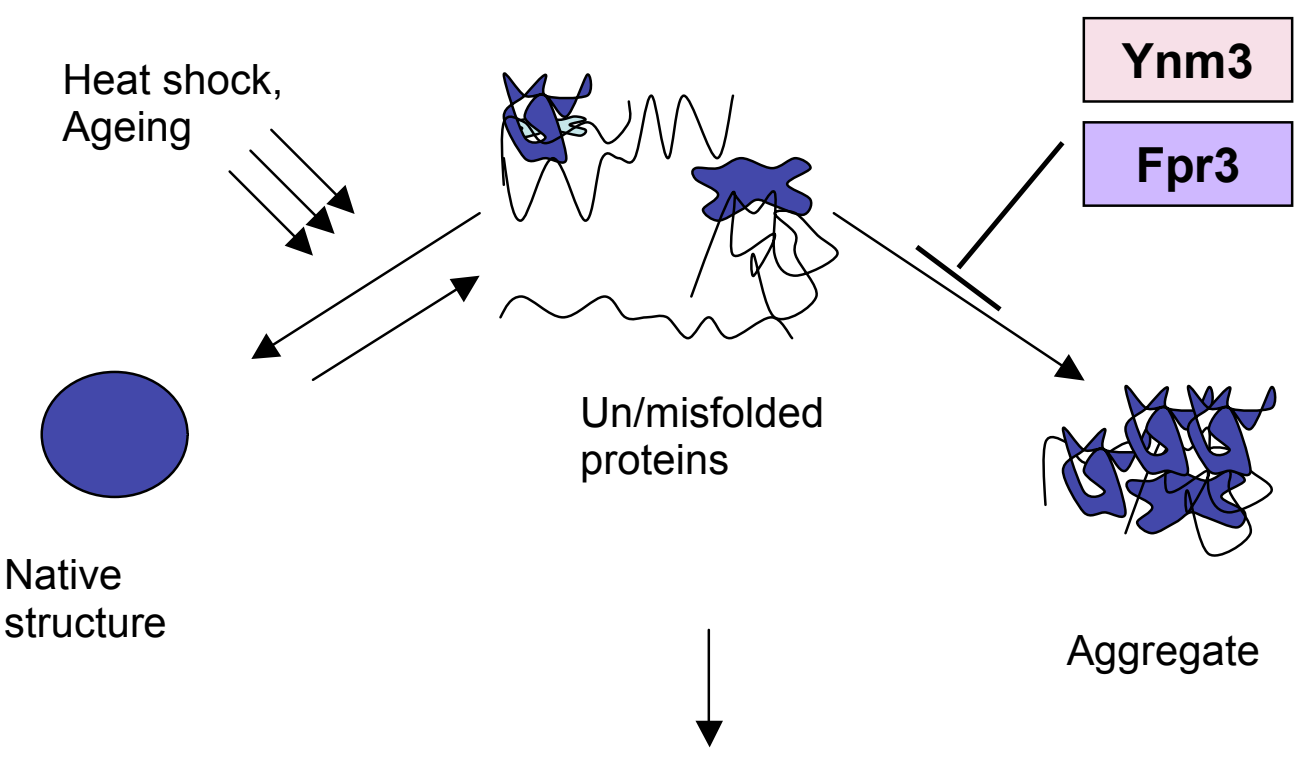

Proteolytic activity of Ynm3

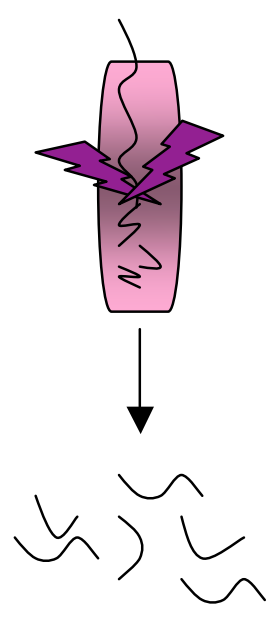

Figure 16: Model for Ynm3's role as a dual chaperone protease. Ynm3 is a dual chaperone protease with the chaperone and protease activity residing in the same protein. Ynm3's chaperone activity is able to sequester irreversibly unfolded proteins preventing their aggregation and maintaining them in a soluble state accessible for proteolytic attack. In addition, like the classic quality control proteases of bacteria and the mitochondria, the chaperone activity of Ynm3 could help maintain proteins in their unfolded state for delivery to its catalytic center for degradation in an ATPindependent manner. 


\subsection{Ynm3 may be involved in mitochondrial homeostasis during ageing}

Ynm3's protective role during heat stress is abolished when it is excluded from the nucleus, which indicates that it functions predominantly in the nucleus. However, observations made during this study have provided initial evidence pointing towards a possible mitochondrial function for the protein. The YB322 yeast strain is defective in adenine synthesis due to the ade2 mutation. Upon prolonged incubation on synthetic complete (SC) agar, the colonies turn deep red due to the accumulation of a dark red pigment, which is derived by the covalent and oxidative modification of an adenine biosynthetic pathway intermediate that accumulates in ade2 strains. $\triangle y n m 3$ colonies display a marked decrease in the intensity of this red pigment formation compared with the wild type colonies upon prolonged incubation. The intensity of the red coloration was restored to wild type levels by reintroduction of a single copy of native $Y N M 3$. Since this red pigment formation in ade2 strains like YB322 requires oxidative modifications of the accumulated adenine biosynthetic pathway intermediate by the mitochondrial oxidative phosphorylation system (OXPHOS) (Shadel, 1999), this phenotype is an indication that Ynm3 is either directly or indirectly involved in the proper functioning of mitochondrial respiration in the budding yeast which becomes apparent upon prolonged incubation.

The absence of the mammalian mitochondrial HtrA2/Omi or the protease deactivating mutation in the $m n d 2$ mouse results in decreased mitochondrial density in tissues (Martins et al., 2004). In humans, mutations in HtrA2/Omi affecting its protease activity led to mitochondrial dysfunction and Parkinson's disease (Strauss et al., 2005). Recent reports suggest that HtrA2/Omi may be involved in mitochondrial quality control when the cytoplasmic proteasome is inhibited (Radke et al., 2008). This study hints at a similar phenomenon of compromised mitochondrial function in the budding yeast due to the lack of Ynm3. Moreover, colocalization of endogenous Ynm3-GFP with mitochondrial markers was 
observed in overnight cultures of the BY4741 yeast strain. Since the protein does not possess an obvious mitochondrial targeting sequence, it is possible that it is either passively imported into the mitochondria or may only bind to the mitochondrial surface. This observation raises the question whether Ynm3 plays a protective quality control function in the budding yeast mitochondria or its absence impairs another pathway leading to slowdown of respiration and mitochondrial function in aged yeast cells.

Ageing can result in a diminished ability for cells to maintain strict quality control which is the reason why neurodegenerative diseases like Parkinson's have a late onset. Failure of mitochondrial protein quality control can in turn lead to accumulation of mutations in mtDNA. The observed phenotype indicative of poor respiratory growth became apparent only in older yeast colonies and therefore parallels the manifestation of symptoms related to mitochondrial dysfunction induced neurodegenerative disorders like Parkinson's disease in aged individuals. Since the budding yeast is a valuable model to study oxidative damage and ageing, unraveling the molecular pathway underlying the observed phenotype might lead to a better understanding of the connection between HtrA2/Omi and mitochondrial homeostasis.

\subsection{A genetic screen identified the yeast nucleolar PPIase Fpr3 as a partial suppressor of the heat sensitivity of $\Delta y n m 3$}

A genetic screen was performed using a budding yeast genomic DNA library to identify other candidates that could suppress the heat sensitivity of $\Delta y n m 3$. A plasmid containing the complete coding sequences of two adjacent genes encoding Fpr3, a nucleolar PPIase and Rpl6A, a ribosomal protein of the large subunit was found to enhance the growth of $\Delta y n m 3$ under elevated temperatures. Confirmatory tests were performed subsequently using constructs encoding either Fpr3 or Rpl6A, which led to the identification of the gene encoding Fpr3 as the candidate supressor. Fpr3 is a nucleolar peptidyl prolyl cis-trans isomerase (PPIase) implicated in maintaining meiotic recombination checkpoint activity (Hochwagen et 
al., 2005) in a manner which requires its PPIase domain but not its PPIase activity. PPIases are ubiquitous enzymes whose cellular roles remain largely undefined although these enzymes exhibit PPIase activity in vitro: catalysis of the cis-trans conversion of peptidyl prolyl bonds in polypeptides, which otherwise is a rate-limiting step in protein folding. Several PPIases in the budding yeast are known to be induced under heat stress and some of them are known to interact physically and functionally with heat shock proteins (ArevaloRodriguez et al., 2004). In addition to their PPIase activities, some of them like the budding yeast Cpr6, Cpr7 and the bacterial periplasmic SurA exhibit general chaperone activity in vitro (Behrens et al., 2001; Buchner et al., 1998; Mayr et al., 2000).

A cooperative interaction between HtrA/DegP and a PPIase, SurA exists in E. coli. The periplasmic PPIase, SurA, aids in the folding of cell envelope proteins (Rouviere \& Gross, 1996). Cooperation between HtrA/DegP and SurA in the periplasm of E. coli is exemplified by the synthetic lethality of a surA/degP double deletant (Rizzitello et al., 2001). SurA is the major periplasmic chaperone required for the folding of outer membrane proteins (OMPs). Under normal conditions, HtrA/DegP and another general chaperone Skp rescue those OMPs that have fallen-off the assembly pathway. But the roles of these proteins are greatly amplified under stress or in the absence of SurA (Sklar et al., 2007). The discovery of a similar compensatory interaction between the budding yeast HtrA homologue, Ynm3 and a PPIase Fpr3, where an additional copy of Fpr3 could partly substitute for the lack of Ynm3, was indeed surprising and further confirms that the budding yeast Ynm3 has a role analogous to the bacterial HtrA/DegP.

\subsection{Fpr3 exhibits strong general chaperone activity}

In vitro, the periplasmic PPIase SurA exhibits chaperone activity where a 64-fold molar excess of SurA could completely suppress the thermal aggregation of a non-native substrate like citrate synthase (Behrens et al., 2001). In this work, the possibility that Fpr3 
might also possess chaperone activity was tested and indeed it was found that substoichiometric amounts of purified Fpr3 could completely suppress the thermal aggregation of a non-native substrate like citrate synthase (CS) indicating that Fpr3 has excellent ATP independent chaperoning ability. This most likely contributes to the suppression of the heat sensitivity of the $\Delta y n m 3$ strain mediated by Fpr3. Equimolar amounts of Fpr3 reduced the rate of thermal inactivation of CS which follows apparent first order kinetics (Buchner et al., 1998). In the experiment depicted in Figure 15, the presence of equimolar amounts of Fpr3 reduced the rate constant of thermal inactivation of CS by about 18 fold. This demonstrates that Fpr3 binds to CS conformers that are native-like or are able to refold to their native states. This is unlike the case with Ynm3, which tightly sequesters irreversibly unfolded proteins, preventing their aggregation and hence has no influence on the inactivation kinetics of CS.

In E. coli, lack of both SurA and HtrA/DegP is synthetically lethal. In the budding yeast, whereas just an additional copy of FPR3 could suppress the heat sensitivity of a $\triangle y n m 3$ strain, deletion of FPR3 alone did not lead to detectable heat sensitivity and double deletion of YNM3 and FPR3 was not synthetically lethal. This suggests that Fpr3 under normal conditions may have other physiological roles and is not indispensable for tackling heatdenatured substrates due to other redundant and probably more prominent protein quality control mechanisms like that conferred by Ynm3. The chaperoning activity of Fpr3 gains importance under heat stress only in the absence of Ynm3, probably by rescuing substrates common to both Ynm3 and Fpr3 from denaturation and aggregation. Thus, the chaperoning function of Fpr3 gains significance under conditions of heat stress only in the absence of Ynm3. The interaction between Ynm3 and Fpr3 observed in this study is depicted in Figure 17. Such a compensatory chaperoning mechanism in the budding yeast nucleus resembles that between HtrA/DegP, SurA and Skp in the bacterial periplasm (Sklar et al., 2007). 


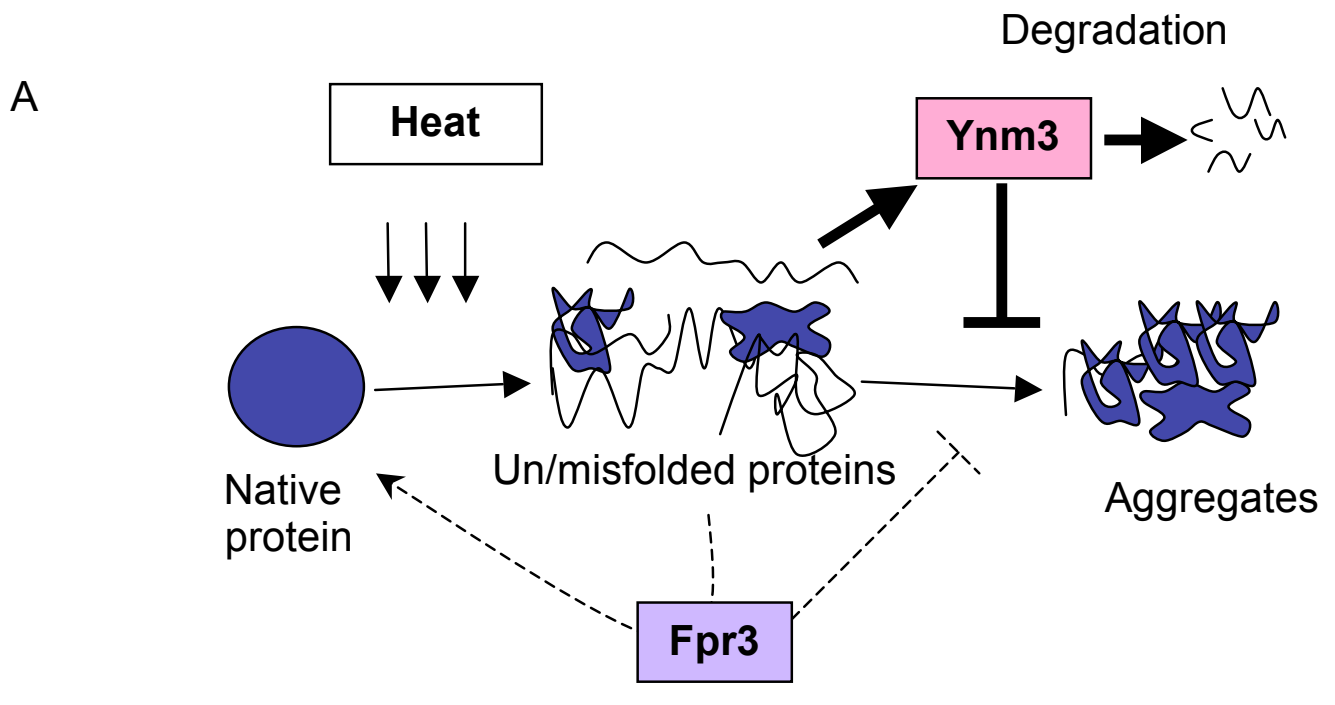

B

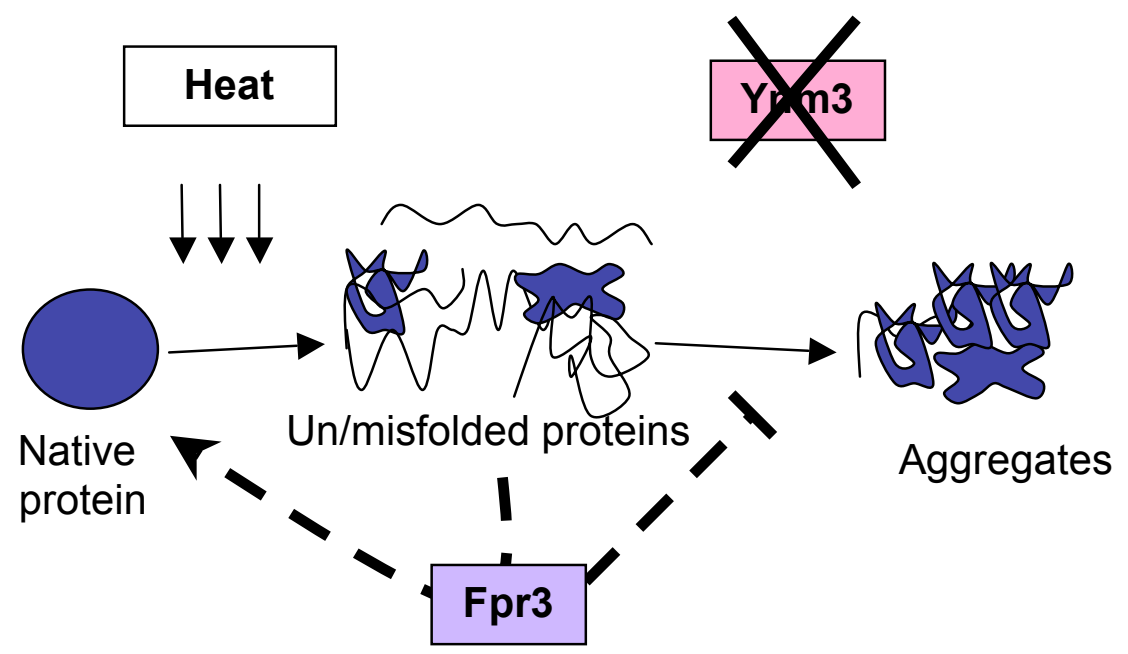

Figure 17: Fpr3 partly compensates for the lack of Ynm3 under heat stress. (A) In the presence of Ynm3, the chaperone activity of Fpr3 is dispensable to counter the unfolding stresses arising due to exposure of yeast to higher temperatures. Fpr3's function is redundant with that of Ynm3. (B) In the second scenario, i.e, in the absence of Ynm3, the chaperone activity of Fpr3 gains prominence where it binds unfolding substrates, preventing their aggregation and also providing them a chance to refold to their native structures. The interupted arrows are used here to show that Fpr3 only partly compensates for the absence of Ynm3. 


\section{Summary and Conclusions}

This study has led to the functional characterization of Ynm3, the budding yeast orthologue of the widely conserved HtrA family of proteins whose prokaryotic members are implicated in protein quality control. The well-studied bacterial HtrA/DegP acts as a dual chaperone-protease in the periplasm. A role for the mammalian mitochondrial HtrA2/Omi as a quality control factor is also very likely but not explicit. This study shows that the budding yeast $\mathrm{Ynm} 3$ has retained through evolution the characteristic chaperone-protease function reminiscent of its prokaryotic homologues.

In the YB322 yeast strain, the proteolytic activity of Ynm3 is crucial for handling unfolding stresses arising at elevated temperatures. The lack of Ynm3 or its proteolytic activity renders the strain susceptible to heat stress resulting in drastic growth impairment. From this work, the active site serine of Ynm3 has been identified as the serine residue at position 236 of the polypeptide and not Ser235 as proposed in earlier reports.

Overexpression of this otherwise beneficial protease is toxic resulting in growth impairment. This toxicity could be abolished by exchanging the active site serine (Ser 236) to alanine. The observed growth impairment might be due to the mistargeting of functional native proteins for proteolytic cleavage, which are otherwise strategically avoided. This could exhaust components of essential cellular pathways since under conditions in which quality control factors are overexpressed, the "triage" mechanism of substrate recognition fails.

In addition to acting as a protease, Ynm3 exhibits a strong general chaperone activity in vitro, which is able to prevent the thermal aggregation of a non-native substrate in an ATP independent manner. The chaperone activity of $\mathrm{Ynm} 3$ alone is not sufficient to confer thermoprotection since the protease dead Ynm3S236A was unable to rescue the heat sensitivity of $\Delta y n m 3$ even when overexpressed. I propose a model in which the chaperone activity of Ynm3 helps bind irreversibly unfolded proteins to prevent their aggregation, which 
could otherwise render them refractory to proteolytic attack. On the other hand, the chaperone activity might function to deliver substrates in an unfolded form into the proteolytic center like in the case of classic ATP-dependent proteases of bacteria and the eukaryotic mitochondria whose proteolytic chambers do not accommodate native or partially folded proteins.

In conclusion, this work has led to the identification of a novel ATP-independent chaperone-protease apparatus in the nucleus of the budding yeast. There is initial evidence that Ynm3 could also play a role in mitochondrial homeostasis during ageing since the $\Delta y n m 3$ strain shows signs of poor respiratory metabolism upon prolonged incubation. Further studies could lead to a better understanding of the function of the mammalian HtrA2/Omi with respect to protein quality control in the mitochondria.

During the course of the study, a nucleolar PPIase was identified as a knockout suppressor of Ynm3. Subsequent work led to the identification of a strong chaperone activity in Fpr3, which could prevent the thermal aggregation and also slow down the thermal inactivation of citrate synthase, a non-native substrate. Presumably, the chaperone activity of Fpr3 is able to partially compensate for the lack of Ynm3 in tackling unfolded proteins under heat stress. A similar phenomenon of compensatory chaperoning mechanism operates between HtrA/DegP and the PPIase, SurA in the periplasm of E. coli. 


\section{References}

Abou-Sleiman, P. M., Muqit, M. M. \& Wood, N. W. (2006). Expanding insights of mitochondrial dysfunction in Parkinson's disease. Nat Rev Neurosci 7, 207-219.

Apweiler, R., Attwood, T. K., Bairoch, A. \& other authors (2000). InterPro--an integrated documentation resource for protein families, domains and functional sites. Bioinformatics 16, 1145-1150.

Arevalo-Rodriguez, M., Wu, X., Hanes, S. D. \& Heitman, J. (2004). Prolyl isomerases in yeast. Front Biosci 9, 2420-2446.

Baker, T. A. \& Sauer, R. T. (2006). ATP-dependent proteases of bacteria: recognition logic and operating principles. Trends Biochem Sci 31, 647-653.

Bass, S., Gu, Q. \& Christen, A. (1996). Multicopy suppressors of prc mutant Escherichia coli include two HtrA (DegP) protease homologs (HhoAB), DksA, and a truncated R1pA. $J$ Bacteriol 178, 1154-1161.

Behrens, S., Maier, R., de Cock, H., Schmid, F. X. \& Gross, C. A. (2001). The SurA periplasmic PPIase lacking its parvulin domains functions in vivo and has chaperone activity. Embo J 20, 285-294.

Ben-Zvi, A., De Los Rios, P., Dietler, G. \& Goloubinoff, P. (2004). Active solubilization and refolding of stable protein aggregates by cooperative unfolding action of individual hsp70 chaperones. J Biol Chem 279, 37298-37303.

Benaroudj, N., Zwickl, P., Seemuller, E., Baumeister, W. \& Goldberg, A. L. (2003). ATP hydrolysis by the proteasome regulatory complex PAN serves multiple functions in protein degradation. Mol Cell 11, 69-78.

Bence, N. F., Sampat, R. M. \& Kopito, R. R. (2001). Impairment of the ubiquitinproteasome system by protein aggregation. Science 292, 1552-1555.

Bennett, E. J., Bence, N. F., Jayakumar, R. \& Kopito, R. R. (2005). Global impairment of the ubiquitin-proteasome system by nuclear or cytoplasmic protein aggregates precedes inclusion body formation. Mol Cell 17, 351-365. 
Bochkareva, E. S. \& Girshovich, A. S. (1992). A newly synthesized protein interacts with GroES on the surface of chaperonin GroEL. J Biol Chem 267, 25672-25675.

Bomeke, K., Pries, R., Korte, V., Scholz, E., Herzog, B., Schulze, F. \& Braus, G. H. (2006). Yeast Gen $4 p$ stabilization is initiated by the dissociation of the nuclear Pho85p/Pcl5p complex. Mol Biol Cell 17, 2952-2962.

Buchner, J., Grallert, H. \& Jakob, U. (1998). Analysis of chaperone function using citrate synthase as nonnative substrate protein. Methods Enzymol 290, 323-338.

Bukau, B., Weissman, J. \& Horwich, A. (2006). Molecular chaperones and protein quality control. Cell 125, 443-451.

Challa, M., Malladi, S., Pellock, B. J., Dresnek, D., Varadarajan, S., Yin, Y. W., White, K. \& Bratton, S. B. (2007). Drosophila Omi, a mitochondrial-localized IAP antagonist and proapoptotic serine protease. Embo $J$ 26, 3144-3156.

Chapman, E., Farr, G. W., Usaite, R. \& other authors (2006). Global aggregation of newly translated proteins in an Escherichia coli strain deficient of the chaperonin GroEL. Proc Natl Acad Sci U S A 103, 15800-15805.

Chernoff, Y. O., Lindquist, S. L., Ono, B., Inge-Vechtomov, S. G. \& Liebman, S. W. (1995). Role of the chaperone protein Hsp104 in propagation of the yeast prion-like factor [psi+]. Science 268, 880-884.

Chung, C. H. (1993). Proteases in Escherichia coli. Science 262, 372-374.

Ciechanover, A. (2006). Intracellular protein degradation: from a vague idea thru the lysosome and the ubiquitin-proteasome system and onto human diseases and drug targeting. Hematology Am Soc Hematol Educ Program, 1-12, 505-506.

Clausen, T., Southan, C. \& Ehrmann, M. (2002). The HtrA family of proteases: implications for protein composition and cell fate. Mol Cell 10, 443-455.

Dalbey, R. E. \& Chen, M. (2004). Sec-translocase mediated membrane protein biogenesis. Biochim Biophys Acta 1694, 37-53. 
De Los Rios, P., Ben-Zvi, A., Slutsky, O., Azem, A. \& Goloubinoff, P. (2006). Hsp70 chaperones accelerate protein translocation and the unfolding of stable protein aggregates by entropic pulling. Proc Natl Acad Sci U S A 103, 6166-6171.

Deuerling, E., Schulze-Specking, A., Tomoyasu, T., Mogk, A. \& Bukau, B. (1999). Trigger factor and DnaK cooperate in folding of newly synthesized proteins. Nature 400, 693696.

Duguay, A. R. \& Silhavy, T. J. (2004). Quality control in the bacterial periplasm. Biochim Biophys Acta 1694, 121-134.

Ellgaard, L. \& Helenius, A. (2003). Quality control in the endoplasmic reticulum. Nat Rev Mol Cell Biol 4, 181-191.

Faccio, L., Fusco, C., Chen, A., Martinotti, S., Bonventre, J. V. \& Zervos, A. S. (2000). Characterization of a novel human serine protease that has extensive homology to bacterial heat shock endoprotease HtrA and is regulated by kidney ischemia. J Biol Chem 275, 25812588 .

Fahrenkrog, B., Sauder, U. \& Aebi, U. (2004). The S. cerevisiae HtrA-like protein Nma111p is a nuclear serine protease that mediates yeast apoptosis. $J$ Cell Sci 117, 115-126.

Gidalevitz, T., Ben-Zvi, A., Ho, K. H., Brignull, H. R. \& Morimoto, R. I. (2006). Progressive disruption of cellular protein folding in models of polyglutamine diseases. Science 311, 1471-1474.

Glover, J. R. \& Lindquist, S. (1998). Hsp104, Hsp70, and Hsp40: a novel chaperone system that rescues previously aggregated proteins. Cell 94, 73-82.

Goldberg, A. L. (1992). The mechanism and functions of ATP-dependent proteases in bacterial and animal cells. Eur J Biochem 203, 9-23.

Goldberg, A. L. (2003). Protein degradation and protection against misfolded or damaged proteins. Nature 426, 895-899. 
Goloubinoff, P., Mogk, A., Zvi, A. P., Tomoyasu, T. \& Bukau, B. (1999). Sequential mechanism of solubilization and refolding of stable protein aggregates by a bichaperone network. Proc Natl Acad Sci U S A 96, 13732-13737.

Gottesman, S., Maurizi, M. R. \& Wickner, S. (1997a). Regulatory subunits of energydependent proteases. Cell 91, 435-438.

Gottesman, S., Wickner, S. \& Maurizi, M. R. (1997b). Protein quality control: triage by chaperones and proteases. Genes Dev 11, 815-823.

Gray, C. W., Ward, R. V., Karran, E. \& other authors (2000). Characterization of human HtrA2, a novel serine protease involved in the mammalian cellular stress response. Eur $J$ Biochem 267, 5699-5710.

Hahn, C. S. \& Strauss, J. H. (1990). Site-directed mutagenesis of the proposed catalytic amino acids of the Sindbis virus capsid protein autoprotease. J Virol 64, 3069-3073.

Hartl, F. U. \& Hayer-Hartl, M. (2002). Molecular chaperones in the cytosol: from nascent chain to folded protein. Science 295, 1852-1858.

Hegde, R., Srinivasula, S. M., Zhang, Z. \& other authors (2002). Identification of Omi/HtrA2 as a mitochondrial apoptotic serine protease that disrupts inhibitor of apoptosis protein-caspase interaction. $J$ Biol Chem 277, 432-438.

Heydari, A. R., Takahashi, R., Gutsmann, A., You, S. \& Richardson, A. (1994). Hsp70 and aging. Experientia 50, 1092-1098.

Higuchi, R., Krummel, B. \& Saiki, R. K. (1988). A general method of in vitro preparation and specific mutagenesis of DNA fragments: study of protein and DNA interactions. Nucleic Acids Res 16, 7351-7367.

Hinault, M. P., Ben-Zvi, A. \& Goloubinoff, P. (2006). Chaperones and proteases: cellular fold-controlling factors of proteins in neurodegenerative diseases and aging. $J$ Mol Neurosci 30, 249-265.

Hinault, M. P. \& Goloubinoff, P. (2006). [The toxic aggregation of proteins: a kind of "molecular delinquency" actively fought in the cell by molecular chaperones and proteases]. Ann Cardiol Angeiol (Paris) 55, 74-78. 
Hochwagen, A., Tham, W. H., Brar, G. A. \& Amon, A. (2005). The FK506 binding protein Fpr3 counteracts protein phosphatase 1 to maintain meiotic recombination checkpoint activity. Cell 122, 861-873.

Horwich, A. L., Farr, G. W. \& Fenton, W. A. (2006). GroEL-GroES-mediated protein folding. Chem Rev 106, 1917-1930.

Horwich, A. L., Fenton, W. A., Chapman, E. \& Farr, G. W. (2007). Two families of chaperonin: physiology and mechanism. Annu Rev Cell Dev Biol 23, 115-145.

Hoskins, J. R., Singh, S. K., Maurizi, M. R. \& Wickner, S. (2000). Protein binding and unfolding by the chaperone ClpA and degradation by the protease ClpAP. Proc Natl Acad Sci US A 97, 8892-8897.

Huang, H. C., Sherman, M. Y., Kandror, O. \& Goldberg, A. L. (2001). The molecular chaperone DnaJ is required for the degradation of a soluble abnormal protein in Escherichia coli. J Biol Chem 276, 3920-3928.

Huh, W. K., Falvo, J. V., Gerke, L. C., Carroll, A. S., Howson, R. W., Weissman, J. S. \& O'Shea, E. K. (2003). Global analysis of protein localization in budding yeast. Nature 425, 686-691.

Imai, J., Yashiroda, H., Maruya, M., Yahara, I. \& Tanaka, K. (2003). Proteasomes and molecular chaperones: cellular machinery responsible for folding and destruction of unfolded proteins. Cell Cycle 2, 585-590.

Inobe, T. \& Matouschek, A. (2008). Protein targeting to ATP-dependent proteases. Curr Opin Struct Biol 18, 43-51.

Ischiropoulos, H. \& Beckman, J. S. (2003). Oxidative stress and nitration in neurodegeneration: cause, effect, or association? J Clin Invest 111, 163-169.

Iwata, A., Christianson, J. C., Bucci, M., Ellerby, L. M., Nukina, N., Forno, L. S. \& Kopito, R. R. (2005). Increased susceptibility of cytoplasmic over nuclear polyglutamine aggregates to autophagic degradation. Proc Natl Acad Sci U S A 102, 13135-13140. 
Janke, C., Magiera, M. M., Rathfelder, N. \& other authors (2004). A versatile toolbox for PCR-based tagging of yeast genes: new fluorescent proteins, more markers and promoter substitution cassettes. Yeast 21, 947-962.

Johnson, D. R., Knoll, L. J., Levin, D. E. \& Gordon, J. I. (1994). Saccharomyces cerevisiae contains four fatty acid activation (FAA) genes: an assessment of their role in regulating protein $\mathrm{N}$-myristoylation and cellular lipid metabolism. J Cell Biol 127, 751-762.

Jones, J. M., Datta, P., Srinivasula, S. M. \& other authors (2003). Loss of Omi mitochondrial protease activity causes the neuromuscular disorder of mnd 2 mutant mice. Nature 425, 721-727.

Kandror, O., Busconi, L., Sherman, M. \& Goldberg, A. L. (1994). Rapid degradation of an abnormal protein in Escherichia coli involves the chaperones GroEL and GroES. $J$ Biol Chem 269, 23575-23582.

Kapatai, G., Large, A., Benesch, J. L., Robinson, C. V., Carrascosa, J. L., Valpuesta, J. M., Gowrinathan, P. \& Lund, P. A. (2006). All three chaperonin genes in the archaeon Haloferax volcanii are individually dispensable. Mol Microbiol 61, 1583-1597.

Kessel, M., Maurizi, M. R., Kim, B., Kocsis, E., Trus, B. L., Singh, S. K. \& Steven, A. C. (1995). Homology in structural organization between E. coli ClpAP protease and the eukaryotic 26 S proteasome. J Mol Biol 250, 587-594.

Kim, D. Y. \& Kim, K. K. (2005). Structure and function of HtrA family proteins, the key players in protein quality control. J Biochem Mol Biol 38, 266-274.

Kim, K. I., Park, S. C., Kang, S. H., Cheong, G. W. \& Chung, C. H. (1999). Selective degradation of unfolded proteins by the self-compartmentalizing HtrA protease, a periplasmic heat shock protein in Escherichia coli. J Mol Biol 294, 1363-1374.

Kim, Y. I., Burton, R. E., Burton, B. M., Sauer, R. T. \& Baker, T. A. (2000). Dynamics of substrate denaturation and translocation by the ClpXP degradation machine. Mol Cell 5, 639648.

Komatsu, M., Ueno, T., Waguri, S., Uchiyama, Y., Kominami, E. \& Tanaka, K. (2007). Constitutive autophagy: vital role in clearance of unfavorable proteins in neurons. Cell Death Differ 14, 887-894. 
Krojer, T., Garrido-Franco, M., Huber, R., Ehrmann, M. \& Clausen, T. (2002). Crystal structure of DegP (HtrA) reveals a new protease-chaperone machine. Nature 416, 455-459.

Langer, T., Kaser, M., Klanner, C. \& Leonhard, K. (2001). AAA proteases of mitochondria: quality control of membrane proteins and regulatory functions during mitochondrial biogenesis. Biochem Soc Trans 29, 431-436.

Lashuel, H. A., Petre, B. M., Wall, J., Simon, M., Nowak, R. J., Walz, T. \& Lansbury, P. T., Jr. (2002). Alpha-synuclein, especially the Parkinson's disease-associated mutants, forms pore-like annular and tubular protofibrils. J Mol Biol 322, 1089-1102.

Lee, D.H., M.Y. Sherman, and A.L. Goldberg. 1995. Cold Spring Harbor Symp. Quant. Biol. VX:111a

Lee, C., Schwartz, M. P., Prakash, S., Iwakura, M. \& Matouschek, A. (2001). ATPdependent proteases degrade their substrates by processively unraveling them from the degradation signal. Mol Cell 7, 627-637.

Leidhold, C. \& Voos, W. (2007). Chaperones and proteases--guardians of protein integrity in eukaryotic organelles. Ann N Y Acad Sci 1113, 72-86.

Li, W., Srinivasula, S. M., Chai, J., Li, P., Wu, J. W., Zhang, Z., Alnemri, E. S. \& Shi, Y. (2002). Structural insights into the pro-apoptotic function of mitochondrial serine protease HtrA2/Omi. Nat Struct Biol 9, 436-441.

Lipinska, B., Fayet, O., Baird, L. \& Georgopoulos, C. (1989). Identification, characterization, and mapping of the Escherichia coli htrA gene, whose product is essential for bacterial growth only at elevated temperatures. J Bacteriol 171, 1574-1584.

Lipinska, B., Zylicz, M. \& Georgopoulos, C. (1990). The HtrA (DegP) protein, essential for Escherichia coli survival at high temperatures, is an endopeptidase. J Bacteriol 172, 17911797.

Lu, K. P., Finn, G., Lee, T. H. \& Nicholson, L. K. (2007). Prolyl cis-trans isomerization as a molecular timer. Nat Chem Biol 3, 619-629.

Madeo, F., Frohlich, E. \& Frohlich, K. U. (1997). A yeast mutant showing diagnostic markers of early and late apoptosis. J Cell Biol 139, 729-734. 
Madeo, F., Frohlich, E., Ligr, M., Grey, M., Sigrist, S. J., Wolf, D. H. \& Frohlich, K. U. (1999). Oxygen stress: a regulator of apoptosis in yeast. $J$ Cell Biol 145, 757-767.

Madeo, F., Engelhardt, S., Herker, E., Lehmann, N., Maldener, C., Proksch, A., Wissing, S. \& Frohlich, K. U. (2002a). Apoptosis in yeast: a new model system with applications in cell biology and medicine. Curr Genet 41, 208-216.

Madeo, F., Herker, E., Maldener, C. \& other authors (2002b). A caspase-related protease regulates apoptosis in yeast. $\mathrm{Mol}$ Cell 9, 911-917.

Martins, L. M., Iaccarino, I., Tenev, T. \& other authors (2002). The serine protease Omi/HtrA2 regulates apoptosis by binding XIAP through a reaper-like motif. $J$ Biol Chem 277, 439-444.

Martins, L. M., Morrison, A., Klupsch, K. \& other authors (2004). Neuroprotective role of the Reaper-related serine protease HtrA2/Omi revealed by targeted deletion in mice. Mol Cell Biol 24, 9848-9862.

Maupin-Furlow, J. A., Wilson, H. L., Kaczowka, S. J. \& Ou, M. S. (2000). Proteasomes in the archaea: from structure to function. Front Biosci 5, D837-865.

Maurizi, M. R. (1992). Proteases and protein degradation in Escherichia coli. Experientia 48, 178-201.

Mayr, C., Richter, K., Lilie, H. \& Buchner, J. (2000). Cpr6 and Cpr7, two closely related Hsp90-associated immunophilins from Saccharomyces cerevisiae, differ in their functional properties. J Biol Chem 275, 34140-34146.

Moczko, M., Schonfisch, B., Voos, W., Pfanner, N. \& Rassow, J. (1995). The mitochondrial ClpB homolog Hsp78 cooperates with matrix Hsp70 in maintenance of mitochondrial function. J Mol Biol 254, 538-543.

Mogk, A., Haslberger, T., Tessarz, P. \& Bukau, B. (2008). Common and specific mechanisms of AAA+ proteins involved in protein quality control. Biochem Soc Trans 36, 120-125. 
Morimoto, R. I. (1998). Regulation of the heat shock transcriptional response: cross talk between a family of heat shock factors, molecular chaperones, and negative regulators. Genes Dev 12, 3788-3796.

Motohashi, K., Watanabe, Y., Yohda, M. \& Yoshida, M. (1999). Heat-inactivated proteins are rescued by the DnaK.J-GrpE set and ClpB chaperones. Proc Natl Acad Sci U S A 96, 7184-7189.

Mumberg, D., Muller, R. \& Funk, M. (1994). Regulatable promoters of Saccharomyces cerevisiae: comparison of transcriptional activity and their use for heterologous expression. Nucleic Acids Res 22, 5767-5768.

Murata, S., Minami, Y., Minami, M., Chiba, T. \& Tanaka, K. (2001). CHIP is a chaperone-dependent E3 ligase that ubiquitylates unfolded protein. EMBO Rep 2, 1133-1138.

Pajic, A., Tauer, R., Feldmann, H., Neupert, W. \& Langer, T. (1994). Yta10p is required for the ATP-dependent degradation of polypeptides in the inner membrane of mitochondria. FEBS Lett 353, 201-206.

Pallen, M. J. \& Wren, B. W. (1997). The HtrA family of serine proteases. Mol Microbiol 26, 209-221.

Parsell, D. A., Kowal, A. S., Singer, M. A. \& Lindquist, S. (1994). Protein disaggregation mediated by heat-shock protein Hsp104. Nature 372, 475-478.

Plun-Favreau, H., Klupsch, K., Moisoi, N. \& other authors (2007). The mitochondrial protease HtrA2 is regulated by Parkinson's disease-associated kinase PINK1. Nat Cell Biol 9, $1243-1252$.

Ponting, C. P. (1997). Evidence for PDZ domains in bacteria, yeast, and plants. Protein Sci 6, 464-468.

Radke, S., Chander, H., Schafer, P., Meiss, G., Kruger, R., Schulz, J. B. \& Germain, D. (2008). Mitochondrial protein quality control by the proteasome involves ubiquitination and the protease Omi. J Biol Chem 283, 12681-12685.

Rattan, S. I. \& Derventzi, A. (1991). Altered cellular responsiveness during ageing. Bioessays 13, 601-606. 
Ravikumar, B., Vacher, C., Berger, Z. \& other authors (2004). Inhibition of mTOR induces autophagy and reduces toxicity of polyglutamine expansions in fly and mouse models of Huntington disease. Nat Genet 36, 585-595.

Rizzitello, A. E., Harper, J. R. \& Silhavy, T. J. (2001). Genetic evidence for parallel pathways of chaperone activity in the periplasm of Escherichia coli. J Bacteriol 183, 67946800 .

Rouviere, P. E. \& Gross, C. A. (1996). SurA, a periplasmic protein with peptidyl-prolyl isomerase activity, participates in the assembly of outer membrane porins. Genes Dev 10, 3170-3182.

Saibil, H. R. (2008). Chaperone machines in action. Curr Opin Struct Biol 18, 35-42.

Sanchez, Y. \& Lindquist, S. L. (1990). HSP104 required for induced thermotolerance. Science 248, 1112-1115.

Schirmer, E. C., Glover, J. R., Singer, M. A. \& Lindquist, S. (1996). HSP100/Clp proteins: a common mechanism explains diverse functions. Trends Biochem Sci 21, 289-296.

Shadel, G. S. (1999). Yeast as a model for human mtDNA replication. Am J Hum Genet 65, 1230-1237.

Shan, X., Xue, Z. \& Melese, T. (1994). Yeast NPI46 encodes a novel prolyl cis-trans isomerase that is located in the nucleolus. J Cell Biol 126, 853-862.

Shang, F., Gong, X., Palmer, H. J., Nowell, T. R., Jr. \& Taylor, A. (1997). Age-related decline in ubiquitin conjugation in response to oxidative stress in the lens. Exp Eye Res 64, 21-30.

Sherer, T. B., Kim, J. H., Betarbet, R. \& Greenamyre, J. T. (2003). Subcutaneous rotenone exposure causes highly selective dopaminergic degeneration and alpha-synuclein aggregation. Exp Neurol 179, 9-16.

Sherman, M. Y. \& Goldberg, A. L. (2001). Cellular defenses against unfolded proteins: a cell biologist thinks about neurodegenerative diseases. Neuron 29, 15-32. 
Sigler, P. B., Xu, Z., Rye, H. S., Burston, S. G., Fenton, W. A. \& Horwich, A. L. (1998). Structure and function in GroEL-mediated protein folding. Annu Rev Biochem 67, 581-608.

Sikorski, R. S. \& Hieter, P. (1989). A system of shuttle vectors and yeast host strains designed for efficient manipulation of DNA in Saccharomyces cerevisiae. Genetics 122, 1927.

Sklar, J. G., Wu, T., Kahne, D. \& Silhavy, T. J. (2007). Defining the roles of the periplasmic chaperones SurA, Skp, and DegP in Escherichia coli. Genes Dev 21, 2473-2484.

Skorko-Glonek, J., Wawrzynow, A., Krzewski, K., Kurpierz, K. \& Lipinska, B. (1995). Site-directed mutagenesis of the HtrA (DegP) serine protease, whose proteolytic activity is indispensable for Escherichia coli survival at elevated temperatures. Gene 163, 47-52.

Smith, D. M., Benaroudj, N. \& Goldberg, A. (2006). Proteasomes and their associated ATPases: a destructive combination. $J$ Struct Biol 156, 72-83.

Snider, J., Thibault, G. \& Houry, W. A. (2008). The AAA + superfamily of functionally diverse proteins. Genome Biol 9, 216.

Spiess, C., Beil, A. \& Ehrmann, M. (1999). A temperature-dependent switch from chaperone to protease in a widely conserved heat shock protein. Cell 97, 339-347.

Strauch, K. L., Johnson, K. \& Beckwith, J. (1989). Characterization of degP, a gene required for proteolysis in the cell envelope and essential for growth of Escherichia coli at high temperature. J Bacteriol 171, 2689-2696.

Strauss, K. M., Martins, L. M., Plun-Favreau, H. \& other authors (2005). Loss of function mutations in the gene encoding Omi/HtrA2 in Parkinson's disease. Hum Mol Genet 14, 2099-2111.

Suzuki, C. K., Rep, M., van Dijl, J. M., Suda, K., Grivell, L. A. \& Schatz, G. (1997). ATP-dependent proteases that also chaperone protein biogenesis. Trends Biochem Sci 22, 118-123. 
Suzuki, Y., Imai, Y., Nakayama, H., Takahashi, K., Takio, K. \& Takahashi, R. (2001). A serine protease, HtrA2, is released from the mitochondria and interacts with XIAP, inducing cell death. Mol Cell 8, 613-621.

Tauer, R., Mannhaupt, G., Schnall, R., Pajic, A., Langer, T. \& Feldmann, H. (1994). Yta10p, a member of a novel ATPase family in yeast, is essential for mitochondrial function. FEBS Lett 353, 197-200.

Tautz, N., Kaiser, A. \& Thiel, H. J. (2000). NS3 serine protease of bovine viral diarrhea virus: characterization of active site residues, NS4A cofactor domain, and protease-cofactor interactions. Virology 273, 351-363.

Teter, S. A., Houry, W. A., Ang, D., Tradler, T., Rockabrand, D., Fischer, G., Blum, P., Georgopoulos, C. \& Hartl, F. U. (1999). Polypeptide flux through bacterial Hsp70: DnaK cooperates with trigger factor in chaperoning nascent chains. Cell 97, 755-765.

Thompson, M. W. \& Maurizi, M. R. (1994). Activity and specificity of Escherichia coli ClpAP protease in cleaving model peptide substrates. J Biol Chem 269, 18201-18208.

Tomoyasu, T., Yuki, T., Morimura, S., Mori, H., Yamanaka, K., Niki, H., Hiraga, S. \& Ogura, T. (1993). The Escherichia coli FtsH protein is a prokaryotic member of a protein family of putative ATPases involved in membrane functions, cell cycle control, and gene expression. J Bacteriol 175, 1344-1351.

Tong, F., Black, P. N., Bivins, L., Quackenbush, S., Ctrnacta, V. \& DiRusso, C. C. (2006). Direct interaction of Saccharomyces cerevisiae Faalp with the Omi/HtrA protease orthologue Ynm3p alters lipid homeostasis. Mol Genet Genomics 275, 330-343.

Vande Walle, L., Lamkanfi, M. \& Vandenabeele, P. (2008). The mitochondrial serine protease HtrA2/Omi: an overview. Cell Death Differ 15, 453-460.

Venkatraman, P., Wetzel, R., Tanaka, M., Nukina, N. \& Goldberg, A. L. (2004). Eukaryotic proteasomes cannot digest polyglutamine sequences and release them during degradation of polyglutamine-containing proteins. Mol Cell 14, 95-104.

Verhagen, A. M., Ekert, P. G., Pakusch, M., Silke, J., Connolly, L. M., Reid, G. E., Moritz, R. L., Simpson, R. J. \& Vaux, D. L. (2000). Identification of DIABLO, a mammalian protein that promotes apoptosis by binding to and antagonizing IAP proteins. Cell 102, 43-53. 
Verhagen, A. M., Silke, J., Ekert, P. G. \& other authors (2002). HtrA2 promotes cell death through its serine protease activity and its ability to antagonize inhibitor of apoptosis proteins. J Biol Chem 277, 445-454.

Voges, D., Zwickl, P. \& Baumeister, W. (1999). The 26S proteasome: a molecular machine designed for controlled proteolysis. Annu Rev Biochem 68, 1015-1068.

Wagner, I., Arlt, H., van Dyck, L., Langer, T. \& Neupert, W. (1994). Molecular chaperones cooperate with PIM1 protease in the degradation of misfolded proteins in mitochondria. Embo J 13, 5135-5145.

Waller, P. R. \& Sauer, R. T. (1996). Characterization of degQ and degS, Escherichia coli genes encoding homologs of the DegP protease. J Bacteriol 178, 1146-1153.

Walsh, N. P., Alba, B. M., Bose, B., Gross, C. A. \& Sauer, R. T. (2003). OMP peptide signals initiate the envelope-stress response by activating DegS protease via relief of inhibition mediated by its PDZ domain. Cell 113, 61-71.

Walter, D., Wissing, S., Madeo, F. \& Fahrenkrog, B. (2006). The inhibitor-of-apoptosis protein Birlp protects against apoptosis in $S$. cerevisiae and is a substrate for the yeast homologue of Omi/HtrA2. J Cell Sci 119, 1843-1851.

Wawrzynow, A., Wojtkowiak, D., Marszalek, J., Banecki, B., Jonsen, M., Graves, B., Georgopoulos, C. \& Zylicz, M. (1995). The ClpX heat-shock protein of Escherichia coli, the ATP-dependent substrate specificity component of the ClpP-ClpX protease, is a novel molecular chaperone. Embo J 14, 1867-1877.

West, S. M., Kelly, S. M. \& Price, N. C. (1990). The unfolding and attempted refolding of citrate synthase from pig heart. Biochim Biophys Acta 1037, 332-336.

Wickner, S., Gottesman, S., Skowyra, D., Hoskins, J., McKenney, K. \& Maurizi, M. R. (1994). A molecular chaperone, ClpA, functions like DnaK and DnaJ. Proc Natl Acad Sci US A 91, 12218-12222.

Wickner, S., Maurizi, M. R. \& Gottesman, S. (1999). Posttranslational quality control: folding, refolding, and degrading proteins. Science 286, 1888-1893. 
Wilken, C., Kitzing, K., Kurzbauer, R., Ehrmann, M. \& Clausen, T. (2004). Crystal structure of the DegS stress sensor: How a PDZ domain recognizes misfolded protein and activates a protease. Cell 117, 483-494.

Wilkinson, B. \& Gilbert, H. F. (2004). Protein disulfide isomerase. Biochim Biophys Acta 1699, 35-44.

Winklhofer, K. F., Tatzelt, J. \& Haass, C. (2008). The two faces of protein misfolding: gain- and loss-of-function in neurodegenerative diseases. Embo $J$ 27, 336-349.

Zwickl, P., Ng, D., Woo, K. M., Klenk, H. P. \& Goldberg, A. L. (1999). An archaebacterial ATPase, homologous to ATPases in the eukaryotic $26 \mathrm{~S}$ proteasome, activates protein breakdown by $20 \mathrm{~S}$ proteasomes. J Biol Chem 274, 26008-26014. 


\section{Publication}

Nirmala Padmanabhan, Lars Fichtner, Achim Dickmanns, Jörg B.Schulz, and Gerhard H.

Braus. The Yeast HtrA orthologue Ynm3 is a protease with chaperone activity that aids survival under heat stress. Under revision. Molecular Biology of the Cell. 


\section{Curriculum vitae}

$\begin{array}{ll}\text { Name } & \text { Nirmala Padmanabhan } \\ \text { Date of Birth } & \text { 26 February 1980 } \\ \text { Place of Birth } & \text { Trivandrum, India } \\ \text { Nationality } & \text { Indian }\end{array}$

\section{Education}

2003-Present: MSc-PhD Program in Molecular Biology, International Max Planck Research School, Georg August University, Göttingen, Germany.

Masters Thesis: Analyses of Saccharomyces cerevisiae strains impaired in the COP9 signalosome.

PhD thesis at the Department of Molecular Microbiology and Genetics, Institute of Microbiology and Genetics, Georg August University, Goettingen.

2001-2003: MSc Biotechnology, University of Hyderabad, India. Masters thesis: Biochemical and immunological characterization of the enzyme alphafucosidase from the invertebrate Unio.

1998-2001: BSc in Microbiology, Genetics and Chemistry. Bhavan's Vivekananda College of Science, Humanities and Commerce, Osmania University, Hyderabad.

1995-1997: Loyola Academy, Hyderabad. Intermediate Public Examination, Board of Intermediate Education, Andhra Pradesh.

1995: Takshasila Public School, Hyderabad. All India Secondary School Examination, Central Board of Secondary Education. 